University of Massachusetts Amherst

ScholarWorks@UMass Amherst

Doctoral Dissertations 1896 - February 2014

$1-1-1983$

\title{
Anger as a dissociative phenomenon: a contribution to an integrated theory of personality.
}

Gregory Michael Chilenski

University of Massachusetts Amherst

Follow this and additional works at: https://scholarworks.umass.edu/dissertations_1

\section{Recommended Citation}

Chilenski, Gregory Michael, "Anger as a dissociative phenomenon: a contribution to an integrated theory of personality." (1983). Doctoral Dissertations 1896 - February 2014. 1708.

https://doi.org/10.7275/tfpm-xs20 https://scholarworks.umass.edu/dissertations_1/1708

This Open Access Dissertation is brought to you for free and open access by ScholarWorks@UMass Amherst. It has been accepted for inclusion in Doctoral Dissertations 1896 - February 2014 by an authorized administrator of ScholarWorks@UMass Amherst. For more information, please contact scholarworks@library.umass.edu. 


\section{3}

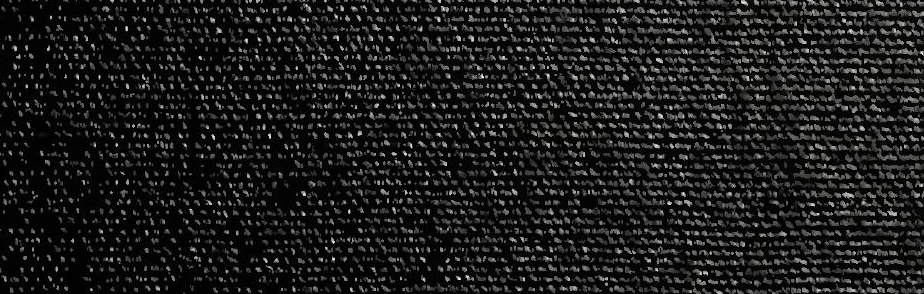

A

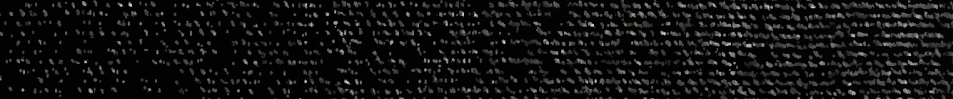

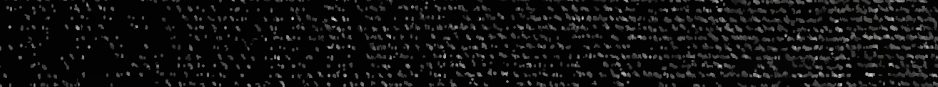
$\therefore \quad \therefore \quad \therefore \quad 20$

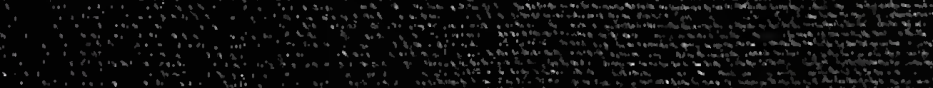

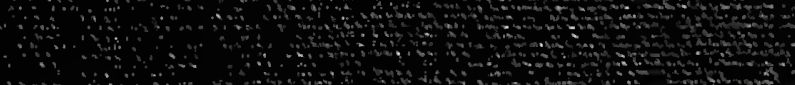

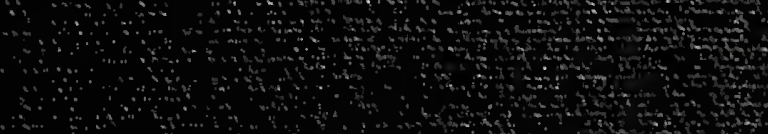
$\therefore \quad \therefore \quad$ and

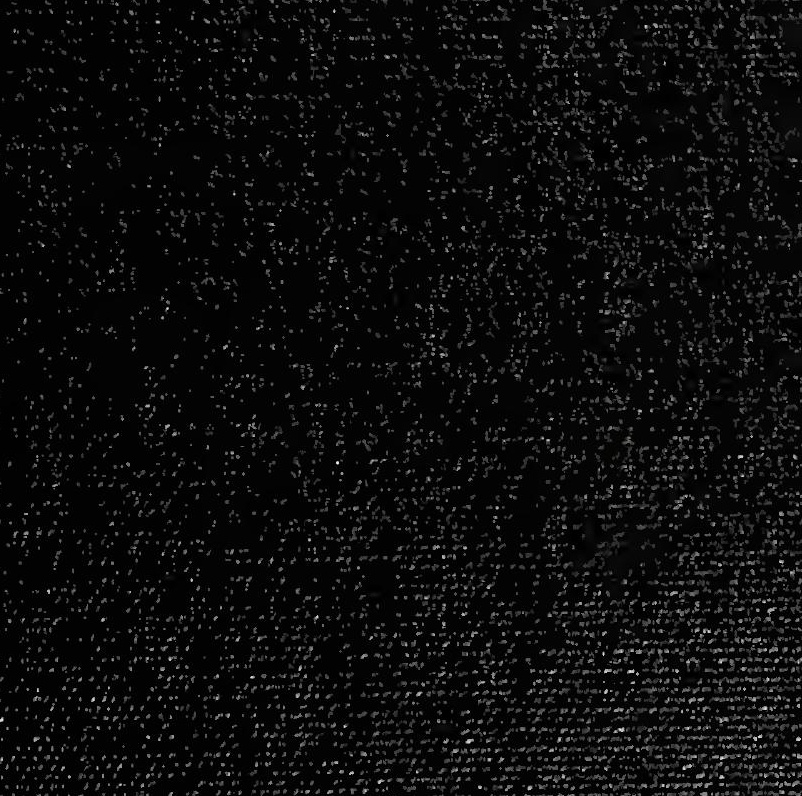
$\therefore$ a d $\therefore$ and a d $\therefore \therefore$ and $\because 40$

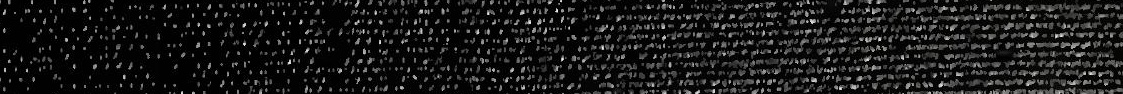
$\because \quad \therefore \quad \therefore$, (2)

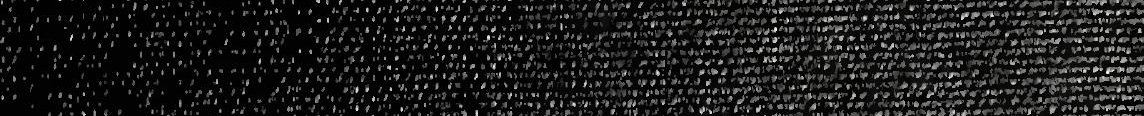
(2. 2. 2 $\therefore \therefore \therefore \therefore$, 


\section{ANGER AS A DISSOCIATIVE PHENOMENON: \\ A CONTRIBUTION TO AN INTEGRATED THEORY \\ OF PERSONALITY}

A Dissertation Presented

By

GREGORY MICHAEL CHILENSKI

Submitted to the Graduate School of the University of Massachusetts in partial fulfillment

of the requirements for the degree of DOCTOR OF PHILOSOPHY

September 1983

Department of Psychology 


\title{
ANGER AS A DISSOCIATIVE PHENOMENON: \\ A CONTRIBUTION TO AN INTEGRATED THEORY OF PERSONALITY
}

\author{
A Dissertation Presented \\ By
}

GREGORY MICHAEL CHILENSKI

Approved as to style and content by:
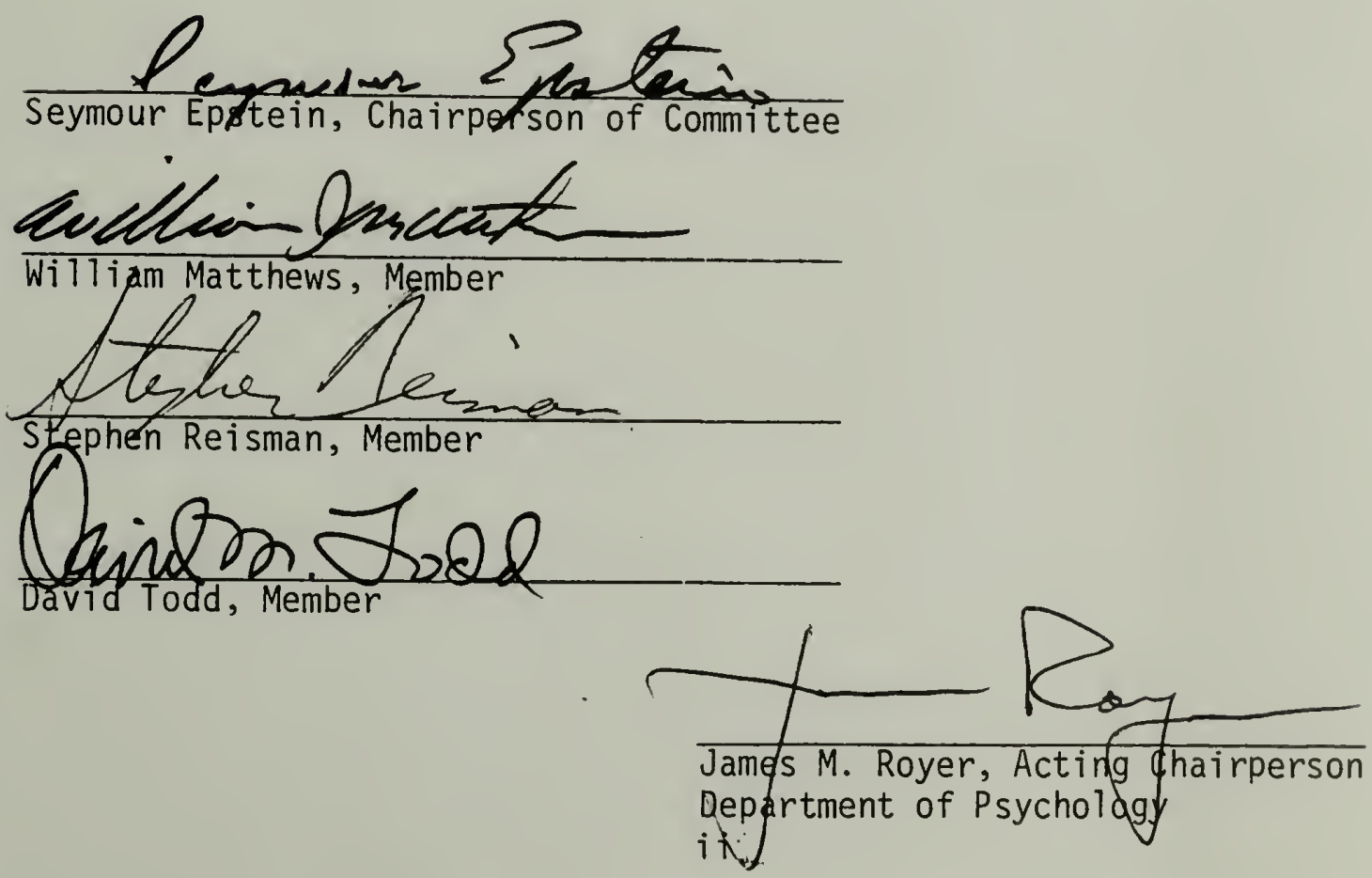


\section{DEDICATION}

To Gail, without whom I can do nothing of lasting value. 


\section{ACKNOWLEDGEMENTS}

I wish gratefully to thank:

Sy Epstein for his energetic and brilliant assistance at every step of the way and for knowing I could do better at each step before I myself knew it.

Dave Todd for guiding me into and through the entire clinical training program.

Steve Reisman for his unfailing support through numerous permutations of my professional and personal life.

Bill Matthews for opening several new windows on self change. 


\section{PREFACE}

The concept of dissociation, in recent years, has received increased use by psychologists and by mental health practioners after a long period of neglect. Hilgard (1977) reported numerous experimental studies in which subjects were able through hypnosis to reproduce the hysterical symptoms first reported by pre-Freudian clinical investigators such as Janet. Hilgard argues that dissociation is a naturally occurring phenomenon of consciousness. He states that his "neodissociation theory" explains the phenomena both of co-consciousness and of partial dissociation which his research has uncovered. Bower (1981) has recently offered an "associative network theory" of the relation between emotions and cognitions. This theory relies on the dissociation of emotions as separate memory units. According to this theory these "emotion nodes" collect together many other aspects of the emotion and connect to them in memory by what are called "associative pointers." These associated networks are organized as relatively discrete cognitive and behavioral sub-systems in the person's overa 11 conceptual system.

In the clinical domain there is increased interest in the dissociative anxiety disorders of psychogenic amnesia and fugue, multiple personality, and depersonalization. This interest is reflected in the 
recently revised Diagnostic and Statistical Manual of the American Psychiatric Association (1980). This manual offers separate diagnostic criteria for these three clinical phenomena which previously had been lumped together with other phenomena under the heading of hysterical neuroses. The dissociative processes characteristic of traumatic stress disorders also have been re-discovered (Horowitz, 1976; Chilenski, 1982).

There are several trends in psychiatry and in clinical psychology that contribute to a new legitimizing both of dissociative phenomena as subjects for study and of dissociation as an explanatory concept. Hypnosis, after a long absence from "respectable" clinical practice and journals, is once again receiving increased attention. Cognitively oriented models of disturbance and treatment (eg. Ellis, 1973; Beck, 1976) have partly replaced older models based on the notion of a dynamic unconscious (Bieber, 1980). The same partial replacement is occurring with stress models of disturbance (Selye, 1976) and stress-innoculation models of treatment and prevention (Miechenbaum, 1977). Finally, an historical analys is of Freud's early cases has identified the subsequently neglected dissociative phenomena in those reports (El lenberger, 1970, 1972). This historical analys is may have contributed to a renewed interest in the works of Janet, Prince, and other early dissociation theorists (McKellar, 1979).

Research on sleep and other altered states of consciousness also suggests that the traditional Freudian model of the mind, ie. conscious awareness and a dynamic unconscious separated by the way-station 
of a preconscious, needs revision. This revision should account for what appear to be multiple controls on consciousness, on emotion, and on behavior. Not all of these multiple controls are in conscious awareness nor are they of the kind thought to originate in the dynamic unconscious. The concept of dissociation serves to advance this theoretical effort.

It must be kept in mind, however, that there is no single dissociation theory. In fact, as is often the case in psychology, there is no general agreement about what phenomena are best explained by any dissociation theory. In this paper, dissociation as a general theoretical term denotes the relation to conscious awareness of the individual's controls on cognitive, emotional, and behavioral responding. These controls are not in the person's ordinary awareness but are potentially accessible to ordinary consciousness. This general meaning will be specified further in Chapter I when it is discussed in the context of cognitive self-theory.

This entire investigation, both theoretically and methodological1y, is grounded on Epstein's cognitive self-theory (1973; 1980b), and the research that theory has generated on the central significance of the emotions in personality (Epstein, 1979b; 1982). It is argued that the concept of dissociation is helpful to cognitive self-theory in accounting for the organizing role of the emotions in the self-theory. Emotions are seen as centrally significant organizers of cornition, of physical activation and arousal, and of behavior within the person's 
integrated theory of self. But emotions function as discrete paradigms about the self's interaction with the world. As separate paradigms, emotions are dissociated from each other within an overall hierarchically organized, integrated self-theory. In short, viewed from the perspective of cognitive self-theory, the emotions are structurally dissociated. Evidence is presented here which shows at least one emotion, anger, is indeed so organized. Phenomenological evidence is presented for the existence of dissociative anger.

Anger was chosen to illustrate the theoretical argument for several reasons. First, anger is usually considered one of the primary emotions. Second, anger is an emotion which figures prominantly in theory about psychological disturbance; but there is relatively little known about it from a therapeutic point of view (Frost, 1987; Chilenski, 1982). Third, because anger is often associated with intensity of experience, it offers a rich range of experience for phenomenological investigation (Richardson, 1918). Finally, insofar as anger is related to harm inflicted on others, the task of uncovering the multiple controls of anger is a socially useful one.

The paper is organized into three chapters. Chapter I presents a desciption of Epstein's cognitive self-theory and introduces the concept of dissociation. Next the phenomenology of dissociation and depersonalization are described on the basis of a brief review of clinical material. Finally, dissociative anger is identified from viii. 
clinical case material on the treatment of excessive anger.

Chapter II presents the hypotheses, the procedure, and the results of a study undertaken in the form of multiple quantitative case studies. This research identifies several aspects of dissociative anger.

Chapter III is a discussion of the significance of these results for Epstein's cognitive self-theory, for clinical applications in the control of anger, and for further research: 


\section{ABSTRACT}

Anger as a Dissociative Phenomenon:

A Contribution to an Integrated Theory of Personality September, 1983

Gregory Michael Chilenski, B.A., Oakland University

$$
\begin{aligned}
& \text { M.A., University of Massachusetts } \\
& \text { Ph.D., University of Massachusetts }
\end{aligned}
$$

Directed by: Professor Seymour Epstein

The concept of dissociation was proposed to explain the structural relation between the emotions and a person's overall sense of self. This discussion was based on Epstein's (1973, 1980b) cognitive self-theory. Seven hypotheses were tested concerning the nature of dissociative anger. Data were collected by subjects recording their own anger experiences over several weeks. Grouped intra-subject correlations showed that both anger at another and anger at oneself are dissociative phenomena. It was also found that physical arousal, disinhibition to attack, and the intensity of any emotion which immediately replaces anger are all directly related to intensity of dissociative experience. These relations are independent of any relations which exist between these variables and intensity of anger. Six individual cases were quantitatively analyzed for idiosyncratic departures from the general trends in the grouped data. Implications for psychopathology, for therapy, and for further research were discussed. 
TABLE OF CONTENTS

Dedication ......................... iv

Acknowledgements ................ . . y

Preface ..................... . . $x$

Chapter

I. COGNITIVE SELF-THEORY AND DISSOCiATIVE ANGER . . . . 1

Implicit cognition ......... . . 5

Emotion ............. 9 9

Self-theory unity . . . . . . . 13

Dissociation and the self-theory . . . . . 16

The phenomenology of dissociation ..... . 21

Dissociative anger....... . . . 23

General summary ... . . . . . . . 29

II. EVIDENCE FOR DISSOCIATIVE ANGER

Hypotheses and their rationale...... 32

Strong anger-out as a dissociative

phenomenon ......... 32

Dissociative Anger as Alienation from the Body. . . 34

Dissociative Anger-out as Disinhibition to

Attack ............ 35

Visual imagery ............. . . . 35

Impulses to attack . . . . . . . 36

Dissociative Anger-out as Non-integration in

the Self-theory . . . . . . . . 37

Procedure ............ . . . 38

Subjects............ . . 38

Method . . . . . . . . . 39

Results ............ . . 42

Hypothesis one ............... 45

Hypothes is Two ........... 4 47

Hypothes is Three ........... . 48 48

Hypothes is Four .......... . . 48

Hypothesis Five and Six ....... 50

Hypothesis Seven......... 50 
High dissociation and low dissociation subjects ............... 51

Individual cases ................56

Subject Number 2, Joe, A High Dissociation

Subject ............... 57

Subject Number 4, Glen, A High Dissociation

Subject .............

Subject Number 1 , Peter, A High Dissociation

Subject . . . . . . . 71

Subject Number 10, Marcia, A Low Dissociation

Subject . . . . . . . . . 78

Subject Number 12 , Steven, A Low Dissociation

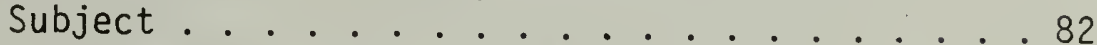

Subject Number 8 , Dave, A Low Dissociation

Subject.............. 89

Chapter

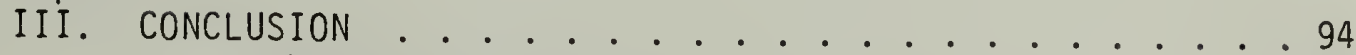

The present study ....... . . . . . . . . .

Unexpected findings and difficulties . . . . .103

Future research ..............109

Summary ............... . . . . . . . .

PEFERENCES ........................... 114 


\section{LIST OF TABLES}

1. Grouped Intra-Subject Intercorrelations for Variables

Assessing Dissociation. . ....... 44

2. Between-Subjects Means and DS's for a 11 Variables; and

Grouped Intra-Subject Correlations for Selected

Variables with Dissociation and with Anger-Out .... 45

3. Grouped Intra-Subject Intercorrelations for Variables

Assessing Symptoms of Physical Change....... 49

4. Between-Subjects Means \& SD's \& Grouped Intra-Subject

Correlations for Selected Variables: High Dissociation

Ss and Low Dissociation Ss. . . ...... 52

5. Means and SD's and Intra-Subject Correlations for

Selected Variables: Subject 2 (Joe)......... 59

6. Means and SD's and Intra-Subject Correlations for

Selected Variables: Subject 4 (Glen). ....... . 66

7. Means and SD's and Intra-Subject Correlations for

Selected Variables: Subject 1 (Peter)........73

8. Means and SD's and Intra-Subject Correlations for

Selected Variables: Subject 10 (Marcia). . . . . . 80

9. Means and SD's and Intra-Subject Correlations for

Selected Variables: Subject 12 (Steven) . . . . . 84

10. Means and SD's and Intra-Subject Correlations for

Selected Variables: Subject 8 (Dave) ........ 90 


\section{List of Figures}

1. Schematic for an Emotion-Node Adapted from Bower (1981) . . 12 


\section{H A P T ER I \\ COGNITIVE SELF-THEORY AND DISSOCIATIVE ANGER}

Historically, the self-concept has been used as a central, hierarchicaliy superior, and order generating concept in many psychological treatments of personality since the time of William James. It could even be said that the continuous controversy between exponents of a social learning approach to personality (eg. Mische 1, 1976; Bandura, 1977) and nearly all other approaches in the field revolves around the issue of the usefulness of the selfconcept as a hypothetical contruct (eg. Rogers, 1967).

A distinctively cognitive and constructivist approach to understanding the function of an individual's self-concept sees the self-concept as being itself a system of concepts

...that is hierarchically organized and internally consistent; that assimilates knowledge, yet, itself, is an object of knowledge; that is dynamic, but must maintain a degree of stability; that is unified and differentiated at the same time; that is necessary for solving problems in the real world; and that is subject to sudden collapse, producing total disorganization when this occurs (Epstein, 1973).

In short, the self-concept is a self-theory. Viewed as a theory which the individual constructs and maintains in order to structure experience and to direct a life, the self-theory can be evaluated by the classical standards of scientific theory: extensivity, parsimony, empirical validity, internal consistency, testability, and 
usefulness (Epstein, 1973; 1980). Just as the adaptiveness of a scientific theory can be judged according to these criteria, so too can the adaptiveness of a person's self-theory.

The extensiveness of a person's self-theory refers to an ability to cope with a wide variety of situations. This coping depends on the person being aware of more facets of his or her feelings, abilities, and personality characteristics than someone with a narrow self-theory. An extensive self-theory allows a person to be more flexible and open to new experiences.

The parsimoniousness of a person's self-theory refers to the efficiency of its organization. That is, an efficient self-theory is one which has both major and minor postulates hierarchically arranged. The broad, integrative postulates refer to general guiding principles such as, "I am a Christian." Minor postulates are situation-specific empirical generalizations which guide immediate responses. A lack of parsimony in the self-theory results in behavior being completely situationally determined.

A11 self-theories are empirically derived, inductive construct systems. They may differ, however, in their degree of empirical validity. Much human learning takes place vicariously. It is possible for vicariously learned postulates to be preserved at the expense of maintaining empirically invalid lower-order postulates. For example, a child may learn to ignore his or her own experience in order to preserve a distorted view of self learned from a pathogenic 
parent.

It is in the realm of internal consistency that a self-theory differs most from a scientific theory. The importance of internal consistency to the self-theory is not so much a matter of whether there exist contradictory postulates, but more a matter of the person's awareness of contradiction and inconsistency. Emotional experience offers the occasions for the person's experience of internal inconsistency. "I am (usually) a kind and loving person." is not easily reconcilable with the empirically-based, "I just viciously attacked this person and hurt his feelings." It is argued below that the organization of the emotions in the self-theory depends on dissociated structure in order to avoid the strain of naturallyoccurring internal inconsistency.

Testability refers to the degree to which postulates in the self-theory are available for disconfirmation. It is assumed that the invalidation of a self-theory postulate produced anxiety and the more general the postulate, the more anxiety experienced when its validity is threatened. It follows that because people tend to avoid anxiety, higher-order postulates are less available for disconfirmation than are lower-order postulates which are based on simple empirical generalizations. For example, the general self-esteem postulate, "I am a worthy person." is much less accessible to invalidation than the empirical generalization, "I am a good ping-pong player." 
Concerning the standard of usefulness, Epstein has proposed three purposes of the person's self-theory. These are: a). to maintain a favorable pleasure/pain balance over the forseeable future, b). to maintain a favorable level of self-esteem, and c). to assimilate the data of personal experience, which requires it to maintain its own organization. Both anxious and pleasant types of arousal are associated with the success or failure of each of these purposes. Developmentally, anxious and pleasant arousal states provide the emotional building blocks for later differentiation of emotional experience.

The central significance of emotion in Epstein's cognitive selftheory is clear:

Individuals unwittingly construct theories about themselves as a way of dealing with their world. Whether they like it or not, they form concepts about emotionally significant experiences that then serve to organize and guide their future behavior.... In the beginning, when the child is mainly responsive to physical needs, the self-theory is subordinate to the emotions. However, in time this becomes reversed, as emotional experience becomes increasingly mediated by the individual's developing conceptual system. (Epstein, 1980a)

For Epstein there are at least three ways that emotions are related to the individual's self-theory. First, whenever the selftheory succeeds at one of its functions (eg. assimilating the data of experience; resolving inner contradictions), the person experiences a satisfying exhileration. If, on the other hand, there is a temporary failure to fulfill a function, the person becomes anxious. 
Second, emotions are aroused whenever anything of significance to an individual's self-theory occurs. For example a perceived threat to the self might be responded to with anger or anxiety. A reduction in self-esteem might be responded to with sadness. Self-esteem enhancement of self-theoretic growth or development might be responded to with joy or happiness. A challenge to the assimilative capacity of the self-theory which is not perceived as threatening might be responded to with curiosity. Third, as Epstein has stated, "behind almost every emotion there is a hidden cognition... it is how we interpret events, not the events themselves, that determine the emotions we feel." (Epstein, 1980a)

It is for these three reasons that Epstein has paraphrased Freud in saying that "emotions are the royal road to the self-theory." That is, the intensive study of the emotional life of individuals is Epstein's method of choice for describing their self-theories.

Implicit cognition. The link between implicit cognition and emotion has been described and clinically investigated by both Ellis (1973) and Beck (1976). While Beck, Ellis, and Epstein differ from each other in many significant ways, they would each maintain the principle that behind every emotion there is an implicit cognition. As James would have it, "The emotion is the observation of the resonance to the meaning of things" (Linschoten, 1968). Whether cognitions are in any final, causal sense prior to emotion, or vice versa, is a the- 
oretical question which will not be argued here. Both Beck and Ellis pragmatically choose the causal direction to be from cognitions to emotions: both have developed therapy techniques which focus intervention on cognitions. Each explicitely states that emotion will "follow suit." Epstein also sees cognition preceding emotion even in childhood.

In the present paper it is assumed with Beck, Ellis, and Epstein that cognition precedes emotion. But there is reason to suspect that the sequential relation is sometimes more complex than this. Deciding this question in any final theoretical sense must take into account many important clinical observations. While i.t is true that cognitive approaches to therapy assume a cognition-to-emotion causal direction, there is also a great deal of evidence that a change in emotional experience can lead to changed cognitions. Cathartic therapy techniques (Breuer \& Freud, 1937; Jackins, 1965; Janov, 1972; Bach, 1974; Lowen, 1974) are based on the idea that the experience of emotions in the present moment of therapy will create new experiences which must then be assimilated into the person's ego or self-structure. It could be argued that this does not necessarily mean that cognitions do not precede emotion. The issue here seems to depend on the meaning of implicit cognition and whether it is possible for cognitions to vary in their degree of implicitness. It seems prudent to avoid foreclosing on either end of the cognition-emotion link and instead to adopt a stance which allows for going from change in one element to 
change in the other, in either direction. This equivocation is not the result of unclarity of thought but rather the result of an attempt to remain faithful to the subjective experience of change in psychotherapy.

A closer examination of Epstein's position regarding the relation between emotion and cognition will show that a cognition, as one element of a complex self-theory, can itself occupy different positions in the hierarchy of the self-theory. Since cognition frequently connotes a single belief, Epstein uses the term postulate to refer to higher-order or hierarchically superior cognitions. Postulates at different hierarchical levels can influence or be influenced by emotional experience and the generality of the postulate is related to the qualities of the emotion. For example, the fundamental exhileration experienced with self-theory success at assimilation of the data of a unique experience presumably engages more of the conceptual system than the perfunctory solution of the daily cross-word puzzle. Similarly, the incapacitating anxiety attendant upon first acknowledging a homosexual desire, for example, will implicate more of the person's self-theory than, say, the person admitting that he doesn't know how to give his own câr a tune-up.

Postulates which are in direct conscious awareness and which generate immediate emotional reactions seem to reciprocally control or influence smaller sub-hierarchies of the self-theory. Thus certain features of emotional experience and expression such as intensity, frequency, consciousness of stimulus, and others can be indices of the 
relative superior or subordinate level of the postulates involved. Cognition as used in this paper refers, as its simplest sense, to the beliefs and perceptions of the individual (Bieber, 1980). However, because the self-theory is assumed to be a hierarchically ordered structure of cognitive postulates, it becomes necessary to distinguish between beliefs and perceptions which are either in awareness, or readily accessible to it, and beliefs and perceptions which are implicit. It is assumed that some of the central or hierarchically superior postulates are not easily accessible to awareness. In addition, perceptual processes which involve emotion or emotionally significant events are also outside of normal awareness. As was mentioned earlier, neither Ellis nor Beck address the issue of postulate hierarchies and therefore they seem to find no need to make a distinction between explicit and implicit but explicable cognitions.

The concern with cognition is a concern with how people represent their world (including themselves) to themselves (Kelly, 1955). The implicitquality of a representation means that it is acted on, yet is not formally explicit. It is sensed rather than reasoned. Tacit knowing (Polyanyi, 1958) is another name for these phenomena. Tacit knowing is knowledge which is a-critical or non-reflective. It is, somewhat paradoxically, knowledge which is unspecifiable, yet the holding of it involves a personal commitment.

Implicit higher order self-theory postulates are representations (or construals) or one's self to oneself. As Epstein (1973) has stated, the self-theory is a highly significant part of the person's 
overall theory of reality. Sub-hierarchies within the self-theory, organized around the memories of significant emotional experiences, are complex cognitive structures which constitute people's "knowing how" (Piaget, 1968) to be themselves.

Emotion. Since the postulates of a person's self-theory are ordinarily implicit, the relation between the postulates and emotion becomes important for the study of self-theories. It can be assumed that whenever an emotion is experienced, some significant events have occurred with respect to the self-theory's functions. An emotion is viewed, in cognitive self-theory terms, as an action-oriented subsystem of the self-theory. Emotional sub-structures focus the person's perceptions on selected aspects of the environment, ready the organism for directed action, and prescribe comparatively more "automatic" responses for enactment than a non-emotional state of consciousness does. This view is best illustrated by a discussion of Bower's (1981) associated network theory of memory and emotion. Bower's theory was proposed to explain the phenomena of state-dependent learning and memory, but the model resembles so well the cognitive self-theory view of emotion that it bears detailed treatment.

Bower cites numerous instances from everyday 1 ife and from his own and others' experiments which show that under certain circumstances "Memories acquired in one state are accessible mainly in that state but are 'dissociated' or not available for recall in an alternate state" (p. 130). From this account, Bower concludes that the affect-depen- 
dent learning and memory produced in his experiments is experimentallyinduced dissociation.

The semantic-network approach to explaining dissociative emotional phenomena supposes that each distinct emotion such as anger, depression, or fear has a specific node or unit in memory, we might say in the self-theory, that collects together by associative pointers many other aspects of the emotion.

Associative pointers indicate the direction which associations flow when the first in a series is activated above some threshold of consciousness. Concepts formed about the self or about the world in an emotional state are associated to that central emotional node or hub. Dissociation is that structural phenomenon which means that the concept or memory is not available to consciousness in a different emotional state.

Included among the connections to an emotion node are associated autonomic reactions, standard role and expressive behaviors, and descriptions of standard evocative situations which when appraised lead to the emotion. Also included are verbal labels commonly assigned to this emotion such as anger, rage, and fury. According to Bower, some of these linkages are innate, while others are learned and elaborated throughout acculturation. In addition, each emotion unit is also linked with propositions or concepts describing events from one's life during which that emotion was aroused.

Figure 1 shows a schematic for a small fragment of the many con- 
nections to a given emotion node. (See p. 14.) As can be seen from Figure 1, the association pointers for most connections go both ways between the implicit conceptual element and the emotion node. In addition, whole chains of memory connections can be set off, symbolized by the connection between memory ${ }_{1}$ and memory ${ }_{n}$. One element in the schematic which was added to Bower's is that labelled "confirming appraisals." This signifies that the evocation of the emotion complex entails an attention-focusing on the environment for further emotionrelevantcues. The inhibitory connection between anger and some other emotion node in the schematic is hypothetical in the sense that there will be different degrees of inhibition or dissociation of other emotion-related material for different self-theories.

The significance of Bower's work for cognitive self-theory is that associative network theory provides a model for understanding the central significance of emotion in the self-theory. In addition, associative network theory fits within a general semantic-network theory of long-term memory of the type common in cognitive psychology. Associative network theory, which is very much like Hilgard's neodissociation theory (1977), allows for divided off segments of the sense of self which are more multifaceted than "repressed impulses" or "split objects" (Gruenwald, 1977). As was noted, emotion nodes are closely associated with autonomic, perceptual, cognitive, and behavioral routines and their dissociation can be viewed, within limits, as efficient organization in the self-theory. 


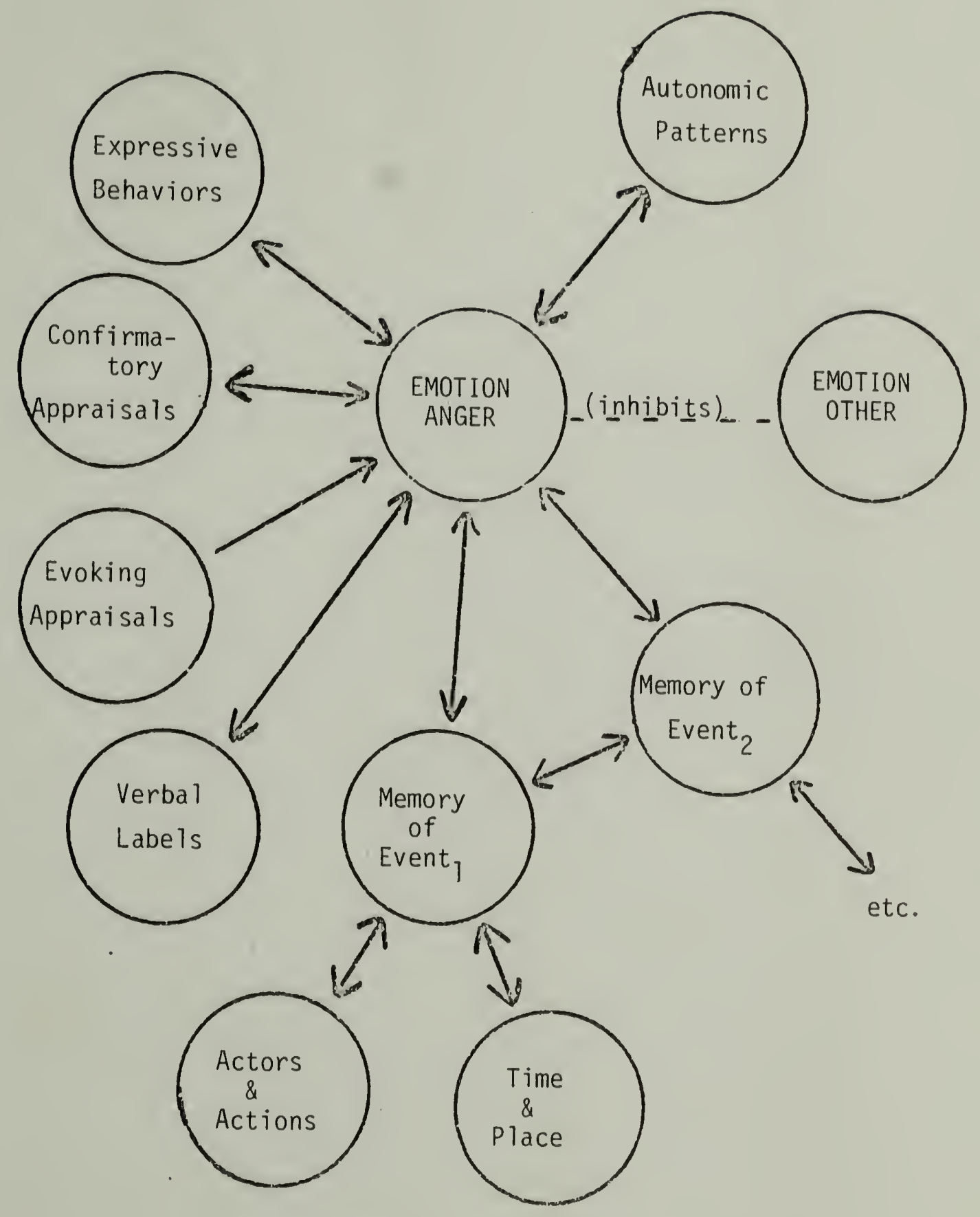

FIGURE 1

Schematic for an Emotion-Node Adapted from Bower (1981) 
Self-theory unity. Epstein has expanded on the idea that one of the purposes of the individual's self-theory is to assimilate the data of personal experience while maintaining its own organization (1978). After reviewing and theories of the self-concept of Goldstein, Lecky, Snygg and Coombs, and Rogers, he concludes that "all the theorists agree that there is essentially one basic need, which is to maintain the unity of the individual's conceptual system." This unity principle is seen as at least as important as any other principle of motivation such as to seek pleasure and avoid pain or to maintain self-esteem. The hierarchical organization of the self-theory and the substance of the central postulates in part determine what is pleasurable or painful. For example, winning at some sport will give me more pleasure if I hold a postulate that I am a good amateur athlete than it will if I do not hold such a postulate.

The unity maintaining activity of the self is seen as a kind of equilibration between the organism and the environment. Unity maintenance is a making sense of experience by a continuous assessment which is directed both outward to the world, especially the social world, and inward to the self-theory itself. One question raised by this view is whether these processes of outward and inward appraisal are carried out simultaneously or in turn. If the former, then what is needed is a theory of co-consciousness much like Hilgard's (1977) views concerning hypnosis. In brief, hypotic subjects can report that they experience a split in consciousness: one conscious- 
ness attends to the operator and the other monitors internal processing. Epstein's view that self-theory cognitions are implicit would seem to indicate that the consciousness which assesses the selftheory in an on-going way is also below awareness threshold. Perhaps one thing which characterizes the hypnotic state is the raising of this inward assessing consciousness into awareness.

When Epstein makes the analogy between the individual's selftheory and the formal sense making activities of the empirical sciences, this writer infers that the sense making activity of the self, governed by the unity principle is primary for cognitive self-theory. Pursuit of pleasure and avoidance of pain are normally hierarchically subordinate as motivational constructs to the unity principle for mature adults. Hence one can observe through history some people's willingness to give up life itself in order to maintain certain central postulates called ideological or religious. The pursuit of unity may also explain the "neurotic paradox," that is, the tendency of the neurotically anxious person to resist opportunities to change despite the discomfort and unhappiness which their postulates engender. Simply stated, the neurotic's daily anxious discomfort is lower than the anxiety he or she anticipates if a major change were to occur in basic postulates of the self-theory in order to reduce the daily discomfort.

A general theory of psychological disturbance based on this view will most easily begin with the simplest assumption: namely, "the assumption that there is a general tendency to assimilate experience 
into a single, unified conceptual system" (Epstein, 1978, emphasis added). Disturbance, from this simplest assumption, occurs when there is tension between discrepant information and the need to assimilate the data of experience into a unified system. In normal living this tension is quickly resolved by an assimilation of new experience through a hierarchical rearrangement of the conceptual system itself or by a modification of the content of one or more postulates. For example, if I hold the postulate that I am good at chess and I begin to lose a lot, I might subsume this postulate under a new one like, "I enjoy playing board games, win or lose." Thus, I can now lose at chess with much less damage to my self-esteem because I am confirming a new higher-order postulate. Alternately, I could simply modify my appraisal of my chess playing ability.

But when this assimilation cannot be accomplished, there will be a tendency to dissociate the material which cannot be taken in. Dissociation sets up a new tension within the self-theory because of the opposed tendency of the unity principle. This "cognitive tension" is experienced as anxiety. If I get anxious and angry in response to a threatened disconfirmation of an important self-theory postulate, then features of the event which threatens disconfirmation will be associated to both emotion nodes in the self-theory. In short, our emotional reaction to the threat of self-theory disconfirmation increases dissociation of the threatening material. These dissociated percepts, concepts, and postulates are not repressed and transformed in a dyna- 
mic unconscious, but are available to consciousness when the same emotion is evoked later.

I have argued elsewhere (Chilenski, 1982b) that the symptoms of combat-related post-traumatic stress disorder are the results of these two opposed tendencies in the self-theory. The self-referential percepts, concepts, and postulates associated with combat trauma are dissociated due to their fundamental incompatibility with the overall self-theory. This dissociation is marked by the denial and numbing phase of the stress-reaction characterized by amnesia, reduced activity, and restricted emotional range. But the operation of the unity principle results in repeated attempts to assimilate these traumatic self-referential data. This assimilation attempt is marked by repetitive and intrusive nightmares, flashbacks, and guilt feelings. In the delayed syndrome, assimilation is not accomplished and the pattern of denial and numbing alternating with repetitive intrusion of the data occurs again.

Dissociation and the self-theory. As will be recalled, Epstein has stated that an individual's self-theory may be evaluated by comparing its efficacy for the person to the classical standards of scientific theory. In this writer's view, Epstein raised the standard of internal consistency to a higher level of importance than the other standards by his later thoughts on the unity principle. It is the issue of unity or internal consistency for which the phenomenon of dissociation has the most important implications. But the introduction of the 
concept of dissociation to cognitive self-theory is a less radical departure from the unity principle than it might first appear to be. For Epstein already recognized the non-rational, non-explicable, and possibly non-unifiable core of the self in his use of emotions as a central theoretical concept and as the phenomena of choice for study. By studying the experience of emotion both perceptual and proprioceptive processes must be acknowledged. These processes occur and recur outside of the person's normal awareness. Intensive study of the emotions, leading to a more elaborated description of the individual's self-theory, therefore requires both analytic modeling and experiential investigation.

The existence of normal dissociation of self-theory material around the emotions may mean that the person's individual self-theory is ultimately non-unifiable. In short, the unity principle may have its limits, and these limits are probably adaptive. A too rigid emphasis on unity within the self-theory will result in a lack of flexibility and, in extreme cases, in the endangering of the entire selftheory structure. Since the opposite of unity in the self-theory is dissociation, it follows that some dissociation in the self-theory is probably and potentially adaptive as well. Hence, the dissociation of elements threatening to the overall self-theory occurs by our reacting to them emotionally.

Within any given emotion-cluster of postulates, the unity principle governs the integration of postulates. But between emotion-clusters, dissociation may be the rule. Thus as emotions alternately be- 
come regnant, there occurs a shifting among different unities. That is, there may be dominant different unities at different times. It is a matter of preference as to whether one wishes to refer to such a condition of shifting unities as a fundamental disunity. Epstein prefers to see this situation through the lens of the unity principle. This writer prefers to see it as a fundamental (and functional) disunity in order to highlight the phenomenological perspective. That is, the emphasis of this paper is on the experience of disunity (dissociation) and its implications for the experience of anger.

The maintenance of organization in the self-theory may depend both on the unity principle and on the ability to dissociate material threatening to that unity. This dissociation occurs within emotional experience. From this view, much of self-theory change in therapy can be seen as the assimilating of previously dissociated self-theory elements. Epstein (1979) has argued that acute schizophrenic disorganization may be an evolutionary adaptive response in the human cognitive system to a massive self-theory crisis brought on by the failure of the self-theory to perform its essential functions. Schizophrenic disorganization is itself described by him as the beginning of a "paradigm shift" which leads to a self-theory revolution. Epstein criticizes treatments of acute disorganization which fail to recognize the potential in these episodes for adaptive reconstitution or reconstruction of the self. It may be that such total self-theory disorganization results from a too rigid emphasis on unity in the person's 
self-theory.

These paradigm shifts of the self-theory, ie. total selftheory reorganization, refer to a significant change in higher order postulates which result in transformations of the entire personality. Such shifts of self-theory include religious conversion, self transformation brought about by ascetic disciplines and meditation, ideological brain washing, severe stress reactions, psychosis, and personality change in depth psychotherapy.

A paradigm shift in the self-theory refers to a phenomenon which is more common than these significant, usually radical, life changes. The emergence into conscious awareness of dissociated aspects of the individual's self-theory constitutes such a paradigm shift in the self-theory. Depending on the degree of relative unification/dissociation, an emotional experience can take on the qualities of a momentary paradigm shift. From a strictly phenomenological viewpoint, emotions are themselves ways in which we apprehend the world. This position has been a long-standing one in philosophical phenomenology (Sartre, 1956; Merleau-Ponty, 1964) but it has not been elaborated on by any psychologists since James. The factualness of this radical phenomenological view, however, is difficult to dispute. It helps account for the difficulties encountered in eliciting people's implicit cognitions. For on the phenomenological level, emotions create our apprehension of our world. Emotions function as paradigms for the person's moment-to-moment experience of himself and his 
world, the world-taken-for-granted.

The organization of significant elements of the self-theory around different emotion clusters constitutes the availability to the person of different emotion paradigms. A person knows how to be angry or loving. But it is nearly impossible to be both at once. Dissociation, then, is a normal limit to the forces of internal consistency or unity which otherwise govern the functioning of the selftheory. This basic phenomenological fact suggests that investigations in this area should take into account the pre-reflective, the perceptual, and the proprioceptive levels of experience in addition to the objectively apprehended cognitive and behavioral levels.

To summarize the argument thus far: the differentiation of an individual's self-theory, and therefore his/her adaptability within a wide range of emotional experience, is due to the separate clustering of significant self-theory postulates around core emotional experiences. Core emotional experiences are stored as memories and as readiness to respond, that is, as perceptual and behavioral routines or programs. These emotional clusters are sub-hierarchies in themselves which may be more or less interconnected with other sub-hierarchies. Tenuously or sparsely connected sub-hierarchies are cognitions and postulates which are dissociated from the more familiar and self-enhancing postulates in the self-theory. "Normal" postulate hierarchies. are those more readily available to conscious awareness. When the dissociation of aspects of the self-theory is extreme, such as in post- 
traumatic stress reactions for example, an emotional experience can have a quality of unreality -- as if the emotion does not really belong to the person experiencing it. Sometimes the unified self has the experience of "observing" some other self feeling the emotion and carrying it out into action. At other times the person may feel "possessed" by an alien emotional force.

From an associative-network view, these more extreme experiences are the result of associative connections being made between the emotion node and the details of an experience which is threatening to the overall integrity of the self-theory. That is, dissociation of threatening knowledge about oneself means that the knowledge remains as potentially part of emotional experience, and it is not integrated into the overall self-theory.

The phenomenology of dissociation. From the perspective of psychopathology dissociation is defined as an altered state of consciousness involving a segregated group of mental processes which are separate from normal consciousness but which function as a unitary whole (Barnes, 1980). Since dissociative phenomena have been recognized, dissociation has always been seen as "a weakness of psychological synthesis (Janet, 1907). This "weakness" is seen as "a defense against a danger-laden piece of psychic reality" (Dince, 1977).

The experience of dissociation can range from an awareness that one is acting in a peculiar manner, to a feeling of acting in the con- 
trol of an outside force, to having no awareness of one's actions until afterwards (Schafer, 1981). Because of these experiences, depersonalization is considered a prominent aspect of dissociation. Phenomenological reports of depersonalization appear in creative literature in most literate cultures. The best known form of depersonalization in literature and myth is the phenomenon of "the double" (Rank, 1971). While the phenomenon of "the double," a split-off and projected other self, is very rare in its pure form, there is some evidence that this extreme form of depersonalized dissociation occurs in partial forms (Damos-Mova \& Eacott, 1980).

What are the features of depersonalized dissociation? Most frequently reported is a feeling of the mind or the self being detached from the body (Noyes \& STymen, 1978; Shapiro, 1978; Barnes, 1980). Sometimes this detachment can result in distortions in the perception of one's body (Meares \& Grose, 1978; Blue, 1979). Hyperalertness can either accompany the perceptual distortion of the body or can occur alone. This hyperalertness to the environment is especially focused on threatening features (Noyes \& Slymen, 1978; Renik, 1978).

More extreme than detachment from the body is the experience of a detached part of the self cooly observing the rest of the acting self, the so-called "observing ego" (Renik, 1978; Shapiro, 19.78; Barnes, 1980). Feelings of self control are altered (B7ue, 1979) so that a person may report he was "not himself" (Barnes, 1980) or that the whole episode was "unreal" (Noyes \& S1ymen, 1978) and almost as 
though he was "not there" (Shapiro, 1978). Finally, there can be the experience of oneself as if the self were an actor or an automaton (Shapiro, 1978).

Dissociative anger. There is some evidence that extreme anger is an occasion for depersonalized dissociation. It will be recalled that there is no restriction on the kinds of associations which can be made to an emotion-node in the self-theory. This means that memories of being angry and of being the target of anger are associated and therefore both triggered by the experience of anger. The more threatening the accompanying memories, percepts, imagery, and impulses to the overall self-theory, the more dissociated from the integrated self is the entire anger complex. A cognition can be threatening to the self-theory because it cannot be integrated, because it lowers self-esteem, or because it produces painful feelings or behavior. This structural relation between anger and the more integrated emotions is likely to produce the subjective phenomena of depersonalized dissociation when the person becomes angry.

Clinical case reports on the direct treatment of excessive anger are few (Frost, 1981; Chilenski, 1982), and among this 1iterature only a few reports give some insight into the phenomenology of anger. It has been noted that psychotherapy clients presenting problems of anger control usually experience their anger as occuring suddenly and cyclically. They complain that their anger seems to arise out of nowhere; 
that is, they report their anger is experienced as unintegrated with their basic sense of self. As further proof of this, the person usually expresses disapproval of the anger and guilt over its consequences (Spiegal, 1980).

Excessive anger is often observed to be a defense against threats to a tenuously integrated sense of self (Bonime, 1976). Both Adler (1956) and Fromm-fieichmann (1950) described the existence of a personality type which uses anger not merely as a defense against anxiety but as the very basis for its tenuous integration and sense of identity.

One type of clinical case in which these processes emerge is in the treatment of child abusers. As for the role of anger in child abuse, data from a representative nationwide sample of incidents of child abuse reported to law enforcement agencies (Gil, 1970) indicate that "disciplinary measures against the child taken in uncontrollable anger" is a frequent antecedent of child abuse. Out of a sample of thirty-six cases of fatal child abuse (Weston, 1974), the reason for injury presented by the parent involved difficulties with crying, toileting, or feeding in $78 \%$ of the cases. All of these children were under six years of age; most were under eighteen months. It seems, then, that in most cases of child abuse, it can be assumed that anger plays a role and that the anger is of a severe, pathological nature.

It is clear that child abuse is a multi-generational problem. The evidence is overwhelming that the child abuser was him or herself 
abused as a child (Green, 1976; Kreindler, 1976; Blumberg, 1977; 1979;

Steele, 1978). There is also strong evidence to the effect that the child abuser suffers from low self-esteem and maintains immature or shallow relations with other adults. This is generally traced to the abuser's history of abuse as a child.

The child abuser has also been described as failing to develop a basic sense of trust as Erikson (1954) described it.

As a result

these patients develop an identity based on a loose collection of unintegrated, disparate concepts of the self. They can feel like a confident parent and quickly change to being nothing but a helpless, ineffectual, inadequate child. They can be a kindly adult and shift suddenly to being a punitive adult. (Kreindler, 1976, emphas is added)

The "sudden shifting" described here is a common experience of the child abuser. The following personal account is from a woman who killed her three-year old son who had been born premature and with a birth defect.

I blamed myself for both the premature birth and the defect... I was so full of fear of harming the babies ... I was overcome with guilt and the fear that I would end up taking my frustrations out on the kids ... The night (it occurred I was) extremely depressed ...something in me seemed to snap and I began slapping his face--hard, crying all the time... knew what was going on but it was as if my mind were above it all, watching. (Dabney, 1976)

We can conclude that there are dissociated areas of the self-theory, arranged around key emotional experiences (usually derived from a personal history of abuse) which "take over" in interpreting the 
child abuser's experience and in directing his or her actions. Possible mechanisms for this process will be described below.

The violent offender who is treated as an outpatient, another type of clinical case where excessive anger is at issue, tends to engage in multiple assaultive episodes which rarely involve planning or property crimes. This fact itself differentiates this group from the inpatient or incarcerated violent offender. Outpatient offenders, in general, Tack the antisocial attitudes which characterize the inpatients. Indeed, they tend to express a consistent set of pro-social values. This suggests that there exists a lack of integration in their sense of self. (Carney, 1977).

The outpatient violent offender tends to have an exaggerated sense of his own importance and an inability to see his own limitations. This leads to levels of aspiration far in excess of his abilities and to frequent conflicts with others, especially with authority figures (Danto, 1975; Sadoff, 1975; Carney, 1977). Violent patients are themselves disturbed by their loss of control. They actually fear losing control; at the same time, the hypervigilance required if they are to maintain control exhausts them. Therapy with these patients emphasizes the therapist's role as the patient's "auxilliary ego" (Kuehn \& Burton, 1969).

It is difficult to judge from the above published reports just what the relationship is between the violent outpatient's aggressive outbursts and feelings of anger. Nevertheless their impulsiveness and 
self-defeating patterns are cited so frequently that we must at least suspect that anger is involved most of the time. This conclusion is based first, on the unpremeditated nature of most of their assaultive episodes. Second, anger serves as a form of social justification for aggressive acts in many places and circumstances in our culture (Averi11, 1979).

Summarizing what can be gleaned from the clinical literature on the personalities of violent offenders and child abusers, one finds that their anger results from two sources. One cause for their anger is the experience of loss or deprivation (Bonime, 1976). Another cause is their own attempt to avoid further loss to an already weak ego or self-structure (Spiegal, 1980). The self-structure's weakness is shown by its exaggerated and idealized nature or by its fragmentation. Anxiety characterizes the anticipation of further loss and the anticipation of the consequences of their anger and impulsiveness (Madden \& Lion, 1978). The anxiety in turn leads to an even greater sense of threat.

In the case of the child abuser, what exactly is dissociated? One possibility is that as an abused child the future abuser is forced to maintain two incompatible sets of postulates concerning the self-child and the abusing parent. Because the child is dependent on the abusing parent in spite of the abuse, the child forms postulates about the parent that maintains a view of him/her as good and right. Postulates concerning the reality of the situation are dissociated. Each 
set of good-parent postulates and pad-parent postulates is associated with "bad me" postulates. The "logic" may be: "This good parent treats me bad when I am bad." That the parent is also bad remains unintegrated.

These postulates do not disappear into a dynamic unconscious but are associated with one or more emotion-nodes. The likely emotionnodes to which the "bad parent-bad me" postulates are associated are anger and fear. During abuse the child fears the abusing parent but cannot flee, the child becomes angry but cannot attack. During the adult, parenting years, anger or anxiety resulting from the normal frustrations and household calamities of child-rearing evoke these "bad parent-bad me" postulates. The misbehaving child becomes a stimulus for the sudden collapse of self-esteem, and for the raising of unintegratable self-theory material in the parent. Because the abuser's "good parent" postulates are hierarchically superior and usually regnant, this self-image is reasserted by the parent behaving as the previous parent did. Thus the parent becomes a "good parent" punishing a "bad child." Of course if the punishment causes physical harm, a new round of anxiety-anger-dissociation is likely to occur in the self-theory so that the intensity of dissociative anger increases and is experienced in a subsequent episode.

A hypothetical mechanism for the violent outpatient offender is more difficult to present because there is no single childhood percurser for violent outbursts as there is for child abuse. But this 
mechanism must be similar to that of the child abuser's. It probably involves the integration of a set of ideal self-other postulates and the simultaneous dissociation of both empirically valid and extremely negative self-other postulates. The dissociated postulates are associated with anger and perhaps fear and are evoked in the violent offender in the same way it occurs for the abusing parent. That is, the appearance of a situation that otherwise evokes anger or fear in most people also evokes a sudden drop in self-esteem of the violent offender because it challenges the integrated self-ideal and brings into focus the previously dissociated self-theory material. Since most such offenders are male, it could be hypothesized that the ideal which is treatened is the postulate hierarchy concerning images of one's own maleness which were formed out of earlier cognitions concerning the father figure.

General summary. The out-of-control nature of excessive anger is both an objective, observable feature when it occurs and it is an internal, subjective experience which changes the quality of the person's anger. Phenomenologically, the qualities of dissociative anger closely resemble features of depersonalization. Dissociative anger involves an experienced split between self and body, sometimes to the point of experiencing a second, observing self. It can involve a feeling of acting as if an automaton. There can be feelings of unreality about the self and about the situation. There can be a hypersensitivity to 
perceived threats to the self, and accompanying distortions of body sensations and perception. Finally, these symptoms and the knowledge of being out of control, or nearly so, serve to increase the already experienced anxiety.

The increased anxiety of dissociative anger is its most disturbing feature from a self-theory point of view. This is so since anger is dissociated in the first place in order to avoid the anxiety which is attendant upon integrating anger into the overall sense of self. This increased anxiety serves as a kind of negative feedback mechanism in the self-theory, causing a "shut-down" of the anger subsystem. It would be expected, then, that a dissociative anger episode would be quick to end once the depersonalized dissociation is experienced.

In summary, it is argued that the concept of dissociation is a necessary one in accounting for the central role of emotion in cognitive self-theory. Bower's associative network theory of memory and emotion provides a useful model for understanding the structure of dissociation within an overall integrated self-theory.

Self-theory relevant elements of any emotional episode which cannot be integrated into the overall sense of self are associated to the emotion sub-system and hence dissociated from the integrated sense of self. In a purely theoretical sense, dissociation is the naturally-occurring, adaptive structural relation among the emotions and between the emotions and the overall self-theory. This is because of the 
experientially unique, action-oriented, and focused perceptual routines set into motion by each emotion. It is argued here that dissociation of emotion is normal, but it can reach "abnormal" or dysfunctional degrees as in the case of anger resulting in child abuse and other violent offenses.

Anger was chosen as a demonstration case for this general view because anger is likely to have associated to it more cognitions and memories of a non-integrated kind than other emotions. There is some evidence from the literature on the treatment of excessive anger that symptoms of depersonalized dissociation are present during excessive anger episodes.

Chapter II presents several specific hypotheses concerning dissociative anger. Also reported is a study which tested these hypotheses with a sample of people with presumably normal degrees of dissociation between anger and their integrated sense of self. 


\section{H A P T E P I I \\ EVIDENCE FOR DISSOCIATIVE ANGER}

Based on the preceeding description of dissociation and on the theoretical argument in Chapter I, six items were created which measure an aspect of dissociation. These items are:

You had a feeling of impending disaster at the peak of of your anger.

At the peak of your anger you felt that you might be passing the "point of no return," as if your anger had a mind of its own.

You had a feeling of being detached from your anger, a detached part of yourself cooly observed your anger, and that detached part didn't experience the anger.

When you passed the peak of your anger you had a feeling of "What happened? How could I have done that? Was it really me?"

You had a feeling as if another person had gotten angry, as if it were not really you.

You had a feeling as if part of your judgement was suspended during part of the incident and you were automatically reacting to events sutside of your control.

These six items were combined into an index of dissociation which was used to test the following seven hypotheses.

Hypotheses and their rationale.

Strong anger-out as a dissociative phenomenon. Episodes of intense anger at another person (anger-out) are viewed as dissociative 
phenomena. This is true for several reasons. First, anger-out usually requires action whereas anger at self (anger-in) does not. Therefore anger-out is more likely than anger-in to be organized within the person's conceptual system as a discrete action-oriented sub-system. Second, there are more learned prohibitions against the outward expression of anger than against anger at oneself. These prohibitions set up an anxiety barrier between the larger conceptual system and the anger sub-system. This functionally and structurally separate action system is experienced as something like "an aspect of me that is not me" when anger is strong. Hence we can naturally observe people say, "He was not himself." or "I was not myself." when someone expresses strong anger which is disapproved. Third, certain perceived situations (perceived stimuli) will tend to magnify dissociative experiences because the situation includes a perceived threat to the person's sense of self. Anxiety is increased by this threat. The impulse to express strong anger is at least in part a form of anxiety avoidance. The actual expression of anger is an attempt to avoid an anxiety provoking situation by altering it. Viewed from the perspective of personal construct theory (Kelly, 1955), anger is an attempt to force confirmation of an already disconfirmed self-referential construct. The following two hypotheses follow from these considerations.

Hypothesis one: Anger-out (item \#1) is a dissociative phenomenon and anger-in (item \#2) is not. It is hypothesized that intensity of dissociation is positively correlated with intensity of felt anger-out, 
and that there is no significant correlation of dissociation with intensity of felt anger-in.

Hypothesis Two: Anxiety (item \#3) is positively correlated with intensity of dissociation since prohibitions against anger-out and perceived threats to self make dissociative anger-out an anxiety related phenomenon. This relation is independent of the direct relation between intensity of anger-out and intensity of anxiety.

\section{Dissociative Anger as Alienation From the Body}

From a phenomenological perspective, one experiences strong impulses to action, in this case to express anger, in one's body. To the extent that these impulses are unacceptable to the self, a person who is aware of physical and/or physiological changes during anger will likely experience such body changes as alien to the self, as a kind of "betrayal by the body." Nonawareness of the functioning of the physical body probably contributes to a subjective sense of self-integration (Sartre, 1956). We are usually unaware of physical and physiological functioning until these functions depart from baseline in arousal or until dysfunction occurs such as in pain or illness. Even in these cases, the self may succeed in re-integrating these body experiences into a relatively unified self-theory.

Dissociative anger-out will be accompanied by an increased awareness of physical or physiological changes. The awareness of these 
body changes will increase one's sense of self-alienation or nonintegration. Therefore the more physical arousal and/or change experienced in anger episodes, the more intensively dissociation will be experienced in those episodes.

Hypothesis Three: The index of dissociation is positively correlated with items which measure the experience of physical arousal and/or changes (items \#6 through \#14). This relation is independent of the direct relation between intensity of anger-out and the itensity of physical arousal.

\section{Dissociative Anger-out as Disinhibition to Attack}

Visual imagery. Spontaneous visual imagery occurs as a private event and is highty idiosyncratic. When it occurs in an interpersonal exchange it is usually highly disruptive to that exchange (Rayher, 1978). The occurrance of spontaneous visual imagery in an interpersonal exchange could also be an index of how severe a disruption to the self that exchange is.

One way the anger sub-system may be linked to the overall selftheory is through organized visual percepts depicting aspects of the person's history with the emotion of anger, either as an actor or as a target or both. These links are then experienced as spontaneous visual imagery as the anger sub-system is activated. An absence of a linkage between the anger sub-system and the usually dominant self- 
system would render the anger sub-system completely dissociated (= unconscious?). Multiple links consisting in verbal, visual, and other types of percepts would indicate an anger sub-system which is well integrated into the self. "Normal" dissociation of a relatively self-alien anger sub-system may depend on visual percepts to activate and to guide the anger.

Questions which assess the occurrance of spontaneous visual imagery ask for reports of images involving attack of others (item \#68), rejection of others (item \#69), being attacked (item \#70), being rejected (item \#71), and being deprived by another (item \#72).

Hypothesis Four: Intensity of dissociation is positively correlated with the intensity of the spontaneous visual imagery of attacking others (item $\# 68$ ). This relation is independent of the direct relation between intensity of anger-out and intensity of attack imagery. Impulses to attack. In most instances, attacking others is a socially prohibited response to an anger-inducing situation. To the extent that this social prohibition is internalized, the felt impulse to attack will increase feelings of depersonalization and self-alienation. On the other hand, increased overall feelings of dissociation serve to inhibit the dominant integrated and integrating self and this makes actual attack of others more likely.

Hypothesis Five: Impulses to attack (item \#82) are positively correlated with intensity of dissociation.

Hypothesis Six: Actual verbal or behavioral attack (item \#99) 
is positively correlated with intensity of dissociation. Both these relations are independent of the direct relations between intensity of anger-out with intensity of impulse to attack or intensity of actual attack.

\section{Dissociative Anger-out as Non-integration in the Self-theory}

Proneness to dissociative anger is an index of the person's lack of integration in the self-theory. Lack of self-theory integration will result in shifts of emotion which are seen as sudden by others, and which are experienced as unaccountable by the person. Non-integration of the anger sub-system with the overall self-theory will make it difficult for the person to terminate voluntarily his or her anger in a controlled or gradual way. A sudden shift into another emotional state, ie. the domination of the self-theory by another action-oriented sub-system, becomes one way of managing this disintegrative experience.

Items \#120 through \#123 of the questionnaire are introduced by the request for the subject to focus on the moment after the primary behavior was carried out and to indicate whether the anger was "immediately replaced" by another emotion. Given the necessity of shifting out of dissociative anger in order to terminate it, it is hypothesized that a successful shift requires a replacement emotion of intensity equal to the intensity of dissociation.

Hypothesis Seven: The intensity of the emotion that immediately 
replaces the person's anger (item \#123) is possitively correlated with the intensity of dissociation in the episode. This relation is independent of the direct relation between intensity of anger-out and intensity of the replacement emotion, if any.

\section{Procedure}

Subjects. Subjects were volunteers from among students enrolled in undergraduate psychology courses and from the writer's personal social network. Students participated for experimental credits, while others did so out of their own interest. A total of fiftyfive undergraduate psychology students were recruited as subjects. Ten completed the required fifteen Anger Episode Records. Seven personal acquaintances or friends of the writer were also recruited. Three finished the study.

All subjects filled out a pre-screening questionnaire. This questionnaire is a personality inventory (AFD Personality Questionnaire, Epstein, 1980), containing 94 self statements that the subject marks either true or false. From this inventory a subscale of conflict over hostility can be derived.

The conflict over hostility subscale for 56 subjects screened yielded a distribution of scores with $\bar{X}=23.11$; $s d=8.00$ (data from 6 subjects were unusable). Ten subjects were recruited whose scores were in the top quartile of the distribution and half of these eventually dropped out before completing the study. In addition, ten other 
subjects, most of whose scores were below the median of the distribution, were also recruited and hal $f$ of these subjects dropped out. Three of the acquaintances finished the study. The total subject $N$ who completed 15 episode records was 13 out of a total recruitment after screening of 27 . Subjects dropped out at various points in the study, but over half did so after the initial instruction session. Most of the rest left after completing only one anger record. This $52 \%$ dropout rate wi1l be discussed further in Chapter III.

Method. Appropriate informed consent forms were used for all subjects. All aspects of the research were revealed to the subjects beforehand except to identify the items assessing dissociation. Beyond this the subjects were treated as the co-investigators they rapidly become in this form of research. This one concealment seemed necessary because the term dissociation may be one which implies a negative evaluation to some people. Subjects' reactivity to this would otherwise be uncontrolled.

The basic contract with the subjects required that they attend two $1 \frac{1}{2}$ hour sessions with the investigator. In the first meeting subjects were instructed how to fill out the Anger Episode Record. The second session, a week later, was used to collect supplementary data, to check on the accuracy of the subjects' work, and to ensure that subjects' understanding of all instructions reached a satisfactory criterion.

Subjects were asked to fill out a complete Anger Episode Record 
whenever they got angry and to do so within twenty-four hours of the anger episode. They turned in their Records every week. Subjects agreed to supply a minimum of fifteen Records for analysis. The criterion for deciding whether an anger episode should be recorded was that subjects experienced some physical arousal; even slight arousal was sufficient. The instructions read: "The anger episode should be one in which you actually felt an increase in tension or physiological arousal, and did not simply think that you disapproved of something and should be angry." Previous pilot testing with a similar population showed that many subjects could average about three episodes per week.

The Anger Episode Record is a questionnaire which is organized into a preliminary worksheet and 123 questions responded to on a computer-scan sheet. It requires thirty to forty-five minutes to complete. The worksheet allows space for the subject to write a brief narrative of the episode. On the bottom half of the worksheet the subject fills out a schema for the episode based on a division of the episode into the objective stimulus, the perceived stimulus, the felt emotion, the felt impulses to action, and the actual behavior carried out. After filling in the schema with his or her own words, the subject uses a standardized list of stimulus and response labels to translate his or her words into codifiable data. Once this is completed, the subject begins the second part of the Record.

The questions which must be answered are arranged into sections 
identical to the five parts of the schema. Most of the 123 items are scored on a five-point scale with a blank indicating that the item does not apply. The items have been created to allow for a broad range of behavioral, cognitive, and physical experiences. It was expected that many items would be left blank on any single record. The content of the items was developed to test the above hypotheses and to gather general data about anger.

Most statistical analyses were conducted with a handheld calculator. The data from the 123-item questionnaire were edited by using the information on the Anger Episode Record worksheet as a check of accuracy in filling in the multiple choices on the scan sheet. The numerical data entries were valued at 0 to 5 .

Most items on the questionnaire are answered on five-point scales which call for subjects' estimates of the intensity of the experience described. (The entire Anger Episode Record is Appendix A.) The response scale usually ranges from "slight" to "extreme" intensity. Transcribing subjects' respcnses to a scale of 1 to 5 (with 0 being "does not apply") produces, in most cases, ordinal scale data. A few items (eg. \#42 to \#45, identifying the target of the anger) produce nominal scale data.

Epstein (1982) has demonstrated that data gathered in this manner can be analyzed in several ways when sampling over subjects, over occasions, and over variables simultaneously. Because of the final subject $\underline{N}$ (13), only grouped intra-subject and individual intra-sub- 
ject relationships between variables over occasions were analyzed. Grouped intra-subject correlations are obtained by eliminating intersubject variance by presenting a subject's score on a given variable as a standard score around the individual's mean. The transformed data can then be pooled across subjects and analyzed for common intra-subject variation. Such correlations are equivalent to the average of the individual intra-subject ocrrelations among all subjects. Correlation matrices for each individual subject describe the ebb and flow of variables for a single subject across the episodes reported by that subject. These correlations describe individual patterns of anger. By comparing the matrix for an individual subject with the matrix for the grouped intra-subject data, idiosyncratic departures from the group averages can be identified.

Results. Hypotheses one through seven were tested using grouped intra-subject correlations. Table 2 presents the between-subjects means and standard deviations for all variables along with grouped intra-subject correlations for selected variables with the dissociation index. (Table 2 is on pages 45-46.)

It should be noted that $\underline{r}^{\prime} s$ based on very low frequencies can be spuriously high. Therefore where the mean value of a variable is less than .5, the r's were not computed. This is not the case, however, for items which eventually comprise a scale, ie. the dissociation items and the physical change items. 
Table 1 presents the grouped intra-subject intercorrelation for the variables used to assess aspects of dissociation. (Table 1 is on page 44.) As can be seen from Table 1, each item is significantly correlated with every other item ( $\underline{p}$ is significant at least at the .05 leve 1). In order to estimate the internal consistency of reliability of combining these six items into a single scale, the SpearmanBrown formula was used. This is a general formula for estimating increased reliability of a scale with increased scale length (Ferguson, 19.71). This calculation is based on the average inter-item correlation multiplied by 6 since in this case six items are being combined. The average inter-item correlation is, $\bar{r}=.31$; the reliability coefficient for the six-item scale, a measure of internal consistency, is, $r_{k k}=.73$.

Al1 six items were combined by adding their values. A value for this dissociation index was created for every subject's fifteen episodes. This index was used to test all hypotheses. Hereafter, dissociation (DISSO) refers to feelings of: impending disaster, passing a point of no return, detached observing of oneself, unreality, depersonalization, and automatic acting.

Hypothesis one. Hypothesis One stated that strong anger-out is a dissociative phenomenon and anger-in is not. As can be seen from Table 2, both anger-out $(r-.35)$ and the partial correlation for anger-in $(r=.14)$ are significantly positively correlated with disso- 


\section{Table 1}

Grouped Intra-Subject Intercorrelations for Variables Assessing Dissociation. ( $N=13$ Subjects)

Variable

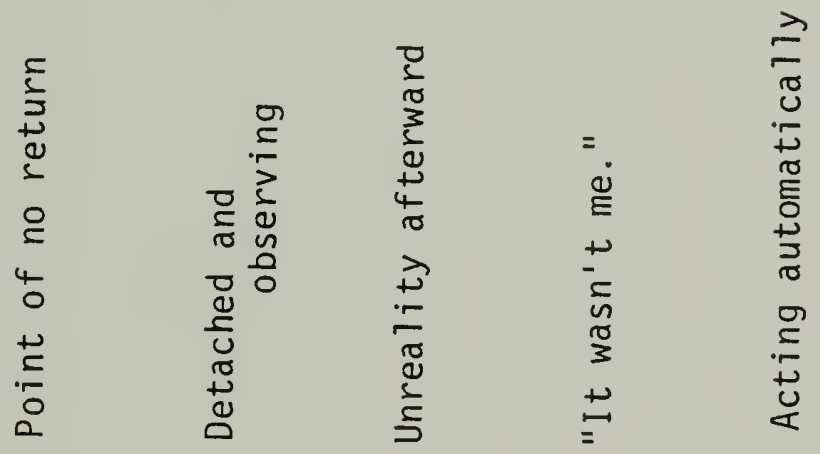

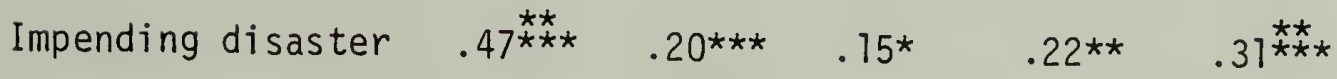

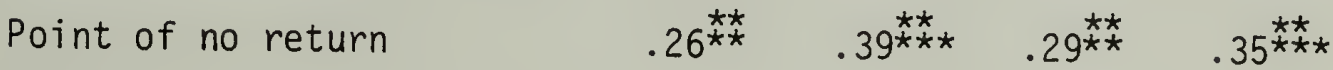

$$
\begin{aligned}
& \text { Detached and } \\
& \text { observing } \\
& \text { Unreality after- } \\
& \text { ward } \\
& \text { "It wasn't me." }
\end{aligned}
$$

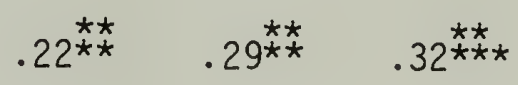

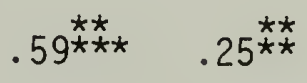

$$
\begin{aligned}
& .34 \stackrel{\star \star \star}{\star \star *} \\
& \text { *p significant at the } .05 \text { level } \\
& \text { ** p significant at the } .025 \text { level } \\
& \text { ***p significant at the .01 level } \\
& \stackrel{\star \star}{\star} \text { p significant at the } .005 \text { level } \\
& \stackrel{\star *}{* \star *} \text { p significant at the } .0005 \text { level }
\end{aligned}
$$


Table 2

Between-Subjects Means and SD's for all Variables; and Grouped Intra-Subject Correlations for Selected Variables with Dissociation and with Anger-Out. $(N=13$ Subjects)

\begin{tabular}{|c|c|c|c|c|c|c|}
\hline Variable & Mean & SD & & Correlati & & \\
\hline & & & $\begin{array}{c}\text { DISSO } \\
r\end{array}$ & $\begin{array}{r}\text { DISSO } \\
\text { partial }\end{array}$ & ANG-OUT & $d f$ \\
\hline $\begin{array}{l}\text { Dissociation } \\
\text { index (DISSO) }\end{array}$ & 2.46 & 4.45 & r & Pug & 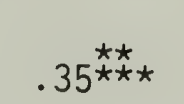 & \\
\hline Anger-out & 3.29 & 1.20 & 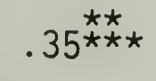 & - & - & 193 \\
\hline Anger-in & 1.03 & 1.43 & .07 & $.14^{\star \star}$ & $-.17^{\star \star}$ & 193 \\
\hline Anxiety & .84 & 1.39 & 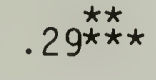 & $.27^{\star \star \star}$ & .14 & 103 \\
\hline $\begin{array}{l}\text { Physical change } \\
\text { index }\end{array}$ & 4.70 & 5.66 & $.37^{\star \star \star \star}$ & 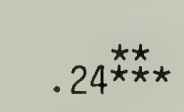 & $.51^{\star \star \star \star}$ & 193 \\
\hline muscle tension & 1.47 & 1.58 & 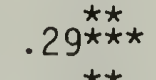 & $.15^{\star \star}$ & 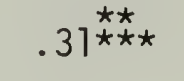 & 193 \\
\hline scalp tension & .19 & .76 & 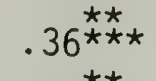 & 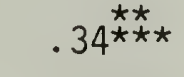 & .14 & 88 \\
\hline headache & .26 & .88 & $.26^{\star \star \star}$ & $.22^{\star \star \star}$ & $.16^{\star}$ & 118 \\
\hline $\begin{array}{l}\text { tremor or } \\
\text { shaking }\end{array}$ & .35 & 1.06 & 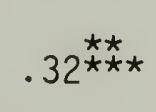 & 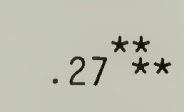 & $.21^{\star \star \star}$ & 133 \\
\hline $\begin{array}{l}\text { increased } \\
\text { heart rate }\end{array}$ & .97 & 1.51 & 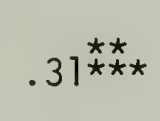 & $.19 \star \star \star$ & 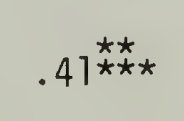 & 163 \\
\hline $\begin{array}{l}\text { changes in } \\
\text { breathing }\end{array}$ & .62 & 1.30 & $.34^{\star \star \star}$ & $.23^{\star \star \star} \star x$ & 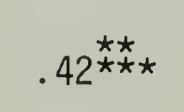 & 163 \\
\hline $\begin{array}{l}\text { difficulty } \\
\text { swallowing }\end{array}$ & .09 & .44 & 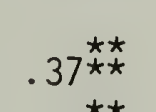 & 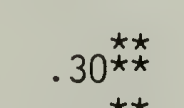 & $.28^{\star \star}$ & 73 \\
\hline voice changes & .43 & 1.30 & 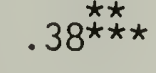 & $.29^{\star \star \star} \star$ & 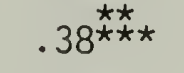 & 133 \\
\hline tears & .20 & .73 & .12 & .06 & $.20 \star \star$ & 133 \\
\hline $\begin{array}{l}\text { visual imagery } \\
\text { of: } \\
\text { attacking other }\end{array}$ & 12 & & & & & \\
\hline & $.4 \angle$ & & & - & $\begin{array}{c}- \\
39 * x \\
* x\end{array}$ & \\
\hline heing a & .00 & & & (1) & $.09 \mathrm{~m}$ & \\
\hline orto & 50 & & & 0 & 75 & \\
\hline being rejected & .52 & 1.22 & 0 & .06 & -.15 & 148 \\
\hline being deprived & .59 & 1.32 & -.13 & $-.18^{\star}$ & .11 & 133 \\
\hline
\end{tabular}


Table 2

(continued)

Between-Subjects Means and SD's for all Variables; and Grouped Intra-Subject Correlations for Selected Variables with Dissociation and with Anger-Out. ( $N=13$ Subjects)

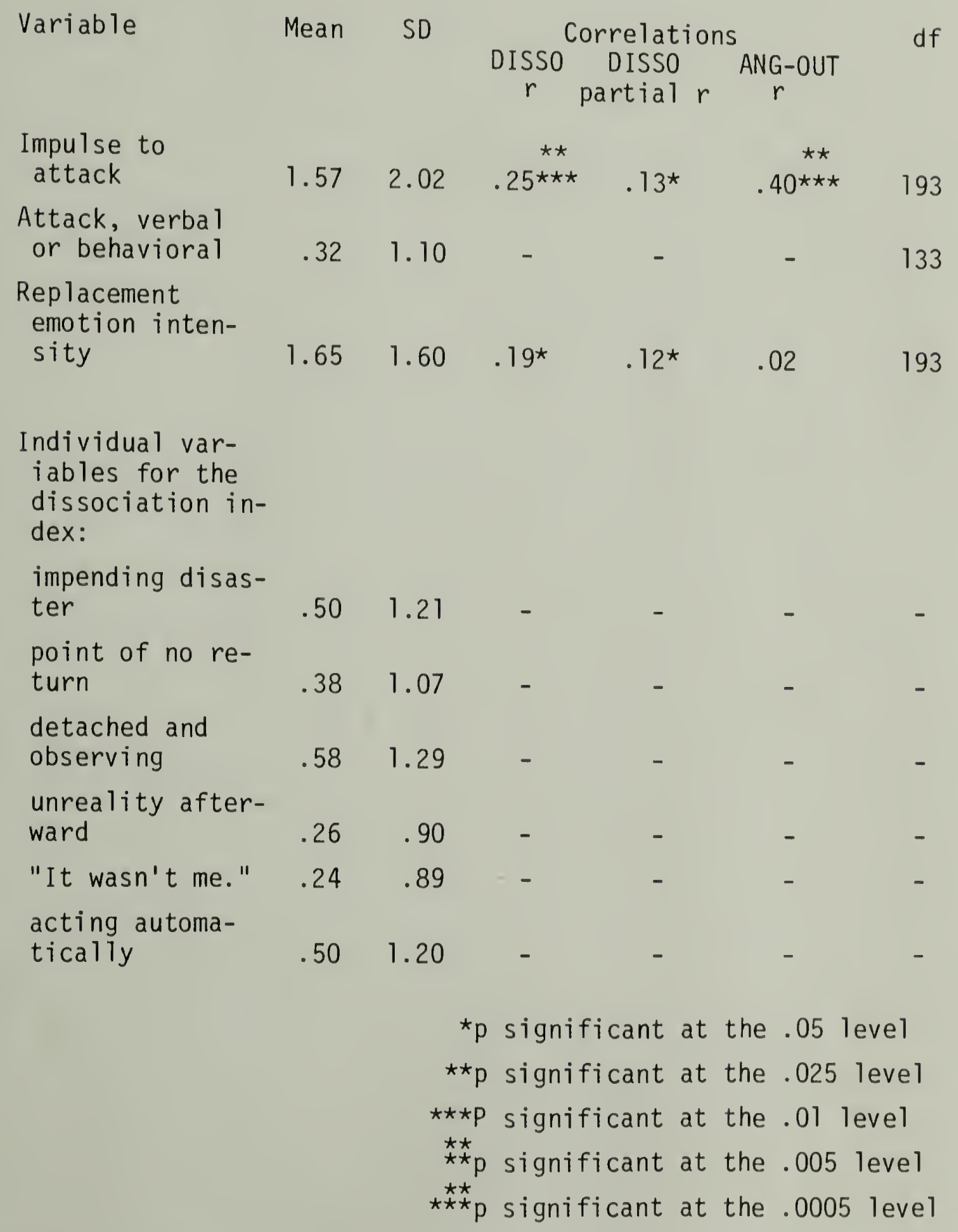


ciation. It should be noted that all correlations with dissociation discussed here (except for dissociation with anger-out) are firstorder partial correlation coefficients (Ferguson, 1971) with the effect of anger-out removed from both dissociation and the variable of interest. Anger-out shows a stronger relation to dissociation than does anger-in. The main point of Hypothesis one is supported by these results, al though the relation of anger-in with dissociation means that dissociative phenomena occur with anger at oneself independently of the occurrance of anger-out. This is a more complicated result than was expected. The negative relation between anger-out and anger-in $(r=-.17)$ al so supports the partial correlation result. A $\underline{t}$-test of the difference between the correlations for dissociation with anger-in vs. anger-out with anger-in was also made (Ferguson, 1971, p. 171). This is a test of which of either dissociation or anger-out is a better predictor of anger-in. It was found that dissociation predicts anger-in better than does anger-out $(\underline{t}=3.91, \underline{p}<.0005)$. This is a result which, when considered with the above results concerning this first hypothesis, requires considerable discussion which will be presented in Chapter III.

Hypothesis Two. Hypothesis two stated that anxiety is directly related to dissociation. As can be seen from Table 2, with the effect of anger-out removed, anxiety shows a positive correlation with dissociation $(r=.27)$ and no significant relation with anger-out. Thus Hypo- 
thesis Two is confirmed.

Hypothes is Three. Hypothesis Three stated that dissociative anger is directly related to physical arousal and/or change. In order to test this hypothesis, a single index of physical change was constructed from the nine items which assessed different physical changes. Table 3 reports the grouped intra-subject intercorrelations for these variables. (Table 3 is on page 49.) As can be seen from Table 3, all but three of the thiry-six intercorrelations are significant at least at the $\underline{p}=.05$ level. The Spearman-Brown reliability coefficient, based on an average inter-item correlation of .35 , for nine items is, $r_{k k}=.83$. The nine items were combined to form a single index of physical change for each of the fifteen episodes of every subject.

As can be seen in Table 2, overall physical change is positively related to dissociation after the effect of anger-out is removed ( $r=$ .24). Of course, as would be expected, physical change is also related to anger-out $(r=.51)$. Hypothesis Three is confirmed.

A $\underline{t}$-test of the difference between the correlations for dissociation and for anger-out was also made. Anger-out is the better predictor of physical change $(\underline{t}=-3.83, \underline{p}<.0005)$. This is not a surprising result given the large role of physical arousal in anger.

Hypothesis Four. Hypothesis Four stated that dissociative anger is directly related to the spontaneous occurrance of visual imagery of 


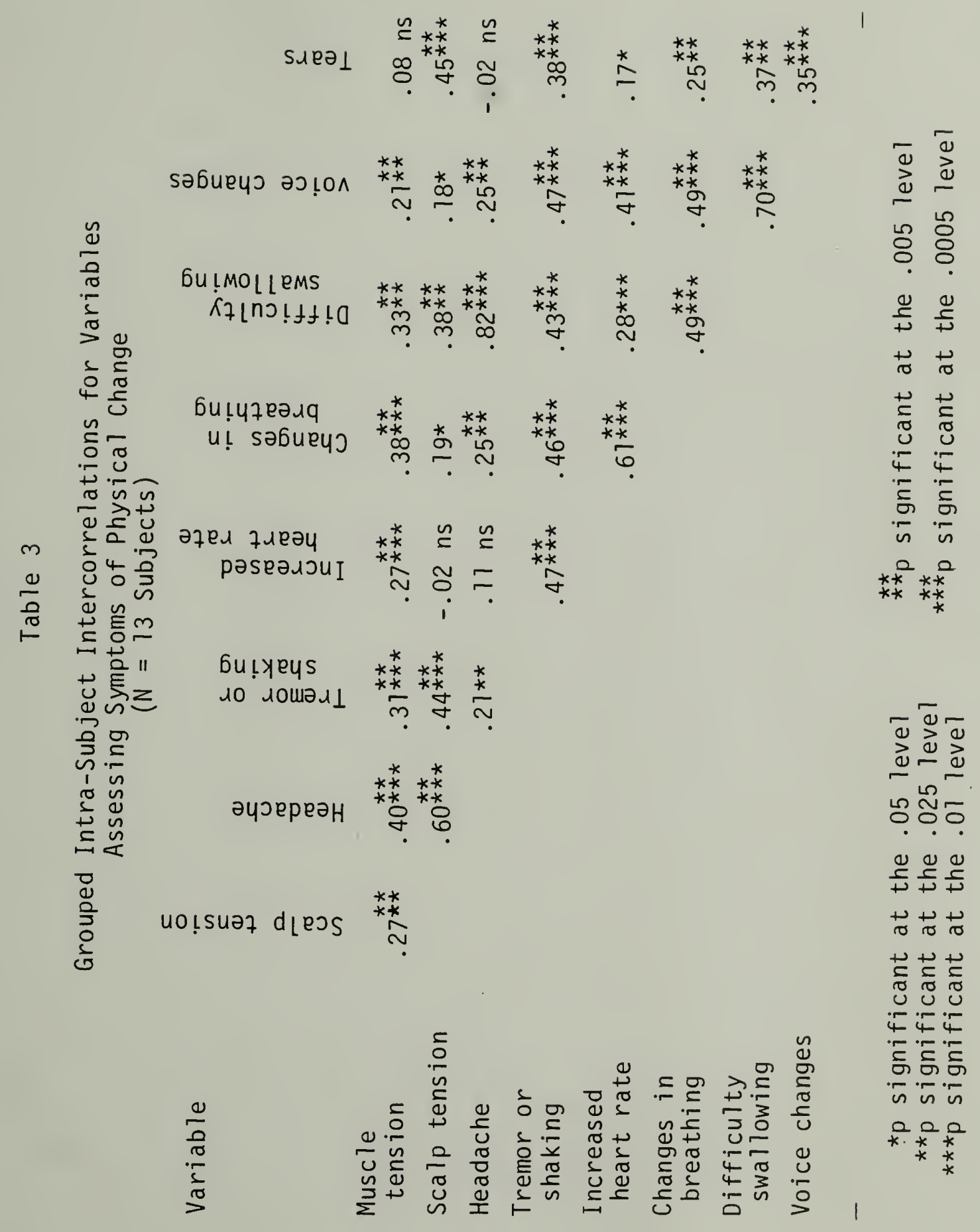


attacking others. Questions were developed to assess other possible spontaneously occurring visual images. As can be seen from Table 2, dissociation is not related to visual imagery of attack. Imagery of rejecting $(r=.39)$ the other are related to anger-out. Hypothesis Four is not confirmed.

Hypotheses Five and Six. Hypotheses Five and Six stated that impulses to attack and actual verbal of behavioral attack are related to dissociation. As can be seen from Table 2, after the effect of anger-out is removed, impulses to attack is related $(r=.13)$ but actual attack is not. This pattern is repeated for anger-out; impulse to attack is related $(r=.40)$ and actual attack is not. Hypothesis Five is confirmed and Hypothesis Six is not confirmed.

I-tests of the differences between the correlations for dissociation and for anger-out with impulses and with actual attack were made. Anger-out is the better predictor of impulses to attack $(\underline{t}=-3.58$, $\mathrm{p}<.0005)$. Neither variable predicts actual attack better than the other $(\underline{t}=-.31$, n.s. $)$.

Hypothesis Seven. Hypothesis Seven stated that the intensity of the emotion which immediately replaces anger is directly related to the intensity of dissociation experienced. As can be seen from Table 2, there is a direct relation between the intensity of replacement emotions and dissociation $(r=.12)$ when the effect of anger-out is re- 
emoved. There is no relation of this intensity measure to anger-out. Hypothesis Seven is confirmed.

High dissociation and low dissociation subjects. This method of data collection and analysis allows for the quantitative as well as the qualitative analysis of individual cases. Individual cases were selected for closer examination on the basis of rank-ordering the thirteen subjects on their average dissociation scores over fifteen episodes.

The top six subjects were designated the High Dissociation Subjects. Table 4 presents the means, standard deviations, and correlations of interest for the High Dissociation and the Low Dissociation groups. (Table 4 is on pp. 52-53.) As can be seen from Table 4, these groups differ in their average dissociation index score such that for High Dissociation Subjects, $\bar{X}=3.92$, and for Low Dissociation Subjects, $\bar{x}=1.20$. By $\underline{t}$-test (for populations with unequal variances), the difference between these means is significant ( $\underline{t}=$ 4.304, $p<.0005,1$-tailed). Interestingly, the means for anger-out for the two groups are nearly equal $(\underline{t}=.346, n . s$.$) . Thus any other$ differences between these groups can be attributed to differences in dissociation intensity with more confidence. It should also be noted in this context that the groups do not significantly differ on their average scores for the conflict over hostility sub-scale of the prescreening questionnaire $(\underline{t}=1.27, d f=11 ; n . s$.$) . (The interested$ 
Table 4

Between-Subjects Means \& SD's \& Grouped Intra-Subject Correlations for Selected Variables:

High Dissociation Ss $(N=6)$

Variable

Mean SD

Correlations
DISSO DISSO ANG-OUT
$r$ Partial $r \quad r$

Dissociation index (DISSO)

$3.92 \quad 5.84$

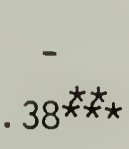

$-\quad .38^{\star \star \star \star *}$

88

Anger-out

$3.32 \quad 1.29$

.09

$-$

$-\quad 88$

Anger-in

$1.39 \quad 1.62$

$.19 *$

$-.21 \star \star$

88

Anxiety

$.92 \quad 1.56$

$.20^{*} \quad .16$

.13

73

Physical change index

6.47

6.50

$.46^{\star \star \star \star *} \cdot 32^{\star \star \star \star}$

$.57 \stackrel{\star \star}{\star \star \star}$

88

Visual imagery

of:

attacking other

rejecting other

.75

1.62

.13

.03

$.26^{\star \star}$

58

rejecting other .88

1.77

.14

.02

$.32^{\star \star \star}$

73

being attacked

$.31 \quad 1.01$

$-$

-

$-\quad 58$

being rejected

being deprived

$.68 \quad 1.41$

.10

.16

$-.12$

73

Impulse to

attack

$.51 \quad 1.19$

$-.15$

$-.22$

.13

73

Attack, verbal

or behavioral

$2.09 \quad 1.63$

$.33^{\star \star \star}$

$.20 *$

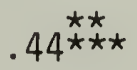

88

$.51 \quad 1.36$

$.37^{\star \star \star} \star 37^{\star \star \star}$

$.24^{\star \star}$

73

Replacement

emotion intensity

$1.59 \quad 1.58$

$.40^{\star \star \star}$

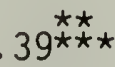

.11

88

(continued on next page) 
Table 4
(continued)

Between-Subjects Means \& SD's \& Grouped Intra-Subject Correlations for Selected Variables:

Low Dissociation Ss $(N=7)$

Variable

Mean SD

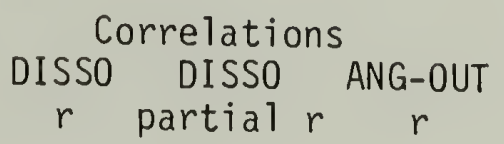

df $r$ partial $r$ ANG

Dissociation index (DISSO)

Anger-out

1.20

2.08

3.26

1.13

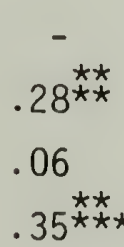

$28 \stackrel{\star \star x}{\star}$

103

Anger-in

.72

1.18

.77

1.24

$.35^{\star \star \star *}$

.10

$-.14$

Anxiety

3.18

4.31

$.30^{\star \star \star *} \star 20^{\star \star *}$

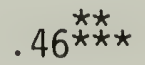

Physical change index

Visual imagery

of:

attacking other

$.14 \quad .66$

- $\quad-$

rejecting other

$.42 \quad 1.16$

- $\quad-$

being attacked

$.02 \quad .20$

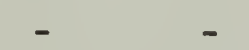

being rejected

$.35 \quad 1.00$

$-$

73

being deprived

$.67 \quad 1.42$

$-.10$

$-.13$

.09

58

Impulse to attack

1.13

1.86

$.28^{\star \star}$

$.20 * \star$

$.37 \stackrel{\star \star \star}{* \star \star}$

103

Attack, verbal or behavioral

$.16 \quad .80$

-

$\begin{array}{ll}- & 58\end{array}$

Replacement emotion intensity

1.69

1.64

.01

.03

$-.06$

103

*p significant at the .05 level **p significant at the .025 level $\star \star * p$ significant at the .01 level $\stackrel{\star \star}{*} p$ significant at the .005 level

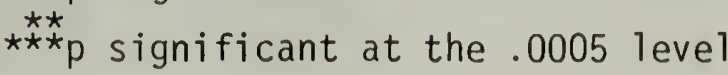


reader will find descriptive data for the screening questionnaire in Appendix B.)

The High Dissociation group is significantly higher than the Low Dissociation group on intensity of anger-in $(\underline{t}=3.27, p<.005)$, intensity of physical change $(\underline{t}=4.20, p<.0005)$, intensity of impulse to attack $(\underline{t}=3.36, p<.005)$, and intensity of actual attack $(\underline{t}=2.13, p<.025)$. There were no significant differences between group means on intensity of anxiety $(\underline{t}=.714$, ns) and on intensity of the replacement emotion $(\underline{t}=-.434, \mathrm{~ns})$.

For High Dissociation subjects, correlations of the dissociation index with other variables (after the effect of anger-out is removed) show several consistencies with the results for all thirteen subjects. These correlations also show some departures from the patterns for all thirteen subjects. Dissociation is positively related to anger-out $(r=.38)$, to anger-in $(r=.19)$, to physical change $(r=.32)$, to impulse to attack $(r=.20)$, and to the intensity of the replacement emotion $(r=.39)$. Unlike the results for the whole group, dissociation does not show a significant relation with anxiety when the effect of anger-out is removed. Consistent with the overall results, visual imagery of attack still does not show a relation to dissociation. The most interesting new results at this step are that anxiety no longer shows a relation to dissociation $(r=.39)$. The correlations of angerout with the other variables show the same pattern as the overall results. 
For Low Dissociation subjects, dissociation is related to angerout $(r-.28)$, to anxiety $(r=.33)$, to physical change $(r-.20)$, and to impulses to attack $(r=.20)$. The correlation patterns for anger-out among the Low Dissociation subjects is similar to the pattern for the High Dissociation subjects.

In summary, the High Dissociation group is characterized by more anger-in, more physical change or arousal, more intense impulse to attack, and more intense actual attack than the Low Dissociation group. The High and Low groups have in common significant correlations between dissociation and anger-out, physical change, and impulse to attack. Only for the High Dissociation group is dissociation correlated with anger-in, with intensity of attack, and with intensity of the replacement emotion. Only for the Low Dissociation group is dissociation correlated with anxiety.

The grouped phenomenological picture of high dissociative angerout, then, includes high levels of physical change and impulses to attack the other. Under conditions of high dissociation, these impulses are more likely to be carried out into words or action. All other things equal, the actual attack is more intense under high dissociation conditions. Finally, and perhaps most importantly, high dissociative anger-out is characterized by high levels of anger at oneself. One possible explanation of this is that there is an internal conflict between strong impulses and idealized schema within the self-theory concerning acceptable behavior. 
Individual cases. Individual subjects for single case analyses were selected to represent the High and Low Dissociation groups. The three subjects with the highest and the three subjects with the lowest average dissociation scores were selected. Tables 5 through 10 present each subject's means, standard deviations, and correlations. The correlations between dissociation and the other variables (except the correlation with anger-out) are all first-order partial correlations with the effects of anger-out removed.

Further correlational analyses were conducted for each of these selected individual cases. First, all the perceived stimuli responses (items \#53 - \#67) and a11 the impulse to action responses (items \#83 \#97) were correlated with the dissociation index and with intensity of anger-out for each subject. Next, dissociation and anger-out were correlated with reports of "self statements", ie. statements to oneself during the episode (items \#74 - \#80). Significant correlations found by these methods are reported in each case discussion.

A more detailed look at these six individual cases serves to "flesh out" the reported quantitative summaries. But there is a need to present here something less than the complete protocol of each subject. The qualitative portion of each case presentation is therefore organized around a consideration of the "part-selves", or social identities, involved in the individual subject's anger episodes.

Depersonalization and dissociation has been found to be more frequent in adolescence than in adulthood. One explanation is that the 
development of the adolescent personality involves a temporary "mismatching" between part-selves or internal identities and the social selves which are yet to be learned and integrated (Meares \& Grose, 1978). From the perspective of cognitive self-theory, anger is aroused in the present subjects when events are perceived by them as being self-relevant. To the extent that dissociated aspects of these subjects' self-theories become involved, they may be experiencing a "mismatching" between their integrated selves and their dissociated part-selves. A qualitative examination of their anger episodes, in each case, reveals their current concerns for their identities, whether they may be considered adolescents or not. The episodes of the High Dissociation subjects, by this reasoning, show more events involving non-integrated part-selves than do the episodes of the Low Dissociation subjects.

\section{Subject Number 2, Joe, a High Dissociation Subject}

Joe is a thirty-one year old divorced, white male who had been in combat in Vietnam and who was, at the time of the study, a sophomore in college with a $C$ average. He is the third of four children and he lives alone off campus with no dependents in his care. He is a recovered alcoholic. He stated that he sometimes considered himself an angry person and that he sometimes had trouble with his anger. He could not say what this trouble was when he was filling out the preliminary questionnaires, but he reported this trouble had been the focus 
of therapy in the past with positive results. At the time of the study he was not in therapy. He stated that he frequently had the experience of suddenly snapping into or out of some intense emotional experience or state. He thought there was no single person who considered him to be an angry person.

Joe ranked first out of a 11 thirteen subjects on the average dissociation rating for fifteen episodes. During the course of the study, Joe frequently visited me in my office for help in filling out the record and just to visit. He stated several times that he had difficulty participating but he persisted because he felt he was getting something worthwhile out of it. Joe is a friendly person who had had a volitile and difficult adult life. At the time of the study he was involved with a Vietnam Veterans group and with Alcoholics Anonymous. He completed fifteen episodes in two months.

Table 5 reports Joe's means, standard deviations, and correlations for the index of dissociation and for anger-out with the variables of interest. (Table 5 is on page 59.) As can be seen from Table 5, dissociation shows no significant relation with anger-out al though the value of $\underline{r}(.41)$ is close to significance. Neither does dissociation show a relation to anxiety.

With the effects of anger-out removed, Joe's data show relations between the experience of dissociation and anger-in $(r=.68)$, physical change $(r=.79)$, impulses to attack $(r=.55)$, and actual attack $(r=$ .66). Anger-out is correlated inversely with anger-in $(r=.78)$, 
Table 5

Means and SD's and Intra-Subject Correlations for Selected Variables: Subject 2 (Joe, High DISSO)

(a11 $\left.d f^{\prime} s=13\right)$

\begin{tabular}{|c|c|c|c|c|c|}
\hline Variable & Mean & SD & $\begin{array}{l}\text { DISSO } \\
r\end{array}$ & $\begin{array}{c}\text { orrelations } \\
\text { DISSO } \\
\text { partial } r\end{array}$ & $\begin{array}{c}\text { ANG-OUT } \\
r\end{array}$ \\
\hline $\begin{array}{l}\text { Dissociation } \\
\text { index (DISSO) }\end{array}$ & 9.00 & 10.21 & - & - & .41 \\
\hline Anger-out & 3.07 & 2.34 & .41 & - & - \\
\hline Anger-in & 1.87 & 2.39 & .07 & $.68^{\star \star \star}$ & 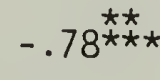 \\
\hline Anxiety & 2.20 & 2.48 & .08 & .19 & -.21 \\
\hline $\begin{array}{l}\text { Physical change } \\
\text { index }\end{array}$ & 10.47 & 10.59 & $.83^{\star \star \star} \star x \star$ & $.79^{\star \star \star}$ & $.50^{\star}$ \\
\hline $\begin{array}{l}\text { Visual imagery } \\
\text { of: } \\
\text { attacking other }\end{array}$ & & 2.44 & .14 & .08 & .17 \\
\hline rejecting other & 3.00 & 2.54 & .25 & .05 & $.57 \star \star$ \\
\hline being attacked & .33 & 1.29 & - & - & - \\
\hline being rejected & .93 & 1.94 & .36 & .36 & .11 \\
\hline being deprived & .60 & 1.59 & -.25 & -.25 & -.05 \\
\hline $\begin{array}{l}\text { Impulse to } \\
\text { attack }\end{array}$ & 3.13 & 2.23 & $.53 \star \star$ & .37 & 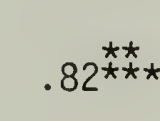 \\
\hline $\begin{array}{l}\text { Attack, verbal } \\
\text { or behavioral }\end{array}$ & .60 & 1.59 & $.67 * \star \star$ & $.55 \star \star$ & .33 \\
\hline $\begin{array}{l}\text { Replacement } \\
\text { emotion inten- } \\
\text { sity }\end{array}$ & 1.13 & 1.55 & $.46^{\star}$ & $.66^{\star \star \star}$ & -.28 \\
\hline
\end{tabular}

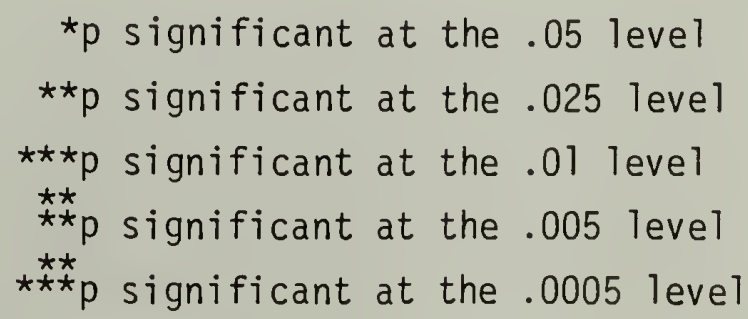


and directly correlated with physical change $(r=.50)$, with visual imagery of rejecting other $(r=.51)$, and with impulses to attack $(r=.81)$. The additional correlational analyses revealed that among perceived stimuli the perception of a threat to values was inversely related to dissociation \#35, $r=-.59$, df $=13, p<.02$, $2-$ tailed). The perception of failing by his own standards was inversely related to anger-out ( $\# 26, r=-.81, p<.0005)$.

Joe's episode \#8 has his highest value for the dissociation index (30) and is also one of the episodes which has the highest score for anger-out (5).

I was explaining to a friend on (sic) how to play tennis. He was being an asshole fucking around. I went bullshit. Flew into a rage. Yell and scream at him Its in the feet, asshole, its in the feet. I was told that I lost complete control of it all and it was funny to other people.

Many of Joe's narratives have this sketchy quality. This may be partly due to the fact that Joe would often re-experience his anger while trying to write the narrative. It appears that Joe's friend would not take his tennis lesson seriously and joe flew into a rage. What is noteworthy here is that joe seems to have no actual memory of what he did. He reports that it was other people who reported to him that he lost complete control. This is certainly a face valid case of dissociation. Joe stated that all measured aspects of dissociation were a part of his experience, and he marked every item comprising the index its maximum value for intensity. His experience includes feelings of depersonalization, self-alienation, unreality, lack of 
control, and impending disaster.

Joe perceived what he later called the inconsideration of his friend as being himself blocked or frustrated from his goal. Perhaps Joe's goal was to demonstrate his own skills, but this is conjecture. As his anger built, he experienced strong physical arousal (on seven out of nine variables). He experienced imagery of rejecting his friend and impulses to attack him, to assert himself, and to discharge tension. He carried out all these impulses in behavior. The anger, which was mixed with anger at himself, lasted less than thirty minutes during which time he was unaware of any self-statements. In this case despite his correlation over all his episodes, he experienced no replacement emotion.

In this episode there is little mediation between impulses and behavior. Joe expressed his feelings and impulses directly and intensely. The lack of control is so pronounced that he was unaware of its full extent until later. As reported above, Joe also re-experienced his anger when he wrote his narratives. Other episodes involved vivid imagery of attacking another and he thought that these images and their re-experience were similar to combat-related "flashbacks" which he had experienced earlier in his life.

Three of Joe's "part-selves" or social identities: self as recovered alcoholic, self as worker, and sexual self, are involved in his anger episodes. Each of these identities is implicated in four episodes apiece. Self as friend-to-others is involved in two more. 
The average dissociation level for the four anger episodes involving self as worker is 17.5. The episode presented above in detail is one of these. Joe is studying to teach physical education. His reaction to his friend not taking the tennis lesson seriously is more understandable in this light. A similar episode, but one which involved only anger at himself, involved umpiring an intra-mural softball game. This activity is required of students studying coaching. Joe had let his mind wander during the game and consequently he made several bad calls. He was verbally abused by the players and reprimanded by the other umpire. Joe contained his reaction until he could vent his feelings later.

Four anger episodes concern incidents occurring at $A A$ meetings. The average dissociation rating is 8.75 . In one incident, Joe got extremely upset when he thought the anonymity of the meeting was being violated by some visitors who were taking notes. Interestingly, Joe's dissociation rating for this incident is 5 , but he reported another anger episode which wholly consisted in a vivid memory of the anonymity violation. In the first, the actual, episode he did not attack the visitors as he had wanted; but in his memory episode he fantasized attacking them.

In the two anger episodes involving self as friend-to others, he was left behind by a change of friends' plans with no notice (DISSO = 15), and he lost a tape which he had borrowed from a friend (DISSO = 0). Finally, three incidents involved conflicting feelings about a woman and one involved being the target of a homosexual pass. The 
average dissociation rating for these four episodes involving sexual identity is 2.5 .

Based on the average dissociation ratings for the anger episodes clustered by "part-selves" or social identities, Joe is least integrated in his sense of self as worker, followed by self as recovered alcoholic, self as friend-to-others, and sexual self.

Joe's data match well the grouped data for the High Dissociation Group. Joe's data show correlations between dissociation and anger-in, physical change, actual attack, and the intensity of the replacement emotion, as the grouped data do. Joe's correlation for dissociation and anger-out is nearly significant. The only difference in Joe's correlation pattern from the High Dissociation Group pattern is that he does not show a correlation between dissociation and impulse to attack.

In reviewing this first case, it would seem that dissociation can arise from several sources of conflict within Joe's self-theory. First, Joe experiences anger at himself during some of these episodes. Anger-in occurs together with anger-out only in one episode, however. The rest of the anger-in episodes are "pure" anger-in with no angerout reported. Hence, there is a significant inverse relation between anger-in and anger-out. Joe becomes angry at himself for doing "stupid things", that is, things not in conformity with some image, perhaps idealized, which he has of himself.

That Joe actually verbally attacks can be a second source of conflict since this may conflict with his own considered views of how 
he should act. Finally, Joe's experience of dis confirmation in his part-selves is another source of dissociation-producing conflict in his self-theory. The conflict here is one between his ideal partself, for example "a competent coach and trainer," vs. his momentarily real, empirically-derived self: a poor tennis coach or a poor umpire.

\section{Subject Number 4, Glen, a High Dissociation Subject}

Glen is a twenty-one year old, single, white male who at the time of the study was a sophomore in college. He is the fourth of five children and he lives on campus in a dormitory. He stated that he sometimes considered himself an angry person and that he sometimes had trouble with his anger. He wrote, "Depending on what is causing the frustration I have trouble finding a suitable outlet." This trouble had never been the focus of therapy, nor was he in therapy during the study. He indicated that he never had the experience of suddenly snapping into or out of an intense emotional experience or state. He thought there was no single other person who considered him an angry person.

Glen ranked second on the average dissociation score for fifteen episodes. When he was asked to participate in the study he expressed some surprise since he didn't think he got angry enough. Glen was a very cooperative subject, and his approach to participation was efficient. He completed fifteen records in about five weeks. He did not 
develop any more than a business relationship with me during those five weeks.

Table 6 reports Glen's means, standard deviations, and correlations for the index of dissociation and for anger-out with the variables of interest. (Table 6 is on page 66.) As can be seen from Table 6 , dissociation is positively correlated with anger-out ( $r=$ $.64)$, and, when the effect of anger-out is removed, with the imagery of rejecting the other $(r=.54)$. Dissociation is inversely related to imagery of being rejected $(r=-.66)$. For Glen, anger-out is related to physical change $(r=.57)$, to imagery of attacking the other $(r=.72)$, to imagery of being rejected $(r=.52)$, and to impulses to attack $(r=.42)$. Anger-out is inversely related to anxiety $(r=$ $-.49)$

The additional correlational analyses revealed that among impulses, "to be noticed or acknowledged" was inversely related to dissociation (\#89, $r=-.51, p<.05,2$-tailed). The following selfstatements were all positively related to dissociation: "If I don't do something about this, I won't get what I need." (\#74, $r=.64$, $p<.05)$. "I can't stand this person. He/she deserves to be punished or put in his/her place." (\#76, $r=.66, p<.01)$. "If things continue this way, I won't get what I should get." (\#79, $r=.76$, $p<.005)$. In addition, "I can't just sit here and take this." is related to anger-out (\#75, $r=.70, p<.005)$.

Glen's episode \#13 has his highest dissociation score (19) as well as being one of three episodes which has the highest possible intensity 
Table 6

Means and SD's and Intra-Subject Correlations for Selected Variables: Subject 4 (Glen, High DISSO)

(a)11 df's $=13$ )

\begin{tabular}{|c|c|c|c|c|c|}
\hline Variable & Mean & SD & DISSO & $\begin{array}{l}\text { orrelations } \\
\text { DISSO } \\
\text { partial } r\end{array}$ & $\begin{array}{c}\text { ANG-OUT } \\
r\end{array}$ \\
\hline $\begin{array}{l}\text { Dissociation } \\
\text { index }\end{array}$ & 5.00 & 4.91 & - & - & $.64 \star \star \star$ \\
\hline Anger-out & 3.73 & .88 & $.64 \star \star \star$ & - & - \\
\hline Anger-in & 1.47 & 1.60 & -.19 & -.16 & -.11 \\
\hline Anxiety & .27 & .80 & - & - & - \\
\hline $\begin{array}{l}\text { Physical change } \\
\text { index }\end{array}$ & 6.07 & 5.54 & 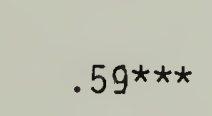 & .36 & $.57 \star \star$ \\
\hline $\begin{array}{l}\text { Visual imagery } \\
\text { of: } \\
\text { attacking other }\end{array}$ & 2.07 & 2.15 & $.60 \star \star \star$ & .26 & 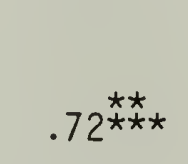 \\
\hline rejecting other & 1.00 & 1.56 & $.62^{\star \star \star}$ & $.54 \star \star$ & .36 \\
\hline being attacked & .40 & 1.12 & - & - & - \\
\hline being rejected & 1.00 & 1.56 & -.10 & $-.66^{\star \star \star}$ & $.52 \star \star$ \\
\hline being deprived & 1.33 & 1.40 & .19 & -.07 & .37 \\
\hline $\begin{array}{l}\text { Impulse to } \\
\text { attack }\end{array}$ & 2.00 & 2.30 & $.49 *$ & .32 & $.42^{\star}$ \\
\hline $\begin{array}{l}\text { Attack, verbal } \\
\text { or behavioral }\end{array}$ & 1.20 & 1.90 & -.14 & -.14 & 0 \\
\hline $\begin{array}{l}\text { Replacement } \\
\text { emotion inten- } \\
\text { sity }\end{array}$ & 2.73 & 1.53 & .20 & 0 & .31 \\
\hline \multicolumn{6}{|c|}{ 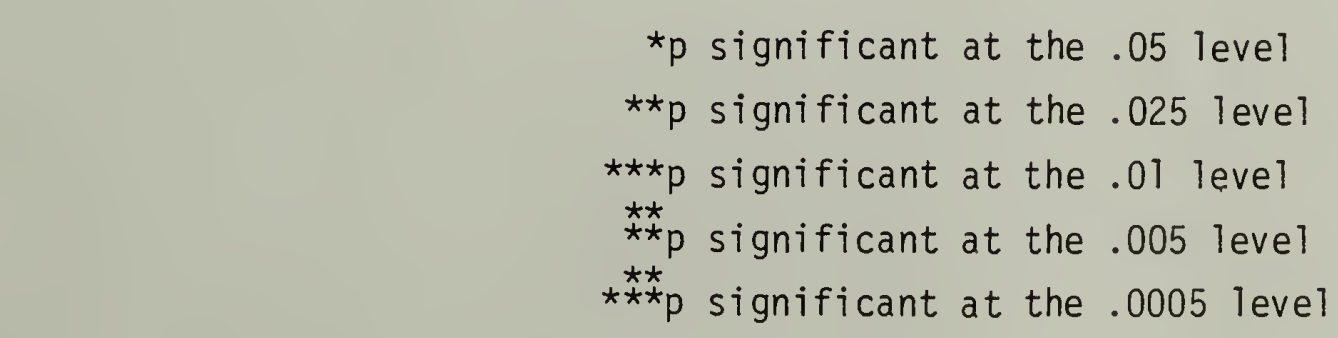 } \\
\hline
\end{tabular}


rating for anger-out (5).

This episode happened later in the afternoon of the "lunch hour" episode. A truck had arrived with a few thousand plants for us to unload and we were tired--but ready. We had him back up to an area that was all set up. Customers--as a rule--always get in the way in these instances. So, at first, I was very, very polite in explaining to them that we could have the truck unloaded for them much quicker if they'd stay clear. And, at first, they were very obliging. But, there was this one lady who couldn't bother waiting and naturally, this caused everyone else to move in. Well, this first lady persisted in somehow being in my way--nomatter where I went! S-0-0, I politely asked her to stay clear (1st time). Two seconds later she cut me off and I almost tripped with an armload of plants. This time I told her to stay clear. To no avail. As soon as I could turn around, there she was--in my way grabbing at her plants. I very sternly told her to get the hell out of there and proceeded to drop a box of plants at her feet so she got spattered with just a touch of mud. She didn't even acknowledge this! I was just inches from exploding! I haven't come this close to literally wanting to punch someone's lights out in a while. The only thing I could do at this stage was to just stay clear of that lady. Just one more confrontation would have blown the top well off this lid. Some people are so f-'ing obnoxious! (The narrative ends with 68 exclamation points!)

Glen's perception of the customer's behavior was that she was being inconsiderate. There is congruence between his perception and his objective evaluation later. As he got angry, he experienced physical change on eight of nine variables. He experienced visual imagery of attacking and of rejecting the customer. All the selfstatements previously seen to be correlated over all his episodes with dissociation and anger were in his awareness. In addition, so were, "I'll show her. What she did was wrong!" and "I should be in control here." Glen's single impulse was to attack the customer, but he actually discharged tension and escaped the situation. He 
stayed angry at the customer for over three hours. His dissociative experience involved every variable which makes up the dissociation index.

Glen's most frequent type of anger episode involves relations with friends: Specifically, either friends not living up to Glen's expectations of them ( 3 episodes), or a friend making too many demands on his ( 2 epidoses). An example of the former involves Glen's teasing a friend over beating him at pool several games in a row. The friend hit Glen in the face and Glen restrained his own physical attack on the friend in order to avoid an "al7-out" fight. He later decided to drop this person as a friend. In a case of inappropriate expectations placed on Glen, an acquaintance of his from the dorm who is from the same hometown as he habitualiy asked Glen to pick up or deliver things when Glen planned to drive home from campus on weekends. The average dissociation level for these five episodes involving Glen's self as friend-to-others is 2.6.

Glen's sense of self as worker involved three anger episodes which have an overall dissociation average of 9.3. The most expreme episode was the one reported above as his most extreme dissociation episode overall. The other two work episodes involved conflict with a supervisor and conflict with a co-worker who attempted to usurp the supervisor role over Glen.

Conflicts over his sense of self as good student occurred in three other episodes which averaged 3.3 for level of dissociation. These all involved conflicts between what he thought a good student 
should do $\underline{v s}$. What Glen felt like doing at the time. For example, one such episode involved a conflict between "partying" in his room with friends vs. "being seen as an asshole" by asking them to leave so he could study.

Two anger episodes involved conflict with authorities. In one he quietly accepted a speeding ticket (DISSO = 3); in another he argued with his parents about moving off campus in the coming academic year (DISSO $=5)$.

Judging by the average dissociation scores for these anger episodes grouped by "part-selves" or social identities, Glen experienced least integration in himself as worker, followed by self as reponsible adult, self as student, and self as friend-to others.

Glen's data do not readily support any simple explanation for his dissociative experiences. His correlation pattern does not follow the High Dissociation Group pattern well at all. In fact the only correlation in common is that between dissociation and angerout. Glen's anger episodes, while they consist of standard anger-inducing scenarios, do not seem to be as weighted toward self-relevant phenomena as do those of Joe. After all Joe's identity as a recovered alcoholic, for example, might be expected to be more self-theory relevant than a college student's identity as a part-time general laborer since for Glen laboring is only a temporary necessity.

Glen's data show correlations with dissociation that do not appear for the High Dissociation Group. These correlations are in the visual imagery variables. Glen also experiences several self-statements dur- 
ing dissociation. There is no comparison for the later with grouped data, but Glen reported more self-statements ( $N=46$ for fifteen episodes) than all but one other subject (Thirteen Ss' range $=9$ to 60). Perhaps all these spontaneous visual images and self-statements indicate some conflict, or at least confusion, in Glen's self-theory, not otherwise measured. This idea was behind the original creation of the visual imagery and self-statement items.

It may be that the occurrence of many different internal verbal and visual events during a dissociative anger episode is yet another symptom of dissociation itself, albeit a highly idiosyncratic one. These occurrences may be symptomatic of some underlying conflict and may represent the person's attempt to find interpretations of the experience which will better fit the existing self-structure and hence reduce dissociation. Alternately, they may be the epiphenomena of elements in associational chains passing the threshold of consciousness. On this later view, these internal events rarely may have a significant bearing on the activation, playing-out, or resolution of a dissociative anger episode. Of course, these two interpretations may both be right, for they are not mutually exclusive. If so, the explanations, taken as a whole, would help explain the highly idiosyncratic nature of these internal phenomena. Speculation, based as it is on a single case, must stop here. 


\section{Subject Number 1, Peter, a High Dissociation Subject}

Peter is a twenty-one year old, single, white male who at the time of the study was college junior with a $A$ - average. He is the second of four children. He lives off campus with some roommates in an apartment. He indicated that he usually considered himself an angry person and that he usually had trouble with his anger. He wrote, "I often think that I don't think about what is making me angry enough. I find it difficult to talk to people who are either close or not so close to my about my feelings. It is hard for me to talk to a therapist about feelings of anger that I have (I have tried). I think I sort of take my anger out against myself and I think that it is hard for me to deal with past break-ups or family problems at this point in my life." He indicated that this trouble had been the focus of therapy in the past, but he could not describe the result. He was not in therapy at the time of the study. He thought that there was at least one other person who considered him an angry person.

Peter ranked third among all subjects on the average dissociation score for fifteen episodes. He is an intense person, much prone to the sort of convoluted analysis suggested by the above quotation. He had difficulty keeping appointments for this study. By his own acknowledgement he had difficulty finishing all fifteen records. It took him nearly three months.

Table 7 presents Peter's means, standard deviations, and corre- 
lations for dissociation and anger-out with the variables of interest. (Table 7 is on page 73) As can be seen from Table 7, with the effect of anger-out removed, dissociation is related to anger-in $(r=.44)$ and to anxiety $(r=.44)$. Dissociation is inversely related to imagery of being deprived $(r=-.62)$. Anger-out is related only to anxiety $(r=.80)$.

The additional correlational analyses revealed several relationships. Perceived rejection was positively related to dissociation (\#28, $r=.57, p .025$ ). In addition, the self-statement (" should be in control here." was positively related to dissociation (\#80, $r=.73, p .005)$. Peter experiences dissociative anger-in when he feels rejected, a set of experiences which would produce his appearance of being tied up in knots in many people.

Several impulses showed a direct relation with intensity of anger-out: "to seek help or understanding" ( $\# 87, r=.52, p<.025)$, "to control, dominate, or exert influence" (\#90, $r=.58, p<.025)$, and "to do nothing" (\#97, $r=.54, p<.025)$. The impulse "to be independent" was inversely related to anger-out (\#92, $r=-.65$, $p<.005)$. The alternation between dominating and doing nothing and the inverse relation between anger at another and being independent certainly confirm the picture of a young man tangled in his own convoluted self-system.

Peter's episode \#1 has his highest rating for dissociation (11). The anger-out rating for this episode was lower than that of three 


\section{Table 7}

Means and SD's and Intra-Subject Correlations for Selected Variables: Subject 1 (Peter, High DISSO) (a)1 $\mathrm{df}^{\prime} \mathrm{s}=13$ )

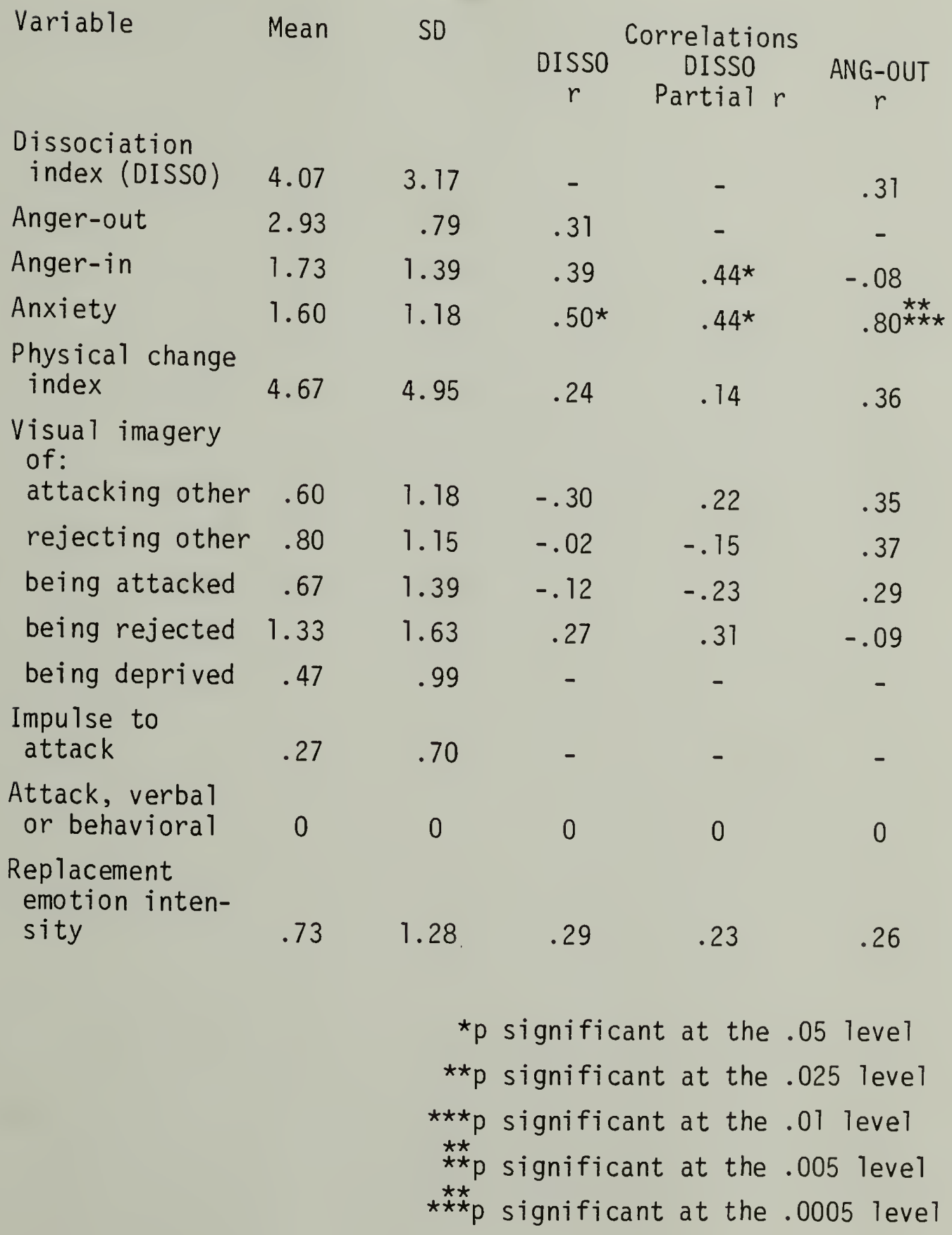


other episodes. This episode was rated " 3 " and there were three others which were rated "4".

Last night my friend had called me and told me that she wasn't able to do anything with me this Wednesday night. We had had tentative plans to do something together that night, and even though it turned out that I had something to do that night anyway (something which precluded my doing anything with her), I felt rejected a little bit. As it turned out, she had a good friend who was upset about something (her friend had just got a new job, which was very difficult) and they were going to get together to talk about it. Even though I knew at that point that they did need time to talk about things, I felt as if I was being set aside a little bit. My friend started to tell me that she was a little bit upset herself because she wasn't sure that she was able to help her friend, and the situation was kind of ambiguous. This only made me more angry, and I really didn't want to listen, so I kind of turned off, and just kind of said uh-huh every couple of seconds in order to let her know I was

there. As it turned out, I felt like talking to her more about it, but I didn't really do anything, and pretty much just accepted the situation.

Peter experienced the prospect of not seeing his girlfriend as rejection. Along with anger at her, he experienced anger at himself and anxiety. He experienced physical change on all nine variables. He had a visual image of being rejected. In addition to "I should be in control here." he told himself, "If I con't do something about this I won't get what I need. I can't just sit here and take this. If things continue this way, I won't get what I should get." His only impulse was to escape, and this is what he did. His anger at the girl was replaced by anger at himself. The episode lasted less than sixty minutes, and his dissociative experience included all six items which comprise the dissociation in- 
dex.

Peter's narratives are longer than any other subject's. He analyzes his experiences in a very complicated way as a matter of course. The impression is strengthened after meeting him. He speaks in a slow manner, in a low voice, with numerous halts in midsentence. The impression is of a person weighing every word. The many self-statements reported in every episode seem to reflect this same characteristic.

Three of Peter's anger episodes involved anger at another person for expressing political or moral views different from his own. The average dissociation rating for these three episodes is 5.3 . In one, he was putting a poster announcing some political activity on the bulletin board at a bookstore and was told to remove it. In another he could not help overhearing the opinions of a fellow student on the need for nuclear arms. In the third episode, he observed a student gleefully tear down a poster announcing a Gay/Lesbian dance event.

The incidents concerning his girlfriend are three involving broken plans or nearly broken plans with her. The incident reported above as Peter's most extreme dissociative incident is included among these. A fourth involves anger at her and at himself for his inability to respond to a minor concern of hers which she was exaggerating. He had wanted to be more sympathetic. The average dissociation rating for these four incidents with his girlfriend is 4.75 . Peter seems to be particularly conscious of sexism in his interactions. He became angry at others for sexist attitudes and at 
himself for failing to live up to his own ideal in these matters. All of the girlfriend episodes seem to reflect a strong ambivalence about the relationship. In all but one of the episodes in this category he seems to be working on his conscious and not so conscious beliefs about the relations between the sexes. The average dissociation index across the six episodes involving his complex attitudes and feelings about the sexes is 5.0 .

Peter is a psychology major, and four anger episodes concern some aspect of this "part-self." The average dissociation rating for these episodes is 3.25. In one, he became angry at a graduate student for whom he was a subject in a cognition experiment. Peter's concern about doing well was turned into anger at the experimenter for not helping him do well (DISSO =9). In a second incident he became angry at a small child at the day-care center where he was doing a practicum. The child would not stop demanding attention by crying and Peter felt unable to cope with the situation (DISSO $=3$ ).

Judged by the average ratings of dissociation intensity for these three clusters of Peter's anger episodes, it can be said that Peter experiences the least integration with his political and moral beliefs, followed by his sense of self as a boyfriend and self as a psychology student.

Peter's correlation pattern, like Glen's, also shows many departures from the pattern for the High Dissociation group. Of all the variables which correlate with dissociation for the group, only angerin does so for Peter. In addition, while there is no group correla- 
tion between them. Based on what has been said about the role of anger-in in Joe's case, Peter's dissociative experiences can be explained in somewhat the same fashion. The task is made easier by the correlation of anxiety with dissociation, for this conforms with one of the original hypotheses.

Peter has no episode of "pure" anger-in. Rather, anger-in accompanies anger-out, although in no systematic pattern. Furthermore, Peter reports anger-in in thirteen of his fifteen episodes. It seems clear that although Peter angers, he feels angry at himself for it, and it makes him anxious. This internal conflict is relevant to his idealized sense of self which is why he experiences dissociation. Perhaps his readiness to perceive himself as being rejected by others is actually a projection of his own ideal-self rejection of his anger at others.

Finally, in light of the discussion of the case of Glen, it should be noted that Peter had the highest number of self-statements reported over all episodes $(N=60)$. Even though only one self-statement shows a systematic relation to dissociation, this wealth of "random" internal events should be seen as an index of confusion about "who" is temporarily in control of Peter's anger: angry Peter, moral Peter, or some other set of central postulates.

Before presenting the case discussions of the three Low Dissociation subjects, a brief summary is in order. The three High Dissociation subjects, Joe, Glen, and Peter, were selected only on the 
basis of their dissociation scores. What is interesting is that the three cases present a range of ways of experiencing dissociative anger. Joe's impulsiveness contrasts sharply with Peter's introspection. Glen's anger seems somewhere between these two. At the two extremes of these cases, Joe and Peter, dissociation is more strongly related to anger-in than it is to anger-out. Glen's data show the relationships originally hypothesized: dissociation is positively correlated with anger-out and is not significantly related with angerin. Glen is also more reliably aware of both visual images and selfstatements that either Joe or Peter.. Oniy for Peter is anxiety positively related to anger. Gien actually reports an inverse relation between anger-out and anxiety. The idiosyncratic departures from the general trends in the data are striking.

\section{Subject Number 10, Marcia, a Low Dissociation Subject}

Marcia is a twenty-one year old white, single female who at the time of the study was a college junior with an A- average. She is the oldest of three children and she lives off campus in an apartment with several others. She indicated that she did not consider herself an angry person and that she had no trouble with anger. She had never been in therapy. She indicated that she occasionally had the experience of suddenly snapping into or out of some intense emotional experience or state. No one she knew considered her an angry person. 
Marcia ranked eleventh out of thirteen subjects on the average dissociation rating across fifteen episodes. She is a good student, works part-time, and is active in campus activities. Her approach to the study was matter-of-fact. She took about five weeks to complete fifteen records.

Table 8 presents Marcia's means, standard deviations, and correlations for dissociation and anger-out with the variables of interest. (Table 8 is on page 80.) As can be seen from Table 8 with the effect of anger-out removed, dissociation is related only to anxiety $(r=$ .57). Anger-out is related to imagery of rejecting the other $(r=$ .61) and to impulses to attack $(r-.68)$.

The additional correlational analyses reveal that the perception of being attacked, deceived, or exploited is directly related to dissociation (\#57, $r=.58, p<.025$ ) as is the impulse to escape (\#85, $r=.49, p<.05)$. Marcia's episode \#15 is among those episodes in which she experienced no dissociation, and the rating for anger-out intensity was the highest one for her (5).

I got home from classes after a long day and went to get a glass of ice tea. I looked up in the cabinet and there were no clean glasses. I looked in the sink and it was full. My roommate and I hadn't eaten at the apartment for a few days. The other two apartment mates were too lazy to load the dishwasher and turn it on and knew we'd do it if they didn't. I got mad and frustrated. I wanted to scream but I talked to my roommate about it.

Al though Marcia objectively viewed her apartment mates' behavior as inconsideration, at the time she perceived it as an attack. Accompanying very strong anger at them was a little anger at herself. All 


\section{Table 8}

Means and SD's and Intra-Subject Correlations for Selected Variables: Subject 10 (Marcia, Low DISSO)

$$
\text { (a) } \left.11 f^{\prime} s=13\right)
$$

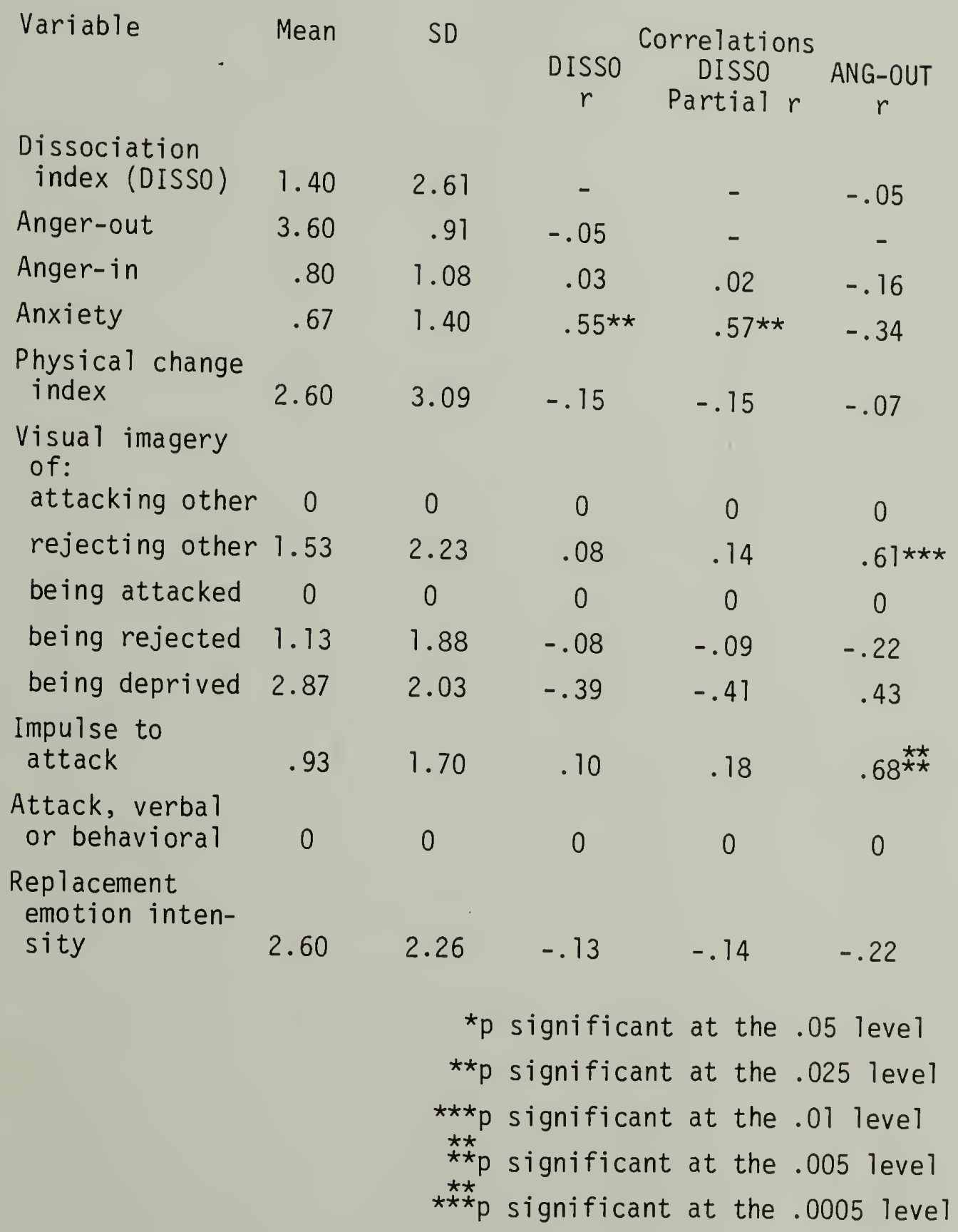


she noticed physically was a slight increase in muscle tension. She experienced visual imagery of rejecting the others and of being deprived herself. She was aware of saying to herself, "If I don't do something about this, I won't get what I need. I can't just sit here and take this. I can't stand this person. She deserves to be punished or put in her place." Her only impulse was to attack, but instead she talked about the experience with a sympathetic roommate who was in the same situation as she. The episode lasted less than one minute.

Marcia appears to be level-headed and in control, but not overcontrolled. Much of her perceived experience involves others being inconsiderate of her, making dependent demands on her, or trying to control her. She frequently has impulses to attack, to discharge tension, or to counter-control. These impulses are nearly always converted into actions such as communicating, understanding, complying, and asserting. The conversion of impulses to attack and to discharge tension into understanding and communication could represent some overcontrol of her impulses. Marcia, however, is also able to assert herself when she thinks it is necessary.

Six of Marcia's anger episodes involve relations with friends. The average dissociation rating for the six episodes is 2.83 . In most of these episodes Marcia experienced a conflict between her view of what friends should do for or demand of each other, and what was actually taking place. Marcia sees herself as a loyal friend but 
feels her loyalty is often unappreciated by her friends. She would like more consideration from them since she often goes out of her way for them herself.

During the course of the study, Marcia had a lot of "roommate trouble." In all, five of her anger episodes involve the kind of incident described in detail above. Only one of these was rated above zero for dissociation intensity (DISSO $=4$ ). In this single dissociative incident, one of Marcia's roommates refused to state her intention to move out until a friend of Marcia's who wanted to move in had to find other living arrangements. In a way, this incident might be classified as a "friendship" episode rather than as a "roommate" episode; but the evidence is equivocal.

The remaining anger episodes involved no dissociation. Two concerned work, one involved a disagreement with her father over her ability to choose a car to buy with her own money, and one involved angry disappointment with her boyfriend for going home for two weekends in a row. From the average dissociation ratings for these clusters of anger episodes it would seem that Marcia was attempting to achieve better integration of her self as friend-to-others. Other "part-selves" or social identities seem to be comparatively well integrated.

\section{Subject Number 12, Steven, a Low Dissociation Subject}

Steven is a thirty year old, single, white male who at the time 
of the study lived alone in a studio loft near a large university campus. Steven is the second of three children. He is a struggling painter and at the time of the study he was trying to decide about his future career. He has lived marginally economically for many years, sacrificing much to his artistic development.

Steven indicated that he sometimes considers himself an angry person and that he sometimes has trouble with his anger. He wrote, "I have trouble with anger when the situation involving my anger does not move towards some satisfactory resolution in a reasonable period of time." This trouble had been the focus of therapy in the past with positive results. He was not in therapy at the time of the study. He reported occasionally having the experience of suddenly snapping into or out of some intense emotional experience or state. He thought that there was at least one other person who considered him an angry person.

Steven ranked twelfth out of thirteen subjects on the average rating of dissociation for fifteen episodes. Steven is an intense and serious person who is taken by some as too egocentric. I have known Steven for many years, and I expected his data to show intense anger. Instead, I was surprised to learn this his mean anger-out rating was below the overall group mean. Steven took two months to complete fifteen records.

Table 9 reports Steven's means, standard deviations, and correlations for dissociation and for anger-out with the variables of interest. (Table 9 is on page 84.) As can be seen from Table 9, 
Table 9

Means and SD's and Intra-Subject Correlations for Selected Variables: Subject 12 (Steven, Low DISSO) (a11 df's = 3)

Variable

Mean

SD

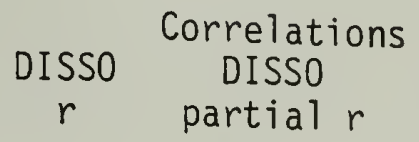
ANG-OUT

Dissociation

index (DISSO)

$1.00 \quad 1.65$

Anger-out

3.07

Anger-in

Anxiety

$.93 \quad 1.03$

.26

$93 \quad 1.22$

$-.17$

$-.25$

.24

Physical change index

$3.67 \quad 3.87$

.09

.01

Visual imagery

of:

attacking other

rejecting other

0

0

0

.25

.10

$.71^{\star \star *}$

being attacked

0

0

0

0

0

$0 \quad 0$

0

0

being rejected

0

0

0

0

0

being deprived

0

0

0

0

Impuise to

attack

.80

0

0

0

0

Attack, verbal or behavioral

Replacement

emotion intersity

$\begin{array}{lll}.93 & 1.03 & -.25\end{array}$

$-.20$

$-.23$

*p significant at the .05 level **p significant at the .025 level ***p significant at the .01 level $\stackrel{* *}{* *}$ significant at the .005 level $\stackrel{\star * *}{* \star *}$ significant at the .0005 level 
with the effect of anger-out removed, only "impulses to attack" is related to dissociaton $(r=.86)$ and only physical change is related to anger-out $(r=.71)$.

The additional correlational analyses revealed one self-statement to be related to dissociation, "I can't stand this person. He/she deserves to be punished or put in his/her place." (\#76, $r=.70, p<.005)$. The perception of being attacked, deceived, or exploited (\#57, $r=.46, p<.05)$ and the perception of threat to values (\#62, $r=.44, p<.05)$ were both related to intensity of anger-out. Finally, the impulse to assert was related to anger-out $(\# 83, r-.53, p<.025)$.

Steven's episode \#10 is one out of thirteen episodes for which the dissociation index was rated " 0 ". Episode \#10 is also rated " 4 " for intensity of anger-out, the highest rating given for any of Steven's episodes. There were two other episodes rated four.

I have told $C$. that I would try to meet with her in (a city about 30 miles away). I am unable to get a hold of her by phone so I do not stop over. Once home I call and she is angry that I am inconsiderate and that my business with L. (another woman) is more important to me than she is. I am quite angry and agitated by this. That evening when she has returned to her apartment I confront her. I am shaken and disturbed. I tell her that my other commitments are of primary importance to me. And that if she cannot accept it then I cannot see her. We have a reconciliation, but I remain distrustful as I sense she is of me.

Steven saw the woman's behavior objectively as controlling. His perception of it is extremely multifaceted. He sees the situation primarily as being attacked, but also as being rejected, being 
controlled, as being a threat to his values, as disapproval, as a loss of the relationship, and as a dependent demand. (One can only speculate about the degree of retrospective "filling in" involved in this list.) His anger at the woman was accompanied by anger at himself and by anxiety. He experienced physical change on five out of nine variables. He was aware of the self-statement, "I'll show her. What she did was wrong. I should be in control here." His impulses were as complex as his perceptions: to defend his identity was the strongest one. But he also wanted to communicate, to control events, to assert himself, and to understand. He reported that he did all these things as we11. His anger lasted more than three hours.

The pattern of reporting multiple facets of a perceived situation is present in every one of Steven's anger records. Likewise, also present are the patterns of multiple impulses and complicated behavioral responses. The perceived stimulus/impulse patterns indicate a subtle intuitive awareness of the complexity of relationships. While Steven was capable of putting these intuitive experiences into the format of the anger records, he complained that the record was only a rough approximation of his experience. It is interesting to note that Steven recorded no spontaneous visual imagery in any of his episodes, yet he is an artist. His presentation of the episodes shows. him to be a complicated conceptualizer of his experience. His work reflects this, too. My own untutored impression of his art is that 
it is highly conceptual and the visual dimension is extremely controlled.

Six of Steven's anger episodes involve his sense of self as an artist. The average dissociation rating for these episodes is 1.83. Steven supports himself working part-time as a store clerk and picking up odd remodeling and carpentry jobs. At the time of the study he was having financial difficulties and was anxiously waiting to hear about a possible job in a more artistic realm which a friend had tried to get him. Three incidents involved dealing with obnoxious customers in his part-time service job. The average dissociation rating for these three incidents is 3.66 . The three other incidents involved anger, frustration, and disappointment about the artistic job which fell through. The average rating for these three episodes is .66 .

Steven spent a weekend with the father of a very close woman friend. The father was dying and Steven was visiting in order to give some relief to his friend who had been caring for her father for several months. Steven reported three anger episodes during this weekend. The immediate stimulus for his anger was feeling that too many demands were being placed on him. The average dissociation rating for these three episodes is .66 .

Steven had two anger episodes involving difficulties with his roommate. One episode was rated 0 and the other was rated 2 . The later episode reveals Steven to be a very expressive and sensitive person. He begins by confronting the roommate and the roommate is 
obviously moved by the threat of losing the relationship. Steven sees this, realizes that the dirty dishes, etc. are irrelevant to their relationship of otherwise mutual support, and he begins to weep. The episode ends with Steven and his roommate quietly discussing their difficulties over tea.

Steven's remaining anger episodes were all rated zero for dissociation. Two involved disagreement about the terms of the relationship with a current girlfriend, one involved a phone call from his brother from whom Steven rarely hears, and one was what must be called "just a bad day." In this last one, Steven's attempts to conduct errands brings him into unaccountable minor difficulties with acquaintances and strangers. Judged by the average dissociation rating of these clusters of anger episodes, Steven has most difficulty integrating his identity as a menial worker when he sees himself as a working artist. This is probably somewhat functional since he maintains his own self-esteem by thinking of these jobs as temporary and in service of his survival as an artist.

On the other hand, in spite of his disappointment with not getting a desirable job, he had comparatively little trouble integrating the experience. He has a very strong, clear, and integrated sense of himself as an artist. The difficulties with his roommate and the troubling weekend with the dying may show that Steven is a perceptive and caring individual who is little troubled by conflicting senses of himself. 


\section{Subject Number 8, Dave, A Low Dissociation Subject}

Dave is a twenty-two year old, single white, male who at the time of the study was a college junior with an $A$ average. He is the first of six children and he lives in a dormitory on campus. Dave did not consider himself an angry person, nor did he think he had any trouble with anger. He had never been in therapy. He never had the experience of suddenly snapping into or out of an intense emotional experience or state. He could not think of any other person who thought he was an angry person.

Dave ranked last out of all subjects on the average dissociation rating for fifteen episodes. Dave is a friendly and hard working person who was puzzled at first by the study. He was finally able to understand the purpose of the protocol after several instruction sessions. I do not attribute this difficulty to a lack of intelligence, but rather to a low level of psychological-mindedness. Dave was always prompt for appointments and he completed fifteen anger records in less than a month.

Table 10 presents Dave's means, standard deviations, and correlations for dissociation and for anger-out with selected variables. (Table 10 is on page 90.) As can be seen from Table 10 with the effect of anger-out removed, dissociation is related to anxiety ( $r=$ .71). Anger-out is related to actual verbal or behavioral attack $(r=.44)$.

The additional correlational analyses revealed a strong relation 
Table 10

Means and SD's and Intra-Subject Correlations for Selected Variables: Subject 8 (Dave, Low DISSO)

$\left(\right.$ a $\left.11 \mathrm{df}^{\prime} \mathrm{s}=13\right)$

\begin{tabular}{|c|c|c|c|c|c|}
\hline Variable & Mean & SD & $\begin{array}{l}\text { DISSO } \\
\cdot r\end{array}$ & $\begin{array}{l}\text { orrelations } \\
\text { DISSO } \\
\text { partial } r\end{array}$ & $\begin{array}{c}\text { ANG-OUT } \\
r\end{array}$ \\
\hline $\begin{array}{l}\text { Dissociation } \\
\text { index (DISSO) }\end{array}$ & .33 & 1.05 & - & - & .26 \\
\hline Anger-out & 3.07 & 1.22 & .26 & - & - \\
\hline Anger-in & .87 & 1.36 & -.02 & -.05 & .09 \\
\hline Ansiety & 1.87 & 1.60 & $.70^{\star \star \star}$ & $.77^{\star \star \star}$ & .08 \\
\hline $\begin{array}{l}\text { Physical change } \\
\text { index }\end{array}$ & .73 & 1.16 & $.49 \star$ & .43 & .42 \\
\hline $\begin{array}{l}\text { Visual imagery } \\
\text { of: } \\
\text { attacking other }\end{array}$ & .13 & .52 & - & - & - \\
\hline rejecting other & .47 & .99 & - & - & - \\
\hline being attacked & 0 & 0 & 0 & 0 & 0 \\
\hline being rejected & .20 & .56 & - & - & - \\
\hline $\begin{array}{l}\text { being deprived } \\
\text { Impulse to } \\
\text { attack }\end{array}$ & .06 & .26 & - & - & - \\
\hline $\begin{array}{l}\text { Attack, verbal } \\
\text { or behavioral }\end{array}$ & 1.53 & 1.29 & -.09 & .13 & $.44^{\star}$ \\
\hline $\begin{array}{l}\text { Replacement } \\
\text { emotion inten- } \\
\text { sity }\end{array}$ & 1.27 & 1.43 & -.11 & -.16 & .15 \\
\hline & & 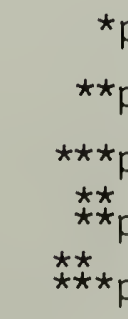 & $\begin{array}{l}\text { p signit } \\
\text { p signif } \\
\text { signif } \\
\text { signif } \\
\text { signif }\end{array}$ & $\begin{array}{l}\text { icant at the } \\
\text { icant at the } \\
\text { icant at the } \\
\text { icant at the } \\
\text { icant at the }\end{array}$ & $\begin{array}{l}.05 \text { level } \\
.025 \text { level } \\
.01 \text { level } \\
.005 \text { level } \\
.0005 \text { level }\end{array}$ \\
\hline
\end{tabular}


between dissociation and perceived threat to values ( $\# 62, r=.95$, $p \quad \check{\gtrless} .0005)$ and between dissociation and the self-statement, "I can't just sit here and take this," $(\$ 75, r=.60, p<.01)$. Dave's episode \#10 is one among thirteen episodes which have a rating of "0" for the dissociation index. Dave's episode \#10 also is an episode in which anger-out is rated highest (5).

I went to put up my shade in the morning to let the sunlight in. I gave the shade several quick tugs, trying to get it to snap up and roll up. Each tug was increasingly harder and the shade each time would not roll up, but would roll down further. Finally I tugged so hard out of anger that the shade ripped off the roll and both came flying to the floor. I instantly swore out loud and picked up the shade and threw it to the floor again. I left it there for five minutes while I continued to dress for school. Meanwhile, I forgot about it for a few minutes-then I repaired the shade and replaced in it the window frame.

Dave interpreted the shade's malfunction as being controlled by the shade. His anger included anger at himself. As for physical changes, he was only aware of moderately increased muscle tension. He was aware of the self-statement, "I should be in control here." He had impulses to attack and to control the situation. He attacked the shade while angry, the episode lasting less than a minute. His anger was replaced by a moderate feeling of guilt.

Overa 11, Dave's episodes show him frequently getting angry over problems within organized activities of which he is a part in the dormitory and on campus. He tends to interpret these predictable problems or organizations as inconsideration and attempts to control him by others. His impulses tend to be to assert himself and to 
counter-control, but he actually talks things through, seeks help from others, or does nothing. It might be said that in these circumstances, he has little outlet for his anger and so he seizes on an opportunity to destroy an object in the shade episode.

Five of Dave's anger episodes involve some frustration (often an important meeting being cancelled) over his activities in dorm governance and the Resident Assistant Program. His narratives show him to be an energetic organizer of dorm activities, but with little power. Three anger episodes involve social plans with friends being arbitrarily cancelled at the last minute by them. Two of these episodes are the only ones out of his fifteen episodes in which he reports some dissociative experience. Two anger episodes each involve taking exams, impulses to destroy malfunctioning inanimate objects (the shade incident is one), and frustration over his thwarted supervision of workers. One anger episode involved being stood up by his girlfriend.

Judging from the dissociation ratings of the incidents involving friends, Dave has most difficulty integrating these experiences into his own self-theory. It is interesting to note that in eleven of his episodes Dave reports that he felt like speaking his mind to the target of his anger, but instead he does nothing to the target, thinks about the incident or talks it over with uninvolved friend. Overa 11, Marcia, Steven, and Dave are the three Low Dissociation subjects and their data reflect this. Among these three there are 
no correlations between dissociation and anger, either anger-out or anger-in. Marcia and Dave show anxiety to be related to dissociation, but Steven does not. Steven shows a relation between physical change and anger-out and Marcia and Dave do not. It is more difficult to identify contrasts and similarities among the three Low Dissociation subjects. Marcia, Steven, and Dave's data are less detailed than Joe, Glen, and Peter's.

As a final point in this Results Chapter, no attempts was made to assess gender differences in dissociative anger patterns. This is true first because there were no a priori differences conceived along gender lines. Second, the N's were, in the end, quite small. There were 4 males and 2 females in the High Dissociation group and 3 males and 4 females in the Low Dissociation group. This difference is not significant by chi square analysis $(x=.739, \mathrm{df}=1, \mathrm{~ns})$. 


\section{HA P TER I I I}

\section{CONCLUSION}

It was argued in Chapter I that the presence of dissociated structures in the self-theory complements the operation of the unity principle, rather than simply contradicts it. For while the tendency toward unity or integration of the sense of self is primary, as all self theorists agree, the tendency toward integration cannot be allowed to override the other functions of the self. Maintaining a favorable pleasure/pain balance and maintaining a tolerable selfesteem level will at times be more important than integrating all experience into a unified theory of self-and-world. Furthermore, the process of integration itself may depend in part on a gradual, rather than a sudden and potentially overwhelming, exposure to selfsignificant material. For most people, the world does not fully cooperate in exposing them to traumatic events gradually. For most of us there are times when the world is a "world according to Garp" (Irving, 1978) filled with events which, willy-nilly, we must either integrate or be destroyed by. The process of dissociation allows us to time our own exposure to these events as we try to integrate them after they occur.

From this perspective, the functions of emotion in the overall self-theory can be conceptually expanded. It has already been pointed out that emotion temporarily creates a paradigm by which the world and 
the self are viewed and experienced (p. 17). An emotion creates for the person a state of readiness to perceive, to process, and to respond in particular ways. An emotion eliminates many possible interpretive and behavioral responses and makes a certain few accessible and more likely to occur. As such, an emotion circumvents some of the usual integrating processes of the person. The result is that emotional action is more direct, automatic, and efficient in terms of the limited goals involved (eg. attack, avoid, approach, recoup).

In light of the complementary relation dissociation has with the integrating tendencies of the self-theory, something more can be said about the significance of emotion to the self-theory. We react emotionally to events which are not immediately integratable into our overall self-theories. Emotional reactions ensure that the data of a traumatic, ie. a self-significant, experience are dissociated long enough for the work of gradual exposure and integration to occur after the events. The mechanisms by which this occurs can be assumed to be those described in Bower's associative network theory (pp. 9.-12). In short, besides their focusing and action-orienting functions, emotions also serve as a protection against the too rapid integration of traumatic data into the overall sense of self. Subsequently, emotional experience provides one means by which later integrative work can occur.

It may be that the work of integrating self-relevant material after an emotion-based dissociation of that material is usually a pre-conscious activity and only becomes apparent under special circum- 
stances. An examination of the phenomenon of "parallel process" in psychotherapy supervision perhaps can shed some light on this. Parallel process refers to perceptual and cognitive distortions of the supervisory relationship. There can be numerous sources for these distortions, but when the distortions result from unprocessed emotion-based reactions of the therapist to the psychotherapy client and his/her material, this is called parallel process. A joint examination by supervisor and training therapist of these distortions can lead to a fuller understanding of the psychotherapy client and of the interaction between the therapist and the client. To some extent, this examination can also lead to the therapist's integration of previousiy dissociated self-relevant material.

What might occur is something like this: Initially the therapist experiences an emotional reaction to something the client does or says, perhaps anger at the client's being twenty minutes late for the meeting. The therapist, wanting to follow a reliable rule-of-thumb for the opening minutes of any therapy session, is aware of the angry feelings but says nothing about it and waits for the client to begin. The meeting proceeds and the therapist "forgets" the client's lateness and the angry feelings. Later, in supervision, the supervisor answers a phone call while meeting with the therapist. The therapist becomes angry at this and expresses it to the supervisor. A discussion of the problem ensues between them and the incident is eventually linked to the client's lateness. This insight aids in a retrospective reinterpretation of the therapy hour under discussion. Perhaps the 
discussion extends to cover aspects of the training therapist's own developing sense of self as a therapist which may be implicated.

This example suggests several features of emotions as facilatators of later integration. First, that the therapist got angry is a sign that he/she perceived the events as self-relevant. Second, these events were not ignored but associated to the anger-complex and forgotten or dissociated. This dissociation occurred in part because the therapist experienced a conflict between impulses: to express anger ( = bad therapist?) vs. to wait for the client to begin and to carry the session ( = good therapist?). Third, feelings of anger are evoked by the supervisor's behavior which acts as a cue. That this anger is expressed is to the advantage of all: supervisor, therapist, and client. It allows for a more informed understanding of the previous therapy hour and perhaps provides an opportunity for the training therapist to continue his/her own itergration of the self-astherapist.

Psychotherapy supervision is, of course, a special set of circumstances. But whenever people reflect upon their emotional reactions to others retrospectively, they may be doing a form of this integrative work. Whether someone takes advantage of this associational organizing function of emotions is a matter of individual difference which even within individuals will vary with timing and circumstances. If this were not the case, training therapists would have no need for supervision. Indeed, people in general might have less need for therapists . 
The positive contribution that the process of dissociation makes to the integrative work of the self-theory must be reconciled with the clinical observation that dissociation is a dysfunctional state of affairs. Simply stated, dysfunctional dissociation is complementary dissociation gone awry. For some reason or reasons, the gradual re-exposure to self-significant traumatic data does not occur. Instead, the traumatic data remain unintegratabie, the self-theory remains unintegrating, and the emotion sub-hierarchy remains problematically dissociated.

Without going into great speculative detail, it seems reasonable to hypothesize that anxiety is significant in the development of dysfunctional dissociation. The complementary function of dissociation breaks down when there is associated with the traumatic data too much anxiety for the person to withstand. This, again, may be a function of the overall integrative capacity of the hierarchically superior self-theory, or of the details of the traumatic data, or of additional associations to the particular emotion-node involved. Likely, it is a combination of these.

What is known about child abusing parents supports this view. As was previously described (pp. 24-25), the typical child abuser was him or herself abused as a child. This abuse, occurring as it does in the early stages of self-theory development, results in a fragile and fragmented overall self-theory incable of integrating the traumatic experiences of childhood. These memories then remain dissociated, not repressed in a dynamic unconscious, but connected to the 
emotional sub-hierarchies of anger, anxiety, and perhaps sadness. When these emotions are invoked the abuser quickly becomes overwhelmed by them and the parent repeats the behavior of his/her own parent when the "good parent-bad child" configuration is reasserted. Thus first-time abuse initiated a vicious circle of increased dissociation, increased vulnerability to trauma, and increased probability of further abuse.

There is growing evidence that multiple personality is a disorder regularly associated with early childhood abuse of the most intrusive and self-violating kind (Saltman \& Solomon, 1982). The abused child excapes his or her pain and anxiety by an extreme dissociation which results in the capacity to develop multiple selves. Most later selves are usually segregated by a complete lack of co-consciousness. This is a fascinating topic of research which has long been dormant and is only recently attracting serious study (Rosenbaum, 1980; Carlson, 1981). In the present context, what is most relevant about multiple personality disorder is the role emotion plays in its development.

The personalities that so-called "multiples" develop earliest are usually the most complex and multifaceted. But usually the personalities are characterized by one dominant emotion (Lester, 1977; Howland, 1983). Anger may be the doma in of an aggressive, assertive male personality, (regardless of the biological sex or social gender of the person). Sexual desire is felt only in the personality of a femme fatale or a Don Juan. Sadness may only be experienced as a young child (who also often knows most about the others). Anxiety may take form only in a "crazy person," the one who gets 
hospitalized.

It seems, then that these facts are consistent with an associative network model of the relation between emotion and the overall self-theory. In the case of the child abuser, the hierarchically superior self-theory is fragmented and unstable. The dissociated traumatic data of experience are associated with several disburbing emotion clusters. In the case of the multiple personality, extreme dissociation (of such strength as to anesthetize the child from physical pain) has occurred so early that it has itself become a paradigm for the further growth of the self. The emotions offer a naturallyoccurring structure for this further development.

The present study. The present study sought evidence for dissociative experience in anger. On the whole, this evidence was found, and it was found among a group of people with no history of severe psychopathy. This counts for support of the general propositions that dissociation is within the normal range of human experience and that it is a phenomenon which is related to certain emotional experiences.

The seven hypotheses tested were developed out of a consideration of and speculation about the structural arrangements of dissociative anger within the self-theory. How did these fare?

With data pooled over all subjects, dissociative experiences were shown to be directly related to anger at another. With the effect of anger-out partialed out, dissociative experiences were shown to be directly related to anger at self, to anxiety, to awareness of a vari- 
ety of physical changes, to impulses to attack someone, and to the intensity of the emotion which replaced anger. With data pooled over the High Dissociation subjects, actual verbal or behavioral attack was also shown to be related to dissociative experiences. In general, six out of seven hypotheses were confirmed.

The experience of dissociation of anger includes feelings of approaching an impending disaster and of reaching a point of no return. In addition, the feelings of being "on automatic" and of being detached and observing give this potentially disastrous situation a depersonalized tone. This depersonalization continues into immediate retrospective reflection with feelings of unreality for the events and feelings that the angry person was somehow "not me." More intense experiences such as these are experienced along with more intense anger, more disinhibition to attack, more anxiety, more felt physical changes, and more intense subsequent emotions. These relations are independent of any relations there might be between anger and the other variables. It therefore can be concluded that dissociative anger is a real phenomenon.

Experience of dissociation in anger is an index of the degree of non-integration in the self-theory. Specifically, dissociative experience in anger is an indicator that associated to the anger emotion node are self-relevant traumatic data which are too incompatible with the overall self-theory to be assimilated. It could also mean that, temporarily at least, the overall self-theory is too 
fragile or fragmented to accomplish the work of integration. Finally, dissociative anger could mean that the anxiety attendant upon integration of traumatic anger-related material is unbearable. Of course there may be degrees of each of these possible conditions in combination with each other. The report of dissociative experience in anger in itself does not suggest any one of these possible conditions.

On a most general level, what can be said about the nature of dissociation? Succintly, dissociation is the result of conflicts within the self-theory. There can be a conflict between impulses to express an emotion and internalized prohibitions against that expression. There can be a conflict between the empirically-derived, immediate, sense of self and an idealized version of self. Finally, there can be a conflict based on the need to interpret events and to act and a lack of adequate conceptual and behavioral schema to do so.

It remains for future research to develop means of identifying the qualities of dissociated self-theory. But this future task should be guided by the notion that dissociation has normal functions. It therefore seems a useful strategy to compare dissociative emotional phenomena between normal and disturbed individuals in order to know more about normal dissociation. Normal and dysfunctional dissociation can be thought of as differing in degree. The reasons for differing degrees of dissociation are complicated, however. They include the nature of the material dissociated, the extensiveness of the overall self-theory, the degree of threat to self-esteem which integration 
would involve, and the degree of anxiety resulting from disorganization in the self-theory. This research should certainly also be expanded to a study of other emotions besides anger. Intense sexual desire, extreme sadness, joy, and fear are some which imeediately come to mind. Epstein's methodology lends itself to this extension, although a clinical population would of necessity be dealt with differently from the present methods.

Unexpected findings and difficulties. The formulation of Hypothesis. One, in retrospect, now seems unnecessarily narrow. As the data showed, both intensity of anger-out and intensity of anger-in are directly related to the intensity of dissociative experience. Consistent with the hypothesis as formulated, however, anger-out shows a stronger relation with dissociation than does anger-in. It was also found that dissociation is a better predictor of anger-in than is anger-out.

The reasoning behind only predicting a relation between dissociation and anger-out was based on the idea that anxiety plays a significant role in the dissociation of anger. It was supposed that the source of this anxiety is social learning about the inappropriateness of expressing anger. This led to the expectation that the expression of anger (anger-out) is more likely to be a dissociative phenomenon than the feeling of anger at oneself. There was also a practical consideration. There simply was no basis on which to predict the frequency of anger at oneself, nor was it as easy as anger at another to 
operationalize.

The discovery of a positive correlation between the dissociation index and intensity of anger-in is therefore not perplexing. Nor does this finding invalidate the theoretical positions advanced here. Anger, and specifically anger-out, was chosen as a test case for the idea that all emotions are organized within the conceptual self-system by complementary degrees of dissociation/integration. The relation between dissociation and anger-in does not contradict Bower's associative network model, either. It would seem that among the routines evoked by anger arousal are those related to anger at oneself.

It should be noted in this context that three subjects each reported one episode of anger-in with no accompanying anger at another. One other subject (Joe) reported five such episodes. This is a total of eight episodes of pure-anger-in out of a total of 195 episodes for all subjects. There were, of course, many more episodes in which anger-in was an accompaniment to anger-out.

The finding that dissociation and anger-in are directly related is welcome, then, because it corrects a too narrow application of the theoretical considerations and it opens the way for considering dissociation in the context of other emotions.

The results for anxiety are more puzzling than this. Hypothesis Three is confirmed using the pooled data for all subjects, ie. there is a direct relation between dissociation and intensity of anxiety. When the same hypothesis is tested with the date from High Dissocia- 
tion subjects, this relation becomes non-significant. At first these data seem extremely troubling for the general theory of dissociation since anxiety plays such a key role in the development and maintenance of dissociative structural relations among self-theory elements.

The hypothesized linear relation between dissociation and anxiety remains for the Low Dissociation subjects. In fact, it is enhanced by removing the data of the High-Dissociation subjects. The curve which describes the data for the High Dissociation is "J-shaped." That is, very high dissociation scores are paired with very high anxiety scores, low dissociation scores are paired with middle-range anxiety scores, and middle-range dissociation scores are paired with very low anxiety scores.

There is no simple way to explain these results. What seems best is to attribute them to idiosyncratic departures from the general case. These individual differences can be understood as due to the several ways, separately or in combination, by which anxiety can be aroused and can create conditions for dissociation in the self-theory. Perhaps precisely because dissociation is an anxiety phenomenon, subjective reports of anxiety levels at high levels of dissociation are unreliable because anxiety is avoided preconsciously. Perhaps better instrumentation is needed to assess anxiety at high levels of dissociation than was attempted here.

It was originally expected that the presence of visual imagery, specifically imagery of attack, would be indicative of dissociative 
anger. Hypothesis Four is not confirmed and, overall, no other interpretable significant relations between visual imagery and dissociation exist. It seems now that this idea was wrongly conceived, for visual percepts should function as links between other cognitive structure. The therapeutic use of visual imagery in hypnosis and free association shows that visual images can be used as entree to previously non-conscious cognitions (Singer \& Pope, 1978). Visual percepts, associative links which become conscious to the person as imagery during an anger episode, serve an integrative function. This is, of course, the opposite of what was originally predicted. As the present data were conceived, however, there can be no confirmation of the presence of dissociation by the absence of significant statistical relations for visual imagery and dissociation. The relation of visual imagery to anger and other emotions is important and could be explored in future research. Whether visual imagery that spontaneously occurs contributes more to feelings of control or feelings of lack of control is still an open question.

One final difficulty should be briefly discussed. This is the problem of subjects' compliance and drop-out rates. Much of Epstein's. previous research used undergraduate psychology students participating in the context of a semester-long course. In this context, completion of the research protocols is a requirement for course completion. The present study did not have this advantage. The results are much more dependent on the willingness of the subjects to contribute to the project and to the investigator personally. The strength of the motiva- 
tion required for completion of fifteen episode records is indicated by the fact that less than half of the writer's friends who were recruited completed the required number of protocols.

It seems clear that subjects must be capable of detailed reflection on their own emotional experiences. They must be willing to share these reflections with a stranger. Their lives must be organized in a way which allows frequent periodic reflection and recording of their experiences, at least for a few weeks. It might be suggested that these are not the qualities of people who have difficulty controlling their anger, or of people who experience dissociative phenomena. Nevertheless, the data show that even these "well socialized" persons experience barely controlled anger and dissociation. If anything, this biased sample supports the theoretical argument better than a more "deviant" sample would since the aim was to demonstrate the existence of normal or complementary dissociation.

Nine of the thirteen subjects wrote a brief paper on their experiences doing the researci after they had completed all requirements. (Four subjects did not comply with this request.) $\Lambda 11$ of these subjects thought that the study required a lot of them, and all reported that the personal rewards made the study worth their effort. Among these nine subjects there is an unanimous claim of personal benefit. The following are representative excerpts from their written statements.

I also started to think more when I started to get angry, in that before the anger got out of hand, I was thinking more about what was going on and what could be done; whereas before the experiment, by the time I started 
to think what was going on or what could be done the episode was more or less over with. (Subject \#3)

I guess that I learned how my anger isn't a simple thing, but also how I don't really let it be easy. All the appraising that I do in anger situations tends to bog me down from acting the way I would like to. (Subject \#1, Peter)

By just participating in the experiment, I became more aware of things that got me angry. Recording the episodes became somewhat therapeutic. Not only did I begin to realize the actual object of my anger, but I also came to realize that little things got me angry. Previously, I believed that I barely got mad except for extreme cases. (Subject \#10, Marcia)

There are probably a variety of reasons for dropping out or completing this study as a subject. One reason for completing it is the expectation, need for, or actual experience or personal change. One way to view this phenomenon is as a contaminant of the "pure" theoretical and methodological issues involved. But a more interesting and fruitful view is that actual self change, at least for the duration of the study, took place. These changes might be revealed in the present data by examining reliability coefficients for selected relationships between variables over different prediction intervals. For example, hypotheses could be derived from the self reports of change and selected variables which might reflect those changes could be examined by a split-half reliability method. It could be predicted that change would be shown by differences in correlation coefficients between a subject's first episodes and his or her last episodes.

These reports of self change are unexpected and welcome. This paper was formulated theoretically as a contribution to Epstein's 
theory of the integrative cognitive self-theory. Methodologically it is an extension of Epstein's methods into a little investigated subject. But there were also other motivations. Cognitive selftheory has implications for any general psychological theory of psychopathology. Points of contact between a theory of psychopathology and cognitive self-theory have been mentioned previously in this paper. Aspects of psychopathy which may be psychologically explained by a fully developed cognitive self-theory include acute schizophrenic disorganization, post-traumatic stress disorders, multiple personality, and impulse disorders such as child abuse and other violent offenses.

The structural relation of the emotions within the oeverall, integrative self-theory has implications for therapy. The complementary functions of dissociation and integration in the self-theory means that emotional experience plays an organizing role as well as an attention-focusing role and an activating role for the self. The implication is that self change in therapy may depend not only on insight and colgnitive change but also on the experience of emotions in the immediate encounter between therapist and client which the therapist can aid the client in later integrating.

Future research. Future research guided by this study and discussion can focus on any of three related areas: 1). the investigation of dissociative phenomena in intense emotional experiences other than anger; 2). the comparative study of normal or complementary dissociation with dysfunctional dissociation in the self-theory; 3 ). the study 
of the organizing function of emotional experience in self change.

Research for which a psychologically "normal" sample suffices should be done in a context which maximizes a subject's motivation to participate and to complete the study. Thus, it seems prudent to carry out future research of this type in the psychology course context already developed by Epstein.

In research with any clinical population, the method will have to be changed. It is questionable whether a clinical population of the kind already mentioned would produce these data on their own. An interview format would likely be more effective. The problems this raises are many, but probably manageable. The retrospective reconstruction of an emotional episode in a subsequent interview is subject to many possible distortions. In addition, the current methods call for sampling over many occasions which entails the devel= opment of a relationship between investigator and subject if interviews are used. The therapeutic relationship is not always the best format for research, so conflicts of interest could easily arise. Nevertheless, assuming these difficulties could be managed adequately, a semi-structured clinical interview could be developed which focused on the features of emotional experiences of interest. These interviews could be recorded and later coded into data values for statistical analyses.

Summary. The self-concept is more correctly understood as a selftheory, a hierarchically organized and internally consistent set of 
cognitions and postulates, which the person holds about him or herself. The postulates and cognitions of the self-theory can be explicit or implicit. The functions of the self-theory are to organize the data of experience while maintaining its own organization, to maintain a favorable pleasure/pain balance for the person, and to maintain selfesteem. Emotion is a central experience whenever something self-significant occurs to the person. Emotional reaction is initiated and guided by cognitive structure.

The unity of the self-theory is always balanced against the other functions. Thus, certain data of experience are dissociated in order to avoid disruption of the self-theory's organization which would in turn affect its functioning. Dissociation occurs naturally in the structural relation of the emotions to each other and to the hierarchically superior self-theory. The emotions serve an orienting function. In this last function, the temporary dissociation of unintegratable experience occurs by reacting emotionally. Later, these data may be available for the work of integration by re-experiencing the emotion. This point is compatible with research results on mood and memory. Information learned in a certain state or mood is more readily available for recall in that same state or mood.

Clinical material on the treatment of child abusers and of outpatient violent offenders suggests that strong anger is at times a dissociative phenomenon. A scale of dissociative experience was constructed on the basis of the phenomenological reports of dissocia- 
tion in this literature. Dissociation includes feelings of impending disaster, of passing a point of no return, of being detached and observing oneself, of acting automatically, of unreality, and of depersonalization.

Thirteen subjects completed a study of their own anger experiences. Each subject recorded data on fifteen anger episodes. These data were used to test several hypotheses about dissociative anger. With data pooled over all subjects, dissociative experiences were shown to be directly related to anger at another. With the effects of anger-out partialed out, dissociative experiences were shown to be directly related to anger at self, to anxiety, to awareness of a variety of physical changes, to impulses to attack someone, and to the intensity of the emotion which immediately replaces anger. The data were also examined among High Cissociation subjects alone $(N=6)$ and it was found that actual verbal or physical attack is also related to intensity of dissociative experiences. Six out of seven hypotheses were confirmed.

Individual cases were examined quantitatively and qualitatively. The quantitative analyses revealed a variety of idiosyncratic departures from the overall group trends. The qualitative analyses showed that each subject's episodes clustered under individually characteristic headings which were interpreted as involving more or less integrated "part-selves" or social identities. The average dissociation intensity of each cluster is seen as an index of the degree of 
non-integration of the "part-self."

Subjects reported that the experience of the study changed them. Especially affected was the way they viewed their own anger. This group of subjects were people who did not complain of their anger nor of their dissociative experiences. Future research should investigate more extreme forms of dissociative anger with an identified clinical population. $\mathrm{nls}$ so of interest is to expand the study of emotional experiences in which dissociation plays a role. These might include fear, sadness or depression, joy, and sexual desire. Finally, empirical verification of the organizing function of emotion is needed. 


\section{REFERENCES}

Adler, A. in Ansbacher, H.L. \& Ansbacher, R.R. (Eds.) The Individual Psychology of Alfred Adler, NY: Harper, 1956.

American Psychiatric Association, Diagnostic and Statistical Manual of Mental Disorders (3rd ed.), 1980.

Averi11, J. Anger. In Nebraska Symposium on Motivation: Human

Emotion. Lincoln: University of Nebraska Press, 1979.

Bach, G.P. Constructive aggression in growth groups. In Jacobs,

A. \& Spraden, W.W. (Eds.) The Group as Agent of Change. NY:

Behavioral Publications, 1974.

Bandura, A. Social Learning Theory. Englewood Cliffs, NJ: PrenticeHa 11, 1977.

Barnes, F.F. Travel and fatigue as cases of partial dissociative reactions. Comprehensive Psychiatry, 1980, $21(1), 55-61$.

Beck, A.T. Cognitive Therapy and the Emotional Disorders. NY: New American Library, 1976.

Bieber, I. Cognitive Psychoanalysis. NY: Aronson, 1980.

Blue, F.R. Use of directive therapy in the treatment of depersonalization neurosis. Psychological Peports, 1979, 45(3), 904-906.

Blumberg, M.L. Treatment of the abused child and the child abuser. American Journal of Psychotherapy, 1977, 31, 204-215.

Blumberg, M.L. Collateral therapy for the abused child and the problem parent. American Journal of Psychotherapy, 1979, 33, 339-353. 
Bonime, 4!. Anger as a basis for a sense of self. Journal of the American Academy of Psychoanalysis, 1976, 4, 7-12.

Bower, G.H. Mood and memory. American Psychologist, 36, 2, 129-148, 1981

Breuer, J. \& Freud, S. Studies on Hysteria (1893-5). Collected works of Freud, vol. 2. (trans. J. Strachey) London: Hogarth. Carlson, E. The history of multiple personality in the U.S.: I. The beginnings. American Journal of Psychitary, 138(5), 666-668.

Carney, F.L. Outpatient treatment of the aggressive offender. American Journal of Psychotherapy, 1977, 31, 265-274.

Chilenski, G.M. A cognitive self-theory formulation of anger disordered persons. Unpublished manuscript. 1982.

Chilenski, G.M. Delayed post-traumatic stress disorder: Drastic personality change "on hold". Unpublished manuscript, 1982b.

Dabney, E.J. Bobby is dead. Caring, 1976, 2, 137-145.

Damos-Mova, J.M.R. \& Eacott, S.E. On heautoscopy or the phenomenon of the double. British Journal of Medical Psychology, 1980, 53(1), 75-83.

Danto, B.L. Psychiatric treatment of violent patients in private practice. International Journal of Offender Therapy and Comparative Criminology, 1975, 19, 67-74.

Dince. P.R. Partial dissociation as encountered in the borderline patient. Journal of the American Academy of psychoanalysis, 1977, $5(3), 327-345$. 
Ellenberger, H.F. The Discovery of the Unconscious. NY: Basic Books, 1970.

Ellenberger, H.F. The story of "Anna 0.": And critical reviews of new data. Journal of the History of the Behavioral Sciences, 1972, $8: 3,267-297$.

Ellis, A. Humanistic Psychotherapy. NY: McCraw-Hill, '1973.

Epstein, S. The self-concept revisited, or a theory of a theory. American Psychologist, 1973, 23, 404-416.

Epstein, S. The unity principle vs. the reality and the pleasure principles, or the tale of the scorpion and the frog. Paper presented at the National Symposium on the Self-Concept, Boston, 1978.

Epstein, S. Natural healing processes of the mind: I. Acute schizophrenic disorganization. Schizophrenia Bulletin, 1979, 5, 313-321.

Epstein, S. The ecological study of emotions in humans. In Pliner, P., Blankenstein, K.R., \& Spigel, I.M. (Eds.) Advances in the Study of Communication and Affect. Vo1. 5. NY: Plenum Press, $1979 b$.

Epstein S. The self-concept: A review and a proposal of an integrated theory of personality. In Staub, E. (Ed.) Personality: Basic Issues and Current Research, Englewood Cliffs, NY: Prentice-Hall, 1980a. 
Epstein, S. The stability of behavior: II. Implications for psychological research. American Psychologist, 1980, 35, 790-806. (b)

Epstein, S. AFD Personality Questionnaire. Unpublished manuscript, University of Massachusetts, 1980c.

Epstein, S. A research paradigm for the study of personality and emotions. Nebraska Symposium on Motivation: 1981. Lincoln: University of Nebraska Press, 1982.

Erikson, E. Childhood and Society. NY: Norton, 1954.

Ferguson, G.A. Statistical Analysis in Psychology and Education (3rd ed.). NY: MCGraw-Hi11, 1971.

Fromm-Reichmann, F. Principles of Intensive Psychotherapy. Chicago: University ofChicago Press, 1950.

Frost, W.D. On the relationship between gender and anger. Unpuslished manuscript, University of Massachusetts, 1981.

Green, A.H. A psychodynamic approach to the study and treatment of child-abusing parents. Journal of the American Academy of Child Psychiatry, 1976, 15(3), 414-429.

Gil, D.G. Violence against Children. Cambridge: Harvard University Press, 1970.

Gruenewald, D. Multiple personality and splitting phenomena: A reconceptulization. Journal of Nervous and Mental Disease, 1977, $164(6), 385-393$. 
Hilgard, E.R. Divided Consciousness: Multiple Controls in Human Thought and Action. NY: Wiley, 1977.

Horowitz, M. Stress Response Syndromes. NY: Aronson, 1976. Howland, F. Personal communication. Dr. Howland has treated scores of multiple personality disorders in the course of her private practice. She is also affiliated with a large research undertaking on the disorder at the National Institutes of Health, Wasington, D.C., 1983.

Irving, J. The World According to Garp. NY: Dutton, 1973. Jackins, H. The Human Side of Human Beings. Seattle: Rational Is land, 1965.

Janet, P. The Major Symptoms of Hysteria. (2nd. ed.) NY: MacMillan, 1907.

Janov, A. The Primal Revolution. NY: Van Nostrand, 1971.

Kelly, G. The Psychology of Personal Constructs. NY: Norton, 1955. Kreindler, S. Psychiatric treatment for the abusing parent and the .abused child: Some problems and possible solutions. Canadian Psychiatric Association Journal, 1976, 21(5), 275-280.

Kuehn, J.L. \& Burton, J. Management of the college student with homocidal impulses: The "Whitman syndrome." American Journal of Psychiatry, 1969, 125(11), 1594-1599.

Lester, D. Multiple personalities: A review. Psychology, 1977, $14(1), 54-59$. 
Lowen, A. The body in personality theory: Wilhelm Reich \& Alexander Lowen. In Burton, A. (Ed.) Operational Theories of Personality. NY: Brunner/Mazel, 1974.

McKellar, P. Mindsplit: The Psychology of Multiple Personality and the Dissociated Self. London: Dent \& Sons, 1979.

Meares, R. \& Grose, D. On depersonalization in adolescence: A consideration from the viewpoint of habituation and identity. British Journal of Medical Psychology, 1978, 51(4), 335-342.

Merleau-Ponty, M. The Primacy of Perception. Edie, J.M. (Ed.) Evanston: Northwestern University Press, 1964.

Miechenbaum, D. Cognitive Behavior Modification. NY: Plenum Press, 1977.

Mischel, W. Introduction to Personality. NY: Holt, Rienhart, \& Winston, 1976.

Noyes, R. \& Slymen, D.J. The subjective response to life threatening danger. Omega: Journal of Death and Dying, 1978-79, 9(4), 313332.

Piaget, J. Structuralism. NY: Harper \& Row, 1968.

Polanyi, M. Personal Knowledge: Towards a Post-Critical Philosophy.

NY: Harper \& Row, 1953.

Rank. 0. The Double, A Psychoanalytic Study. Chapel Hill: University of North Carolina Press, 1971.

Renik, 0 . The role of attention in depersonalization. Psychoanalytic Quarterly, 1978, 47(4), 588-605. 
Reyher, M. Emergent uncovering psychotherapy: The use of imagoic and linguistic vehicles in objectifying psychodynamic processes. In Singer, J.L. \& Pope, K.S. (Eds.) The Power of Human Imagination: New Methods in Psychotherapy. NY: Plenum Press, 1978.

Richardson, F. The Psychology and Pedagogy of Anger. Baltimore: Warwick \& York, 1918.

Rogers, C.R. (Ed.) The Therapeutic Relationship and Its Impact.

Madison: University of Wisconsin Press, 1967.

Rosenbaum, M. The role of the term schizophrenia in the decline of the diagnoses of multiple personality. Archives of General Psyciatry, 1980, 37(12), 1383-1385.

Sadoff, R.L. Treatment of violent sex offenders. International Journal of Offender Therapy and Comparative Criminology, 1975, 19(1), $75-80$.

Saltman, V. \& Solomon, R.S. Incest and the multiple personality. Psychological Reports, $1982,50(3 p t 2), 1127-1141$.

Sartre, J.P. Being and Nothingness. NY: Philosophical Library, 1956. Schafer, D. The recognition and hypnotherapy of patients with unrecognized altered states. American Journal of $\mathrm{Cl}$ inical Hypnosis, $1981,23(3), 176-184$.

Selye, H. The Stress of Life (2nd ed.). NY: McGraw-Hi11, 1976. Shapiro, S. Depersonalization and Daydreaming: A pattern of disturbance in the sense of reality. Bulletin of the Menninger Clinic, $1978,42,4,307-320$. 
Singer, J.L. \& Pope, K.S. The Power of Human Imagination: New Methods in Psychotherapy. NY: Plenum Press, 1978.

Spiegal, R. On psychotherapy of patients with problems of Hostility. American Journal of Psychotherapy, 1980, 34, 2, 178-187.

Steele, B.F. The child abuser. In Katush, I.L. (Ed.) Violence:

Perspectives on Murder and Aggression. San Francisco: JosseyBass, 1978.

Weston, J.T. The pathology of child abuse. In Helfer, R.E. \& Kempe, H. (Eds.) The Battered Child. Chicago: University of Chicago Press, 1974. 
APPENDIX A 
竞

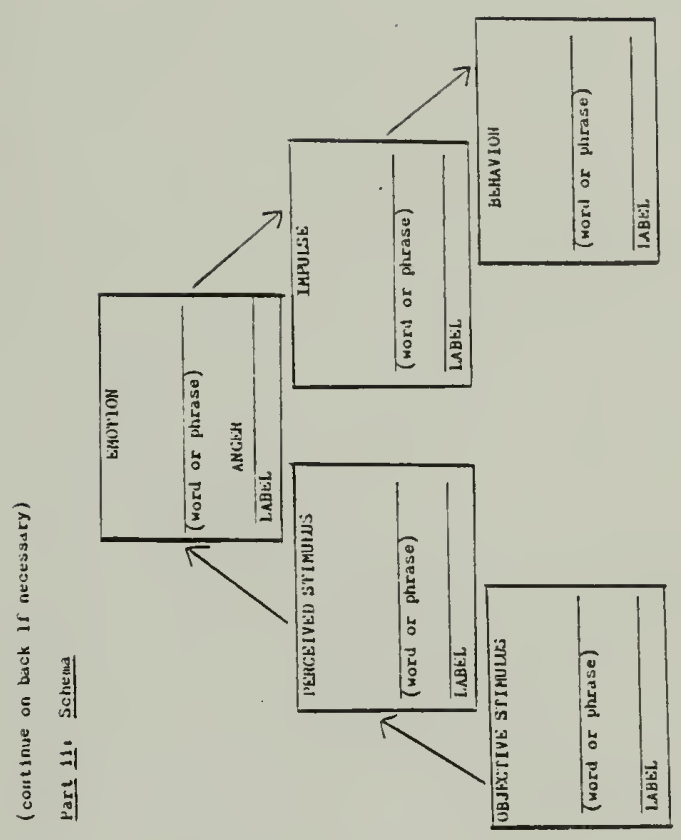

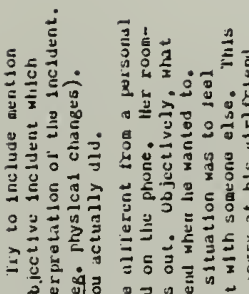

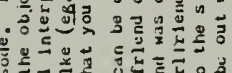

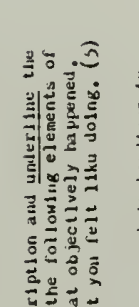

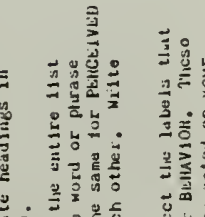

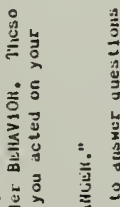

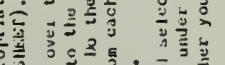

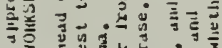

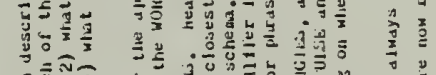

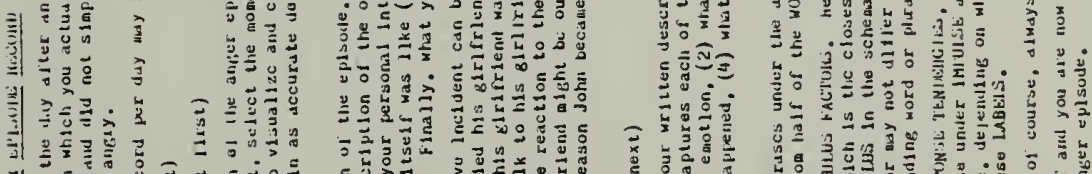

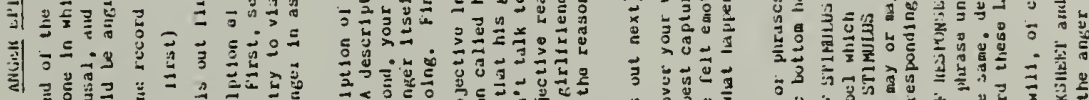

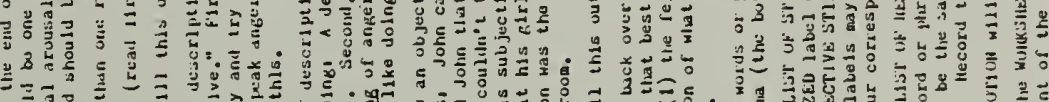

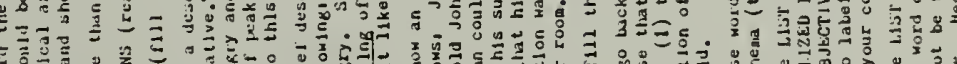
要等

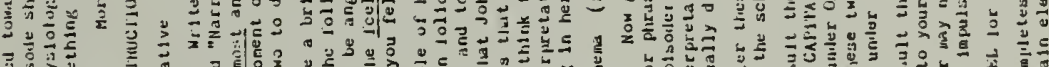

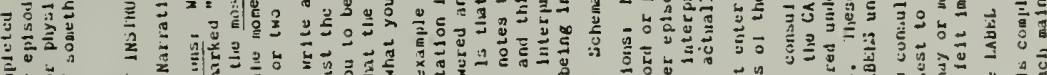

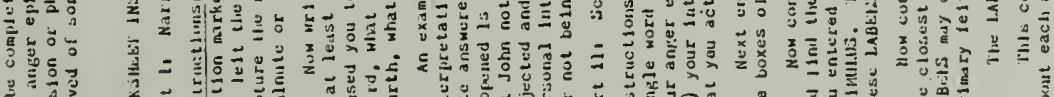

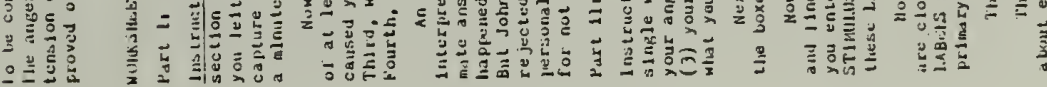



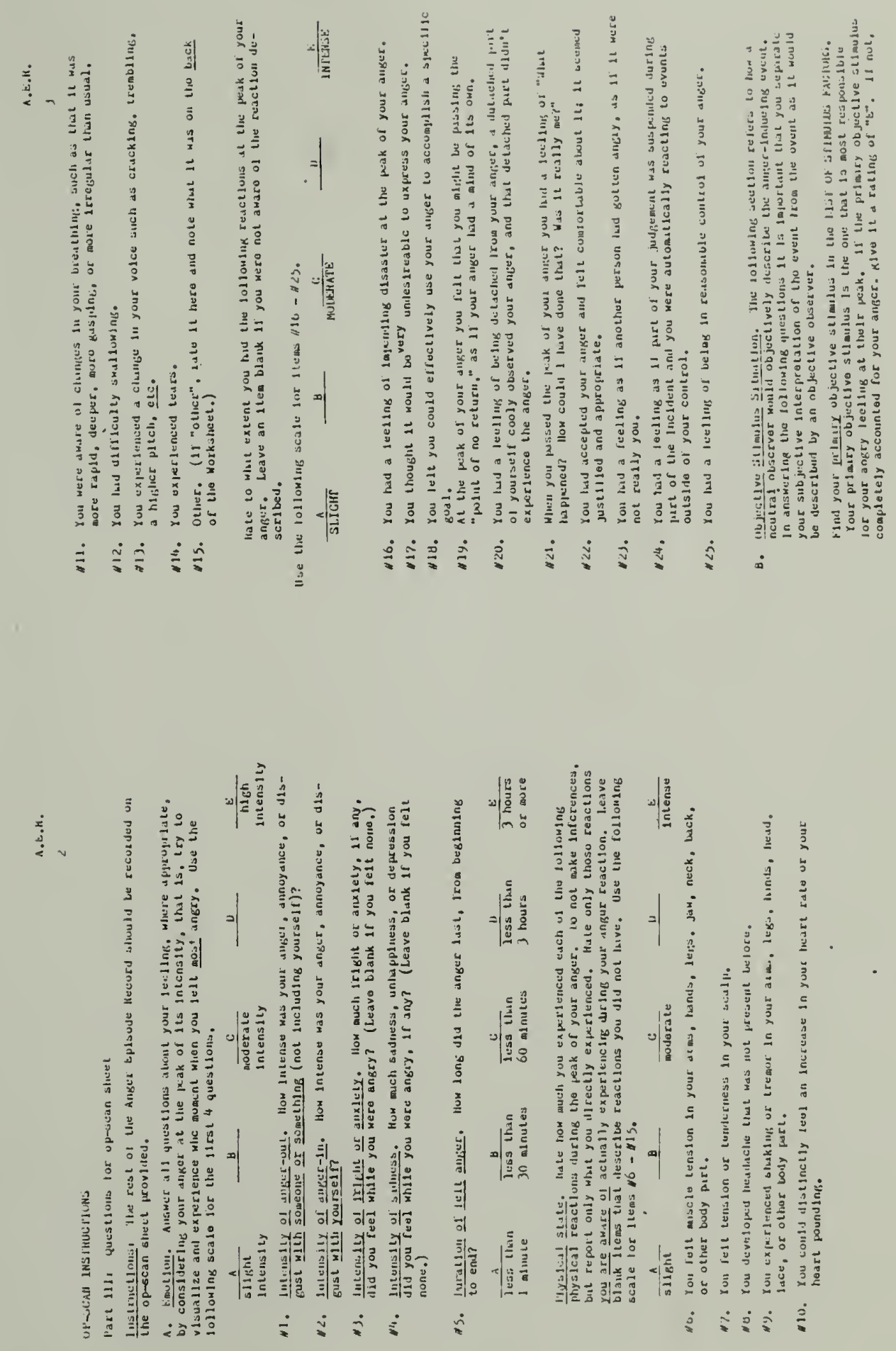

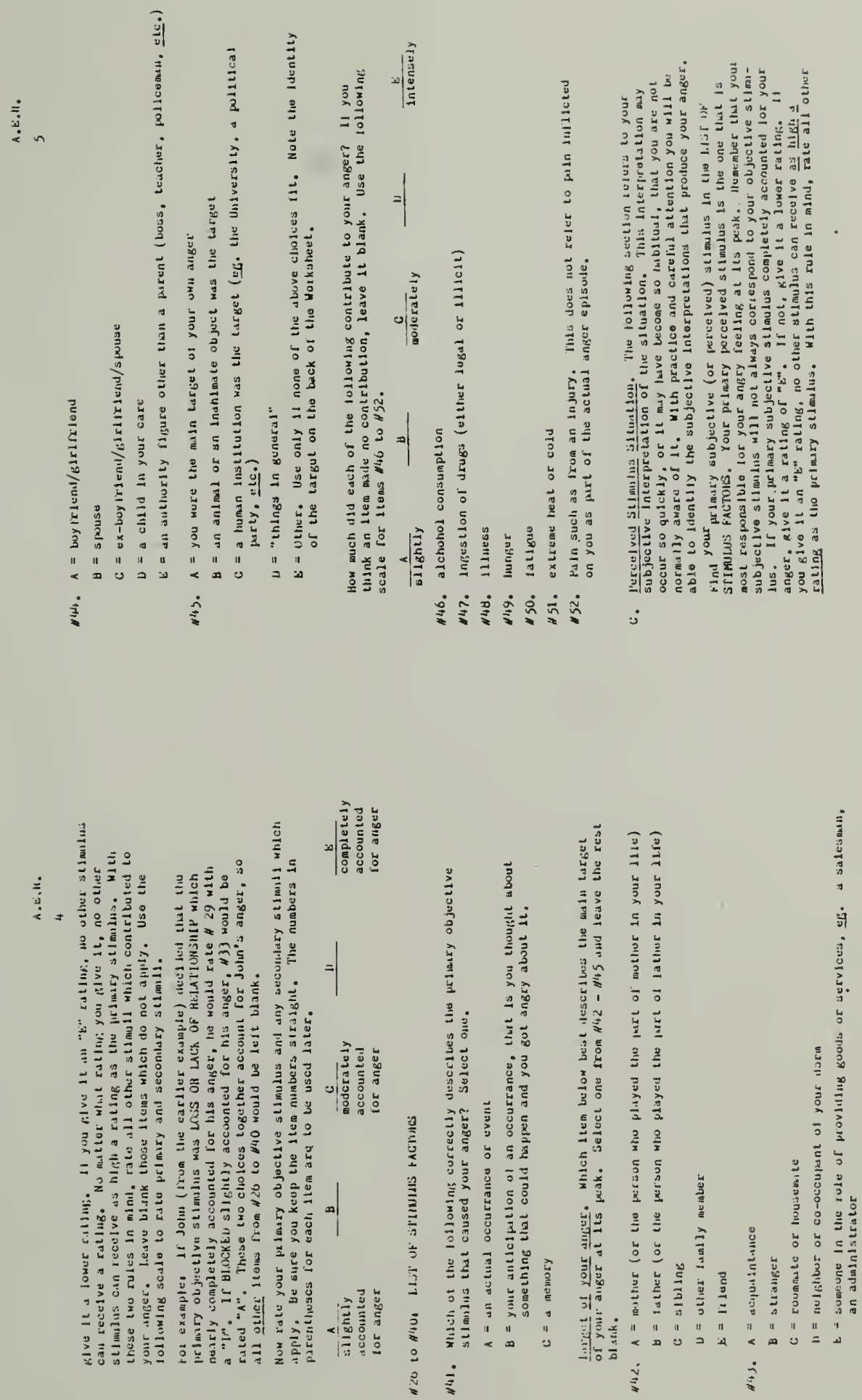


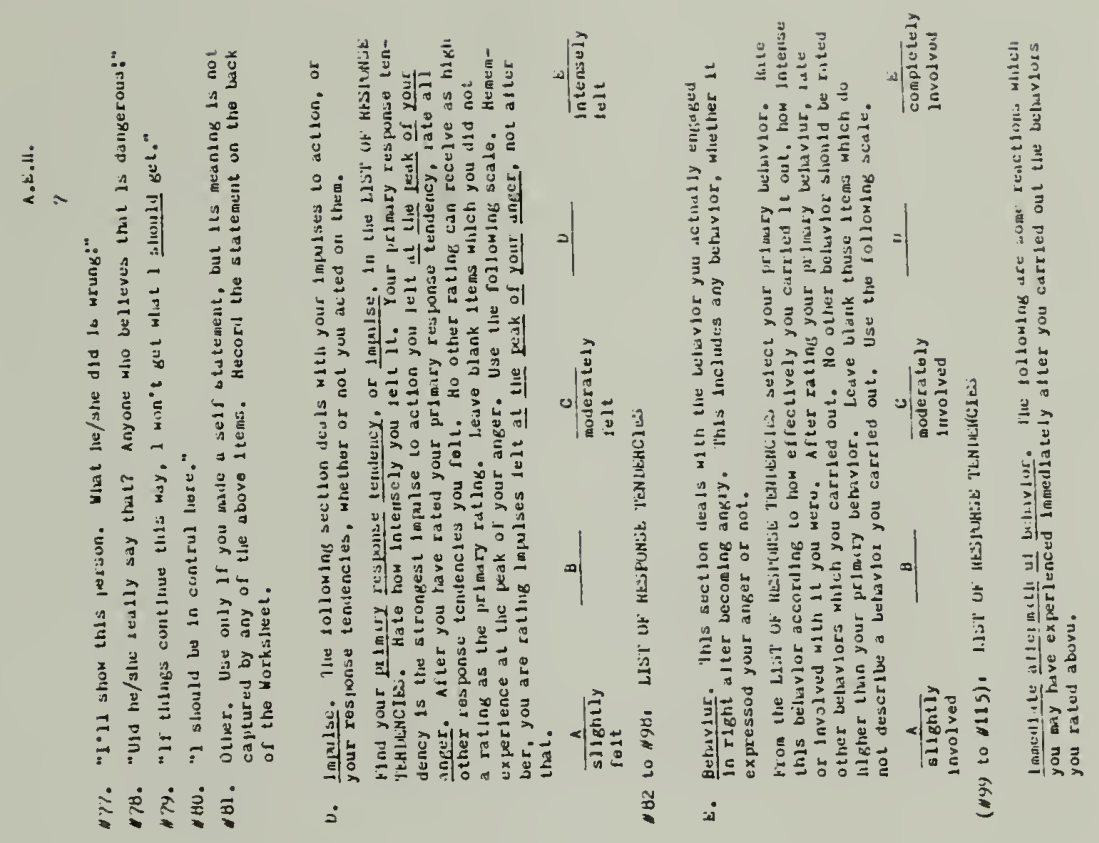

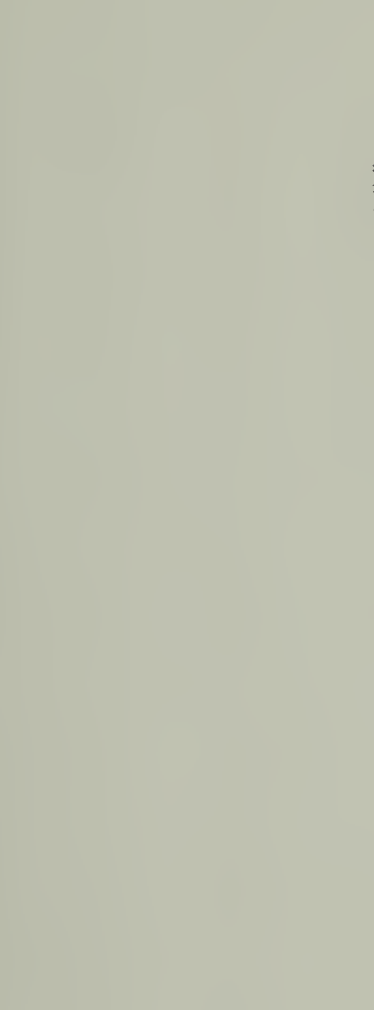

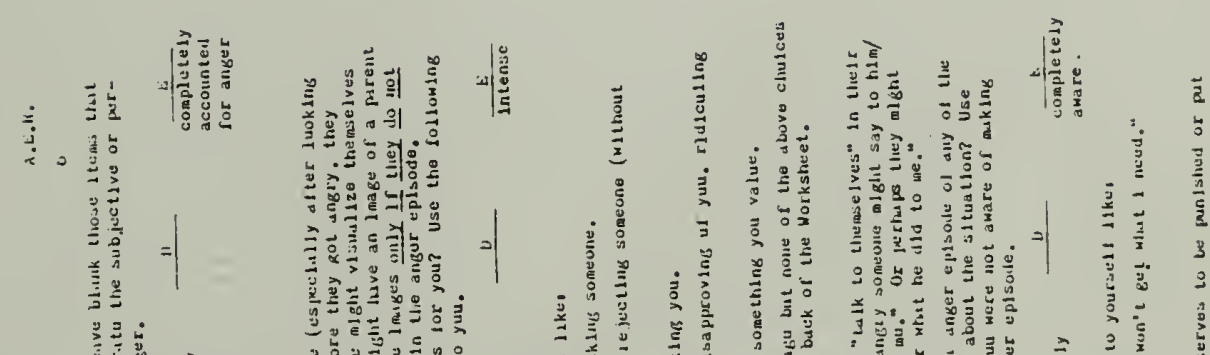

Hent

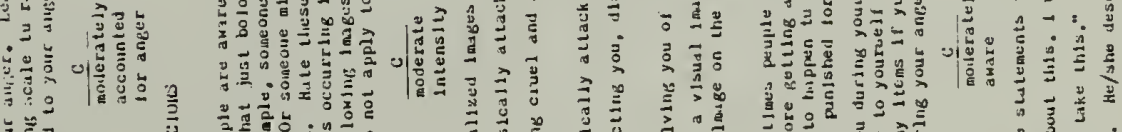
1"

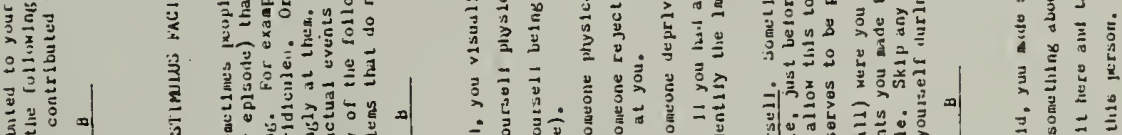

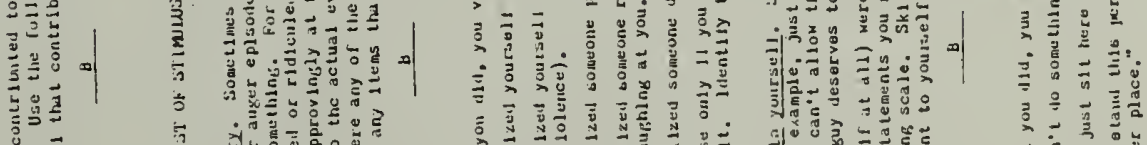

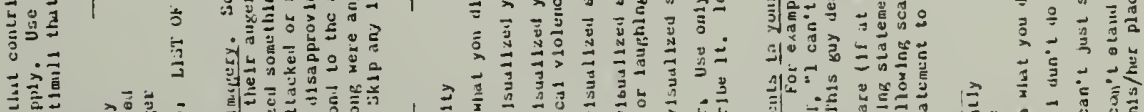

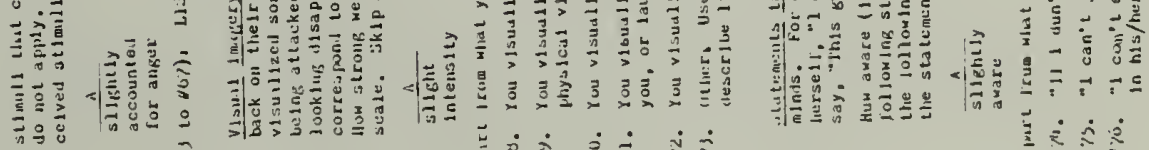

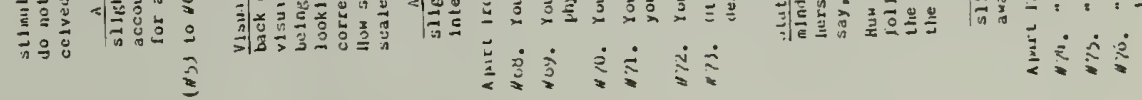



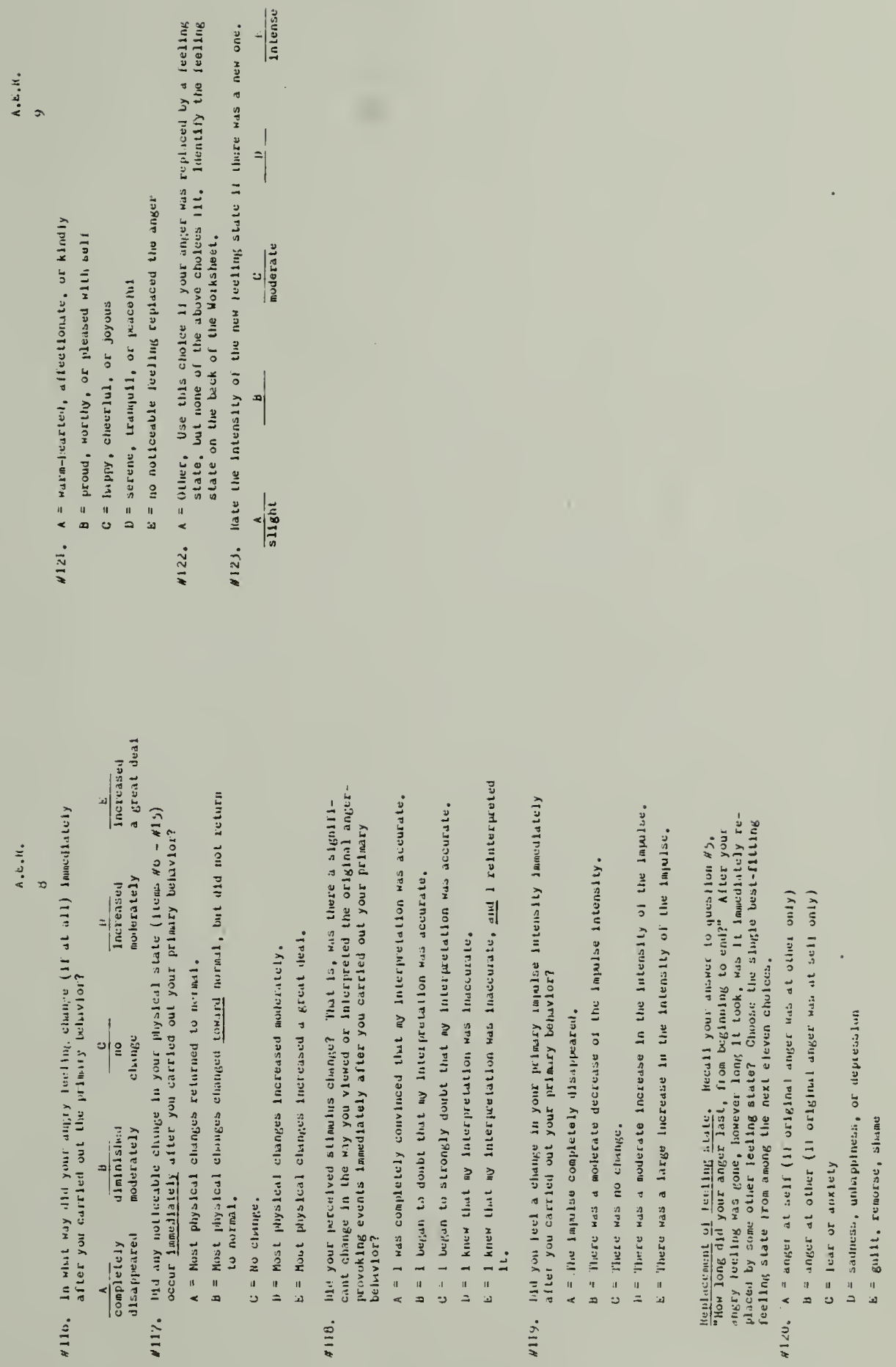

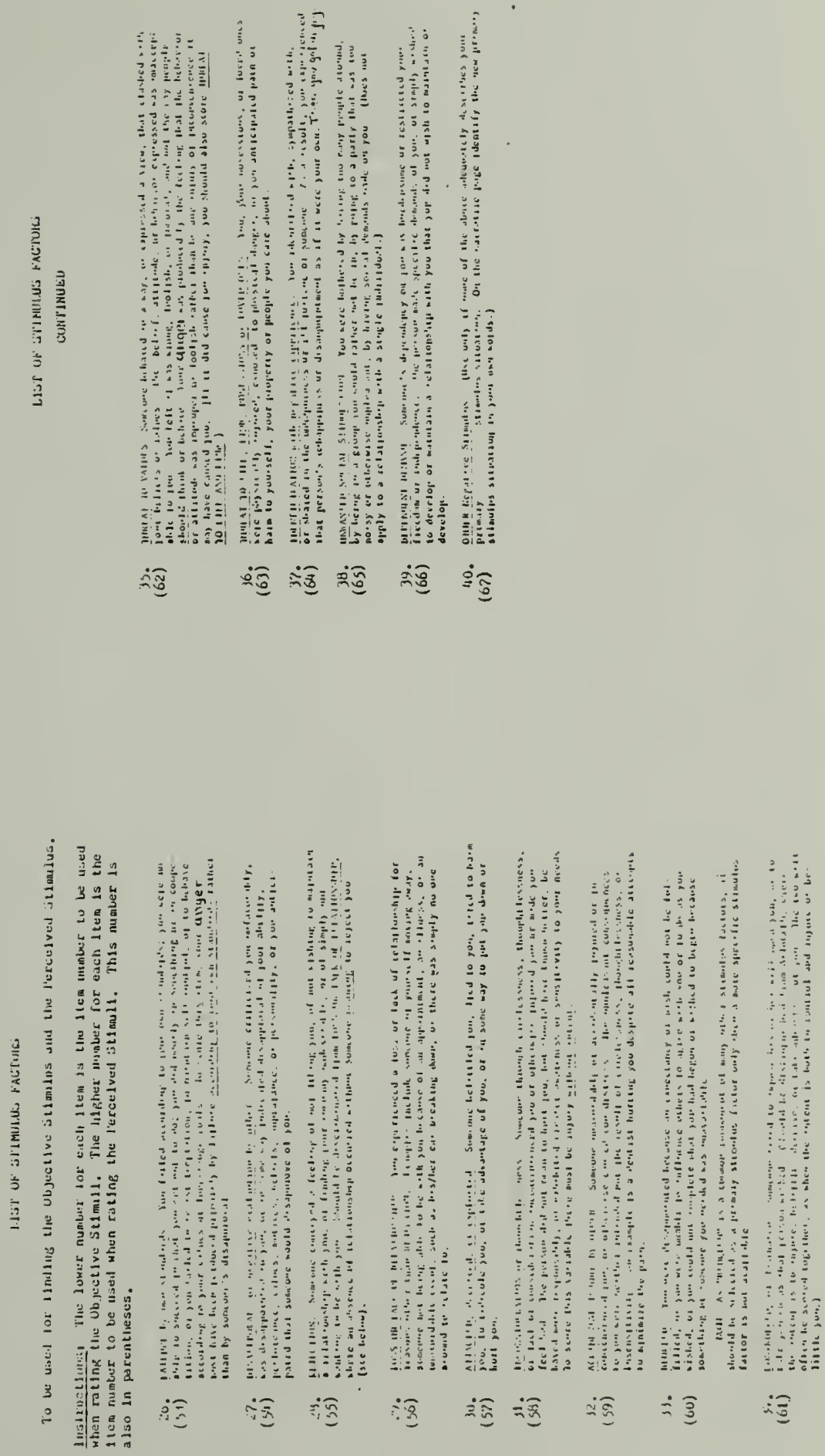

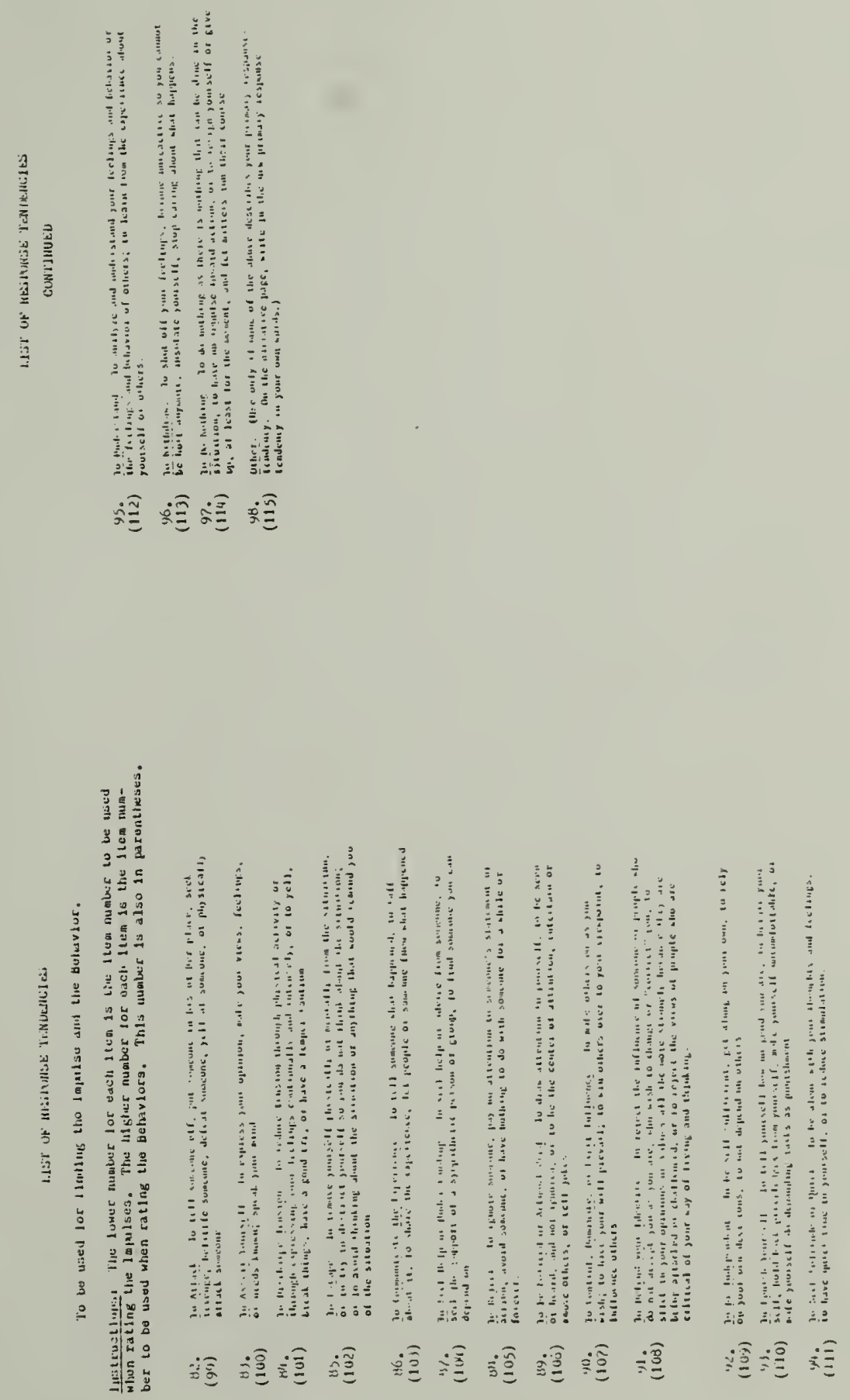
APPENDIX B 


\section{AFD PERSONALITY QUESTIONNAIRE}

SCREENING DATA

Subjects completed the AFD Personality Questionnaire before participating in the study. This instrument consists in 94 statements which can be endorsed as being true of oneself on a fivepoint scale. Several factors, consisting in 10 statements each, have been identified on this scale. The data reported here are the individual scores as well as summary descriptive data for the three Hostility factors from the scale:

Factor I, Conflict over hostility

Factor II, Proneness to Anger and Aggression

Factor III, Hostility Avoidance

For each factor, the higher the value, the more of the quality described can be attributed to the person or sub-group. (Some data are missing for subjects \#11 and \#12.) 


\section{AFD Personality Questionnaire Screening Data}

\section{Factors.}

$\begin{array}{lrrrc}\text { Subject } & \text { I } & \text { II } & \text { III } & \bar{X} \text { DISSO } \\ \text { \#2 (High DISSO, Joe) } & 38 & 37 & 30 & 9.00 \\ \text { \#4 (High DISS0, Glen) } & 31 & 25 & 32 & 5.00 \\ \# 1 \text { (High DISS0, Peter) } & 33 & 20 & 26 & 4.07 \\ \text { \#6 (High DISSO) } & 18 & 38 & 33 & 1.67 \\ \# 11 \text { (High DISSO) } & 24 & \mathrm{md} & \mathrm{md} & 2.13 \\ \# 13 \text { (High Disso) } & 21 & 21 & 32 & 1.67\end{array}$

Summary

$$
\begin{array}{rl}
\bar{X} & 27.50 \\
\text { sd } & 7.71 \\
N & 6
\end{array}
$$

28.20

30.60

3.92

$8.70 \quad 2.79$

2.84

5

5

6

\#10 (Low DISSO, Marcia) 16

\#12 (Low DISSO, Steven) 35

\#8 (LOW DISSO, DAVE) 17

\#9 (Low DISSO)

27

\#7 (Low DISSO)

16

\#5 (Low DISSO)

\#3 (Low DISSO)

32

$\begin{array}{llr}14 & 37 & 1.40 \\ \mathrm{md} & \mathrm{md} & 1.00 \\ 12 & 31 & .33 \\ 27 & 32 & 1.40 \\ 30 & 28 & 1.47 \\ 27 & 34 & 1.47 \\ 30 & 30 & 1.47\end{array}$

Summary

$$
\begin{array}{rl}
\bar{X} & 25.14 \\
\mathrm{sd} & 8.59 \\
\mathrm{~N} & 7
\end{array}
$$$$
23.33
$$$$
32.00
$$

1.22

8.14

3.16

Total Summary

$\begin{array}{rrrr}\bar{X} & 26.23 & 25.55 & 31.36 \\ \text { sd } & 7.95 & 8.36 & 2.94 \\ N & 13 & 11 & 11\end{array}$

2.47

2.33 


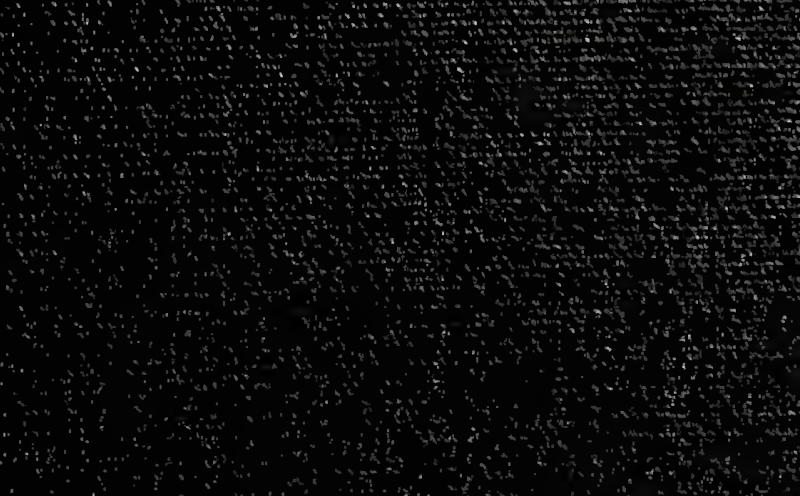

